\title{
Two-photon microscopic imaging of neo-vasculature in atherosclerotic plaques and tumors
}

Citation for published version (APA):

Douma, K. (2009). Two-photon microscopic imaging of neo-vasculature in atherosclerotic plaques and tumors. [Doctoral Thesis, Maastricht University]. Mediview BV. https://doi.org/10.26481/dis.20091111kd

Document status and date:

Published: 01/01/2009

DOI:

10.26481/dis.20091111kd

Document Version:

Publisher's PDF, also known as Version of record

\section{Please check the document version of this publication:}

- A submitted manuscript is the version of the article upon submission and before peer-review. There can be important differences between the submitted version and the official published version of record.

People interested in the research are advised to contact the author for the final version of the publication, or visit the DOI to the publisher's website.

- The final author version and the galley proof are versions of the publication after peer review.

- The final published version features the final layout of the paper including the volume, issue and page numbers.

Link to publication

\footnotetext{
General rights rights.

- You may freely distribute the URL identifying the publication in the public portal. please follow below link for the End User Agreement:

www.umlib.nl/taverne-license

Take down policy

If you believe that this document breaches copyright please contact us at:

repository@maastrichtuniversity.nl

providing details and we will investigate your claim.
}

Copyright and moral rights for the publications made accessible in the public portal are retained by the authors and/or other copyright owners and it is a condition of accessing publications that users recognise and abide by the legal requirements associated with these

- Users may download and print one copy of any publication from the public portal for the purpose of private study or research.

- You may not further distribute the material or use it for any profit-making activity or commercial gain

If the publication is distributed under the terms of Article $25 \mathrm{fa}$ of the Dutch Copyright Act, indicated by the "Taverne" license above, 


\section{Two-Photon Microscopic Imaging of Neo-Vasculature in Atherosclerotic Plaques and Tumors}




\section{ISBN 978-90-77201-32-9}

\section{(C) Copyright Kim Douma, Maastricht 2009}

Cover illustration: Microvasculature of a LS174T colon adenocarcinoma, subcutaneously induced in a Swiss ${ }^{\text {nu/nu }}$ mouse, stained ex vivo with FITC-conjugated monoclonal anti-CD31 antibody and imaged with two-photon laser scanning microscopy.

Lay-out and cover design by PrimaID and Kim Douma

Printed by Sync in Kerkrade

Published by Mediview BV in Maastricht 


\title{
Two-Photon Microscopic Imaging of Neo-Vasculature in Atherosclerotic Plaques and Tumors
}

\author{
PROEFSCHRIFT
}

ter verkrijging van de graad van doctor aan de Universiteit Maastricht,

op gezag van de Rector Magnificus, Prof. Mr. G.P.M.F. Mols

volgens het besluit van het College van Decanen,

in het openbaar te verdedigen

op woensdag 11 november 2009 om 16.00 uur

door

Kim Douma

geboren op 7 augustus 1979 te Apeldoorn 
Promotores:

Prof. Dr. D.W Slaaf

Prof. Dr. M.J. Post

Prof. Dr. M.A.M.J. van Zandvoort

Beoordelingscommissie: Prof. Dr. H.F.P. Hillen (voorzitter)

Prof. Dr. H.C. Gerritsen (Universiteit Utrecht)

Mw. Dr. M.G.A. oude Egbrink

Prof. Dr. J.L. Waltenberger

Prof. Dr. C. Weber (Universitätsklinikum Aachen, Germany)

Financial support by the Netherlands Heart Foundation for the publication of this thesis is gratefully acknowledged.

Schering-Plough, Cardiovascular Research Institute Maastricht (CARIM), Fine Science Tools GmbH and BD Biosciences are also gratefully acknowledged for their contribution. 
Twenty years from now you will be more disappointed by the things you didn't do than by the ones you did do. So throw off the bowlines, sail away from the safe harbor. Catch the trade winds in your sails.

Explore. Dream. Discover.

Mark Twain 



\section{Contents}

Chapter 1

Chapter 2

Chapter 3

Chapter 4

Chapter 5

Chapter 6

Chapter 7

Summary

Samenvatting

Dankwoord

Curriculum vitae

List of publications
General introduction

Neo-vasculature in atherosclerosis and cancer: two-photon laser scanning microscopy

Nanoparticles for optical molecular imaging of atherosclerosis

High resolution vasa vasorum imaging in intact murine atherosclerotic arteries

Evaluation of magnetic resonance vessel size imaging by two-photon laser scanning microscopy

Quantitative molecular magnetic resonance imaging of tumor angiogenesis using cNGR-labeled paramagnetic quantum dots

General discussion 



\section{Chapter 1}

General introduction 

Angiogenesis, i.e., sprouting from pre-existent vasculature, contributes to the growth of atherosclerotic plaques and solid tumors by providing conduits for transport of nutrients and oxygen. Advanced atherosclerotic plaques are characterized by an extensive network of microvessels mostly originating from the vasa vasorum that reside within the arterial wall, ${ }^{1}$ whereas solid tumors are provided with an internal and peripheral microvascular network. ${ }^{2}$ Methods for visualization and quantification of neo-vasculature and angiogenic activity would provide insight in the development of these pathologies and could potentially be an entrance point for therapy. In this thesis, two-photon laser scanning microscopy (TPLSM) and magnetic resonance imaging (MRI) were utilized to visualize and quantify neo-vascular morphology and angiogenic activity in mouse models of atherosclerosis and cancer.

Demarcation of microvasculature from surrounding tissue may be achieved by contrast agents that track with blood plasma ${ }^{3,4}$ or interact with the microvascular endothelium. ${ }^{5}$ Both allow assessment of microvessel diameter, length, and density. Under conditions of for instance angiogenesis, the endothelium reacts to bloodborne mechanical and chemical stimuli by expressing biologically functional epitopes. ${ }^{6-8}$ These epitopes may be specifically targeted by contrast agents for molecular imaging of angiogenic activity ${ }^{5,9}$ or other functional expressions of endothelial cells. Bi-modal contrast agents offer the ability to visualize neo-vasculature with two complementary imaging modalities, e.g., TPLSM and MRI., ${ }^{5,10}$ TPLSM offers a high spatial resolution within a limited sampling volume; MRI allows whole-body imaging with limited spatial resolution.

Atherosclerosis is a chronic inflammatory disease of the large arteries, characterized by the accumulation of inflammatory cells and lipids in the vascular wall. ${ }^{11}$ In The Netherlands, cardiovascular complications, including myocardial infarction and stroke, contributed to about $31 \%$ of overall mortality in 2007 , a number that has decreased from $46 \%$ over the preceding 12 years (www.cbs.nl). Atherosclerotic lesions develop from initial fatty streaks to complex structures with high inflammatory content, intraplaque hemorrhage, and a thin fibrous cap. ${ }^{12-14}$ Plaque progression is accompanied by an increase in vasa vasorum density ${ }^{1}$ and the formation of intraplaque microvasculature. ${ }^{15}$ These features are believed to affect plaque stability, ${ }^{16}$ thereby rendering the plaque prone to rupture and thromboembolic complications. ${ }^{17}$

Cancer can be defined as the uncontrolled growth, invasion or metastasis of a group of cells. ${ }^{18}$ In 2007, cancer accounted for about $31 \%$ of all deaths in The Netherlands and has recently overtaken cardiovascular disease as primary cause of death (www.cbs.nl). Solid tumors require a microvascular network to provide the highly proliferative cancer cells with nutrients and oxygen and remove waste products and metabolites. The rate at which local microvessel density increases is a prognostic indicator of malignancy in various, but not all, tumor types and is the rate-limiting step in solid tumor growth. ${ }^{19-21}$ Tumor microvasculature is highly tortuous and morphologically heterogeneous. ${ }^{22}$

TPLSM is a fluorescence technique that allows optical sectioning of intact biological tissue to a depth of up to several hundreds of micrometers. ${ }^{23}$ It offers several advantages over histological tissue characterization, including preservation of tissue integrity during preparation. ${ }^{24}$ However, tissue sampling volumes are relatively small $\left(<1 \mathrm{~mm}^{3}\right)$ and in vivo measurements suffer from artifacts due to cardiac and respiratory movement. Hence, TPLSM measurements have been predominantly performed ex vivo. ${ }^{25}$ The three-dimensional sub-micrometer resolution ensures visualization of sub-cellular events, e.g., interaction between fluorophore-conjugated ligands and biological epitopes, ${ }^{10}$ and allows unprecedented visualization and quantification of microvascular morphology. ${ }^{26}$ 
MRI is a non-invasive imaging modality that allows functional and anatomical characterization of live organisms. Endogenous contrast enables discrimination between pathological and healthy soft tissue, while contrast may be increased by high-relaxivity exogenous contrast agents. ${ }^{27}$ The sub-millimeter spatial resolution of MRI precludes visualization of individual microvessels with diameters smaller than $200 \mu \mathrm{m}$. However, MRI enables localization and quantification of effects of contrast agents. This allows assessment of measures for microvessel density, dimensions, and flow, which may serve as surrogate markers for detecting angiogenesis. In addition, targeted contrast agents allow molecular imaging of angiogenic activity. ${ }^{28}$ Validation of MRI results requires higher resolution imaging techniques. ${ }^{29}$

As introductory chapter to the experimental sections, chapter 2 provides an overview on the role of microvasculature in atheroand carcinogenesis. In addition, various MRI and TPLSM methods are presented that are used to visualize and quantify neo-vascular characteristics and angiogenic activity.

Chapter 3 provides a review of five recently developed contrastenhancing nanoparticles and targeting ligands for optical and potentially bi-modal molecular imaging of atherosclerosis. One particular nanoparticle, the quantum dot, has been used to detect angiogenic activity in plaque vasa vasorum and tumor vasculature, as presented in chapter 4 and 6, respectively. In addition, several endoscope-compatible optical techniques are discussed that would allow intravascular observation of cardiovascular disease in the clinical setting.

In chapter 4, a feasibility study is presented in which TPLSM was used to visualize vasa vasorum microvessels in intact atherosclerotic murine arteries. Moreover, it is shown that these microvessels display (inhomogeneous) angiogenic activity.

Tumor microvessel density may serve as an indicator of malignant potential of several tumors and of their propensity to metastasize. ${ }^{30}$ Image processing was applied to three-dimensional TPLSM datasets to quantify microvessel radius, density, and length of microvasculature. In chapter 5 this quantification method was applied to evaluate in vivo magnetic resonance vessel size imaging (MR-VSI) in determining the fractional blood volume and an index of microvessel radius of murine tumors and muscle tissue.

Whereas in chapter 5 morphological characteristics of tumor microvasculature were quantified with MR-VSI and TPLSM, in chapter 6 tumor angiogenic activity was visualized with in vivo MRI and ex vivo TPLSM. To enable bimodal imaging, a targeted contrast agent was developed with combined paramagnetic and luminescent properties.

The general discussion in chapter 7 provides a critical evaluation of the results presented in the data chapters. In addition, future perspectives of TPLSM are discussed. 


\section{References}

1. BargerAC, Beeuwkes R, 3rd, Lainey LL, Silverman KJ. Hypothesis: vasa vasorum and neovascularization of human coronary arteries. A possible role in the pathophysiology of atherosclerosis. N Engl J Med 1984;310:175-7.

2. Fukumura D, Jain RK. Tumor microvasculature and microenvironment: targets for anti-angiogenesis and normalization. Microvasc Res 2007;74:72-84.

3. Neimatallah MA, Ho VB, Dong Q, et al. Gadolinium-enhanced 3D magnetic resonance angiography of the thoracic vessels. J Magn Reson Imaging 1999;10:758-70.

4. Leunig M, Yuan F, Menger MD, et al. Angiogenesis, microvascular architecture, microhemodynamics, and interstitial fluid pressure during early growth of human adenocarcinoma LS174T in SCID mice. Cancer Res 1992;52:6553-60.

5. Oostendorp M, Douma K, Hackeng TM, et al. Quantitative molecular magnetic resonance imaging of tumor angiogenesis using cNGR-labeled paramagnetic quantum dots. Cancer Res 2008;68:7676-83.

6. Gong N, Chatterjee S. Platelet endothelial cell adhesion molecule in cell signaling and thrombosis. Mol Cell Biochem 2003;253:151-8.

7. Mina-Osorio $\mathrm{P}$, Winnicka B, O'Conor C, et al. CD13 is a novel mediator of monocytic/ endothelial cell adhesion. J Leukoc Biol 2008;84:448-59.

8. Muller WA. Leukocyte-endothelial-cell interactions in leukocyte transmigration and the inflammatory response. Trends Immunol 2003;24:327-34.

9. Mulder WJ, Strijkers GJ, Habets JW, et al. MR molecular imaging and fuorescence microscopy for identification of activated tumor endothelium using a bimodal lipidic nanoparticle. Faseb J 2005;19:2008-10.

10. Prinzen L, Miserus RJ, Dirksen A, et al. Optical and magnetic resonance imaging of cell death and platelet activation using annexin a5-functionalized quantum dots. Nano Lett 2007;7:93-100.

11. Libby P, Ridker PM, Maseri A. Inflammation and atherosclerosis. Circulation 2002;105:1135-43.

12. Stary HC, Blankenhorn $\mathrm{DH}$, Chandler AB, et al. A definition of the intima of human arteries and of its atherosclerosis-prone regions. A report from the committee on vascular lesions of the council on arteriosclerosis, American Heart Association. Circulation 1992;85:391-405.

13. Stary $\mathrm{HC}$, Chandler AB, Dinsmore RE, et al. A definition of advanced types of atherosclerotic lesions and a histological classification of atherosclerosis. A report from the committee on vascular lesions of the council on arteriosclerosis, American Heart Association. Circulation 1995;92:1355-74.

14. Stary HC, Chandler AB, Glagov S, et al. A definition of initial, fatty streak, and intermediate lesions of atherosclerosis. A report from the committee on vascular lesions of the council on arteriosclerosis, American Heart Association. Circulation 1994:89:2462-78.
15. Virmani R, Kolodgie FD, Burke AP, et al. Atherosclerotic plaque progression and vulnerability to rupture: angiogenesis as a source of intraplaque hemorrhage. Arterioscler Thromb Vasc Biol 2005;25:2054-61.

16. Gössl M, Versari D, Mannheim D, Ritman EL, Lerman LO, Lerman A. Increased spatial vasa vasorum density in the proximal $L A D$ in hypercholesterolemia--implications for vulnerable plaque-development. Atherosclerosis 2007;192:246-52.

17. Corti R, Hutter R, Badimon JJ, Fuster V. Evolving concepts in the triad of atherosclerosis, inflammation and thrombosis. J Thromb Thrombolysis 2004;17:35-44.

18. Hanahan D, Weinberg RA. The hallmarks of cancer. Cell 2000;100:57-70.

19. Canoglu A, Gogus C, Beduk Y, Orhan D, Tulunay O, Baltaci S. Microvessel density as a prognostic marker in bladder carcinoma: correlation with tumor grade, stage and prognosis. Int Urol Nephrol 2004;36:401-5.

20. Zheng H, Tsuneyama K, Cheng C, et al. Expression of KAI1 and tenascin, and microvessel density are closely correlated with liver metastasis of gastrointestinal adenocarcinoma. J Clin Pathol 2007;60:50-6.

21. Trivella M, Pezzella F, Pastorino U, Harris AL, Altman DG. Microvessel density as a prognostic factor in non-small-cell lung carcinoma: a meta-analysis of individual patient data. Lancet Oncol 2007;8:488-99.

22. Jockovich ME, Pina Y, Alegret A, Cebulla C, Feuer W, Murray TG. Heterogeneous tumor vasculature in retinoblastoma: implications for vessel targeting therapy. Retina 2008;28:S81-6.

23. Diaspro A, Robello M. Two-photon excitation of fluorescence for three-dimensional optical imaging of biological structures. J Photochem Photobiol B 2000;55:1-8.

24. Dorph-Petersen KA, Nyengaard JR, Gundersen HJ. Tissue shrinkage and unbiased stereological estimation of particle number and size. J Microsc 2001;204:232-46.

25. Megens RT, Reitsma S, Schiffers PH, et al. Two-photon microscopy of vital murine elastic and muscular arteries. Combined structural and functional imaging with subcellular resolution. J Vasc Res 2007;44:87-98.

26. Padera TP, Stoll BR, So PT, Jain RK. Conventional and high-speed intravital multiphoton laser scanning microscopy of microvasculature, lymphatics, and leukocyteendothelial interactions. Mol Imaging 2002;1:9-15.

27. Mulder WJ, Strijkers GJ, Griffioen AW, et al. A liposomal system for contrast-enhanced magnetic resonance imaging of molecular targets. Bioconjug Chem 2004;15:799-806.

28. Barrett T, Brechbiel M, Bernardo M, Choyke PL. MRI of tumor angiogenesis. J Magn Reson Imaging 2007;26:235-49.

29. Troprès I, Lamalle $\mathrm{L}$, Peoc'h $\mathrm{M}$, et al. In vivo assessment of tumoral angiogenesis. Magn Reson Med 2004;51:533-41.

30. Hlatky L, Hahnfeldt P, Folkman J. Clinical application of antiangiogenic therapy: microvessel density, what it does and doesn 't tell us. J Natl Cancer Inst 2002;94:883-93. 



\section{Chapter 2}

Neo-vasculature in atherosclerosis and cancer: two-photon laser scanning microscopy 

Neo-vasculature contributes to the growth of atherosclerotic plaques and tumors by providing oxygen and nutrients to the metabolically highly active inflammatory cells and tumor cells. In addition, neo-vasculature provides an additional conduit for inflammatory cells to enter the plaque core. In plaques, these inflammatory cells excrete matrix degrading enzymes, thereby causing mechanical destabilization of the plaque. Visualization and quantification of structural and functional vascular features, including vascular morphology and permeability, and of angiogenic activity of vascular endothelial cells (VECs) might therefore allow assessment of vulnerable plaque development. In tumors, the neo-vessels not only sustain growth but may at the same time facilitate cytostatic delivery to the tumor. Visualization of tumor angiogenesis may therefore guide anti-tumor therapy. In addition, the efficacy of antiangiogenic therapy may be monitored.

\section{Neo-vascularization: focus on angiogenesis}

Vascular growth can occur via vasculogenesis (de novo formation of vasculature), angiogenesis (sprouting from pre-existing vasculature), and arteriogenesis (collateral growth). ${ }^{1}$ This thesis concentrates on angiogenesis, since it is the most common way by which neovascularization occurs in pathological tissues. Angiogenesis is involved in physiological processes including embryogenesis and wound healing as well as in pathological conditions such as ischemic heart disease, cancer, diabetic retinopathy, and chronic inflammation including atherosclerosis. ${ }^{2}$ The angiogenic cascade roughly involves four distinct processes: formation, maturation, remodeling, and specialization. ${ }^{1}$ In the formation stage, the angiogenic cascade may be initiated by hypoxia, ${ }^{3}$ metabolic ${ }^{4}$ and mechanical stress, ${ }^{5}$ immuneinflammatory reactions,,${ }^{6,7}$ and genetic mutations, ${ }^{8}$ which disrupt the finely tuned balance between expression and activity of pro- and anti-angiogenic factors. Upon initiation, vascular endothelial growth factor (VEGF) and nitric oxide (NO) cause dilation and increased permeability of the existing vasculature, after which proteolytic enzymes, e.g., matrix metalloproteinases (MMPs), ensure migration of VECs that eventually align into immature tubes under control of pro-angiogenic growth factors. ${ }^{9-11}$ During maturation, attraction of pericytes ${ }^{12}$ and the generation of a basal membrane stabilize the hyperpermeable endothelial sprouts. Subsequent remodeling of the matured vascular network is governed by survival and apoptosis of VECs and pericytes, thereby regulating vascular expansion and regression. The functionality of the neo-vasculature depends on the specialization stage, involving arterio-venous differentiation. ${ }^{13}$

The hypoxia inducible factor (HIF) is considered the main initiator of the angiogenic cascade and has been correlated to neo-vasculature in both atherosclerotic plaques ${ }^{7}$ and various tumor types. ${ }^{14,15}$ HIF is composed of subunits HIF- $1 \alpha / 2 \alpha$ and HIF$1 \beta$, which are oxygen-dependent and constitutively expressed, respectively. The activity and stability of HIF- $1 \alpha / 2 \alpha$ is controlled by numerous factors, including factor inhibiting HIF- $1 \alpha / 2 \alpha$ (FIH), ${ }^{16}$ the macrophage-derived peptide PR $39,{ }^{17}$ and the p53 tumor suppressor gene. ${ }^{18}$ Under normoxic conditions HIF- $1 \alpha / 2 \alpha$ is targeted for proteosomal degradation, ${ }^{19,20}$ causing a half-life of less than 5 minutes. Under hypoxic conditions, however, HIF- $1 \alpha / 2 \alpha$ dimerizes with HIF-1 $\beta$ to form HIF that functions as a transcription factor for hypoxia responsive genes that are involved in angiogenesis, cell proliferation and survival, and glucose and iron metabolism. ${ }^{21}$ These include VEGF and its receptor flt-1, platelet-derived growth factor-A/B (PDGF-A/B) and its receptor PDGFR- $\alpha / \beta$, interleukin- 1 (IL-1), tissue necrotic factor- $\alpha$ (TNF- $\alpha)$, tissue growth factor- $\beta$ (TGF- $\beta$ ), Ang-1 and -2 and its vascular endothelial receptor Tie-2, glucose transporters 1 and 3 (GLUT1/3), and endothelial nitric oxide synthase (eNOS) ${ }^{22-24}$ In addition, HIF-1 $\alpha$ expression may be induced 
by non-hypoxic stimuli, including inflammation. ${ }^{25,26}$ The exact role of reactive oxygen species (ROS) in neo-vascularization is currently unknown since they were shown to induce both angiogenic ${ }^{27}$ and anti-angiogenic effects in vivo. ${ }^{28}$

\section{Atherosclerosis and angiogenesis}

\section{Atherogenesis}

Atherosclerosis is well-accepted as a chronic inflammatory disease of large arteries that is characterized by accumulation of inflammatory cells and lipids in the vascular tree..$^{29}$ Development of atherosclerotic lesions occurs at predisposed sites in the vasculature that are characterized by low and oscillatory endothelial shear stress. ${ }^{30,31}$ Early human atherosclerotic lesions (AHA type I) are characterized by endothelial activation, i.e., endothelial expression of intercellular (ICAM), vascular (VCAM), and platelet endothelial (PECAM) cell adhesion molecules, and the lectin-like oxidized low-density lipoprotein (oxLDL) receptor LOX-1. Supposedly, disruption of the endothelial glycocalyx increases the extravasation of macromolecular structures, e.g., LDL and proteins, to the subendothelial space. ${ }^{32}$ Upon accumulation of inflammatory cells and intracellular lipids, an inflammatory response is initiated, thereby increasing the expression of adhesion molecules to attract increased amounts of inflammatory cells and lipids (AHA type II). AHA type III lesions are characterized by small extracellular lipid pools, apoptotic cells, and MMP activity. Due to continued apoptosis of lipid-laden macrophages, a necrotic core develops in AHA type IV lesions. Moreover, these lesions are characterized by intraplaque microvasculature that predominantly originates from the vasa vasorum (VV), a plexus of adventitial microvessels that continues to expand with plaque growth. AHA type $\mathrm{V}$ lesions are termed fibroatheroma's since these lesions are characterized by a subendothelial fibrotic cap formed by deposition of collagen by SMCs. Complicated AHA type VI lesions develop when surface defects arise due to ongoing inflammation and apoptosis and thinning of the fibrous cap by MMPs. These defects initiate haematoma's, plaque instability, and potentially plaque rupture, leading to thrombus formation and embolization.

\section{Plaque growth and rupture: contribution of vasa vasorum (VV) and intraplaque microvasculature}

The contribution of hypoxia and/or inflammation, which both may initiate the angiogenic cascade, to plaque neo-vascularization appears to vary between species. In mouse, rabbit, and human atherosclerotic lesions, hypoxia has been observed and correlated with the presence of inflammatory cells in the plaque. ${ }^{7,33,34}$ However, in mouse and rabbit a causative relation between hypoxia and neovascularization has not been established. In contrast, in human atherosclerotic plaques, the expression of HIF and VEGF colocalized with the presence of hypoxia ${ }^{7}$ and neo-vasculature. ${ }^{35}$ These findings indicate that both inflammation and hypoxia may be involved in human plaque neo-vascularization.

Both the VV and intraplaque neo-vasculature are believed to contribute to the development of (vulnerable) atherosclerotic lesions by providing additional conduits for nutrients, oxygen, and inflammatory cells to enter the plaque. ${ }^{36,37}$ The vast majority of intraplaque neo-vasculature originates from the vasa vasorum, whereas the remainder is derived from the lumen of the affected blood vessel. ${ }^{38}$ In pigs, which show great similarity to humans considering vasculature, a great variation in $\mathrm{VV}$ density is present among various vascular beds. ${ }^{39}$ This observation may explain the variable propensity of atherogenesis in vascular beds, i.e., the local VV density determines the predilection sites for atherosclerotic plaque development. It has been established that VV density correlates with 
plaque progression and several studies suggest a role for VV neovascularization in the initial stage of atherogenesis in the coronary vascular bed of pigs. ${ }^{40,41}$ However, in carotid arteries of rodents, Khurana et al. identified that the initiation of plaque formation is independent of VV neo-vascularization. ${ }^{42}$ These seemingly contradicting observations between pig and mouse arteries suggest that vessel wall dimensions influence the contribution of VV neovascularization to the initiation of atherogenesis. This hypothesis requires experimental validation.

Intraplaque neo-vasculature is characterized by a paucity of tight junctions, a discontinuous basal membrane, and a lack in smooth muscle cells, indicating that these microvessels have not passed the maturation phase of the angiogenic cascade. ${ }^{43,44}$ Considering the fragility and permeability of these neo-vessels and the effect of intramural pressure on neo-vascular perfusion, intraplaque hemorrhage and/or ischemia-induced infarction may easily be initiated. In addition, the process of neo-vascularization itself, which involves proteolytic activity ${ }^{45}$ may affect the mechanical stability of the plaque. Moreover, plaque neo-vasculature provides a vascular network for infiltration of inflammatory cells, ${ }^{46,47}$ which have been associated with the presence of proteolytic enzymes in atheromatous plaques. ${ }^{48}$ These observations favor the destabilizing effect of neo-vasculature in atherosclerotic plaques. ${ }^{49,50}$

\section{Animal models of atherosclerosis and plaque rupture}

Due to the limited availability of non-invasive detection methods for (longitudinal) characterization of human lesions, mechanistic studies on the initiation, progression, and rupture of atherosclerotic lesions have been predominantly performed in (hypercholesterolemic) animals, including mice, rats, and rabbits. ${ }^{51-55}$ In atherosclerosis research, predominantly mouse models are being used. This is based on the great diversity in available inbred strains and the ability of genetic modifications to over- or under-express specific genes involved in atherogenesis.

In the majority of genetically modified mice, lipid metabolism has been altered to induce hypercholesterolemia, one of the main initiators of atherosclerotic plaque formation. Both apolipoprotein-E $\left(\mathrm{ApoE}^{-/}\right)$and $\mathrm{LDL}$ receptor $\left(\mathrm{LDLR}^{-/}\right)$knockout mice exhibit accelerated lesion formation. ${ }^{56-58}$ Of these, $\mathrm{ApoE}^{-/-}$mice have higher total plasma cholesterol levels and develop more extensive atherosclerotic lesions. ${ }^{59}$ High fat diets exacerbate lesion formation in both mice types. In addition, mice deficient in both ApoE and LDLR (ApoE $E^{-/ /} / \mathrm{LDLR}^{-/-}$double knockout mice) display similar cholesterol levels as ApoE ${ }^{-/}$mice. ${ }^{60}$ However, the progression of atherosclerotic lesions is usually more marked. ${ }^{61}$ In addition, $\mathrm{ApoE}^{-/-}$mice deficient in high density lipoprotein (HDL) receptor scavenger receptor class $\mathrm{B}$, type I (SRBI) or endothelial nitric oxide synthase (eNOS) develop occlusive coronary artery disease ${ }^{62}$ and peripheral coronary atherosclerosis, ${ }^{63}$ respectively. The cellular composition and development of atherosclerotic lesions in these mice resemble those found in humans. Whereas highly developed human atherosclerotic lesions are associated with plaque rupture, spontaneous rupture of murine lesions is limited. However, intraplaque hemorrhage ${ }^{64,65}$ and plaque rupture r6-69 $^{6}$ have been frequently observed in the brachiocephalic artery of $\mathrm{ApoE}^{-/-}$mice. Therefore, this artery is proposed as the preferred site for future systemic intervention studies. ${ }^{70}$ Nevertheless, the physiological and clinical relevance of the presented animal models is under debate due to the lack in typical human features such hemorrhagic lesions and thromboembolic complications. ${ }^{71}$ 


\section{Cancer and angiogenesis}

\section{Carcinogenesis}

Cancer is considered a complex, dynamic disease with high genetic heterogeneity: more than 100 distinct types of human cancer have been distinguished and various tumor subtypes can be found within specific organs. ${ }^{72,73}$ Carcinogenesis is initiated by oncogenesis, i.e., the process by which a normal cell is rendered malignant due to the accumulation of genetic mutations, as well as epigenetic changes that activate pro-oncogenes or downregulate tumor-suppressor genes and lead to uncontrolled cellular division. Mutations of about 300 human genes have been causally associated with oncogenesis. This accounts for more than $1 \%$ of the human genome. ${ }^{74}$ In addition to heritable changes in the phenotype, carcinogenesis may be initiated by food contaminants and oxidative stress. ${ }^{75,76}$

Despite the high genetic heterogeneity, most tumors share the following characteristics. ${ }^{72}$ Self-sufficiency in growth factors and receptors creates a positive feedback in proliferation thereby causing partial independency on host tissue. Disruption of the tumor suppressor proteins retinoblastoma $(\mathrm{Rb})$ and $\mathrm{p} 53$ renders cells insensitive to anti-growth factors and apoptosis, respectively. Maintenance of telomere-length in malignant cells above critical threshold allows limitless replication. Growth of tumors beyond diffusion limits (100 $\mu \mathrm{m})$ initiates local hypoxia and subsequent sustained angiogenesis. Tissue invasion and metastasis are correlated with the expression of cellular adhesion molecules, which allow intercellular or cellenvironment interactions, and of MMPs, which proteolytically degrade the basal membrane. However, due to extensive control of DNA replication at multiple levels, several cooperating oncogenes need to be expressed in order for human cells to become malignant. ${ }^{77}$ Taken together, these characteristics allow extensive expansion of the tumor mass, provided that tumor cells are supplied with oxygen and nutrients to cope with their increased metabolic demands.

\section{Tumor growth: contribution of microvasculature}

Small tumors (less than $1 \mathrm{~mm}$ in diameter) are generally avascular and are characterized by extensive hypoxia. Several studies have shown the presence of hypoxic areas ${ }^{78,79}$ and HIF- ${ }^{80}$ in tumors, dedicating hypoxia as a primary physiological initiator of angiogenesis by which tumors become vascularized and grow beyond the diffusion limits of oxygen. The hypoxic stress in tumors of more than $2 \mathrm{~mm}$ in diameter is significant to initiate production of pro-angiogenic growth factors and trigger neo-vascularization. ${ }^{81,82}$ Persistent hypoxia in perinecrotic regions and intrinsic expression of growth factors by tumor cells in larger tumors (more than $5 \mathrm{~mm}$ in diameter) ensure permanent angiogenic activity and expansion of the microvascular network. Angiogenesis has been shown to strongly contribute to tumor growth and metastasis in a wide array of tumors, including lung cancer, gastric cancer, prostate cancer, neuroblastoma, breast cancer, and colon cancer. ${ }^{83-88}$ Several anti-angiogenic therapies have therefore been developed to inhibit angiogenesis or to impair existent microvasculature in experimental tumors and to attenuate tumor growth and metastasis. ${ }^{89-91}$ Normalization of angiogenic tumor microvasculature reduces angiogenesis, thereby inhibiting tumor growth and potentially therapeutic efficacy. ${ }^{92,93}$ In addition, microvessel density (MVD) has been recognized as a prognostic indicator for various tumor types ${ }^{94}$ and correlates with the extent of hematological dissemination of tumor cells leading to metastasis, e.g., in melanoma. ${ }^{95}$ However, tumor MVD cannot be directly used as indicator for the efficacy of anti-angiogenic therapy due to the interdependence of tumor cell proliferation and microvascular expansion. ${ }^{94}$ 


\section{Murine models of solid tumor growth}

Rodents with genetically induced immune deficiencies, including Swiss $^{\text {nu/nu }}$ and severe combined immunodeficient (SCID) mice, have been used extensively for their reduced ability to reject transplanted human tumor cells. ${ }^{9697}$ Tumor growth in rodents may be induced by intravenous, ${ }^{98}$ left ventricular, ${ }^{99}$ intraplenic, ${ }^{100}$ and intraperitoneal ${ }^{82}$ injection of human tumor cells to yield tumors in the lung, bone, liver, and peritoneum, respectively. However, with respect to visualization of tumor microvasculature, subcutaneously induced tumors offer several advantages: (1) because tissue-invasion is limited, neovasculature in implanted tumors can be clearly discriminated from pre-existing vasculature of surrounding tissue; (2) in vivo imaging of subcutaneous tumors in the flank of the mouse is not obstructed by cardiac, respiratory, and/or peristaltic movements; (3) subcutaneous tumors are close to the surface and, hence, can be visualized with imaging modalities with limited penetration depth; and (4) a minimally invasive procedure is required for implantation of tumor cells.

\section{Animal experiments in this thesis}

In this thesis, Apo $\mathrm{E}^{-/}$mice, fedaWesterntype diet, and Swiss ${ }^{\mathrm{nu} / \mathrm{nu}}$ mice, subcutaneously injected with human colorectal adenocarcinoma cells, were used as animal models for atherosclerosis and cancer, respectively. Using ApoE ${ }^{-/}$mice and two-photon laser scanning microscopy (TPLSM), we developed a method to visualize (angiogenic activity of) the vasa vasorum in intact aortic segments in order to determine the feasibility of this method for future (in vivo) experiments. In the tumor-bearing mice, we performed in vivo MRI to visualize and quantify angiogenic activity and vascular morphology, i.e., measures for vessel size radius and fractional blood volume. Subsequent ex vivo TPLSM was used to evaluate the angiogenic activity as assessed by MRI. Dedicated image processing was performed on the obtained TPLSM data, in order to yield quantitative measures for the microvessel radius, fractional vessel volume, microvessel length, and the number of branching points to determine the degree of branching.

\section{Techniques for visualizing neo-vasculature}

\section{Morphology, permeability, and angiogenic activity}

Neo-vasculature has distinct features that differentiate it from preexisting microvessels. Intraplaque and tumor neo-vasculature consists of tortuous microvessels with a high heterogeneity in diameter. The morphology deviates from the strongly organized microvasculature in, for example, muscle tissue. Clinical imaging modalities, including $\mathrm{X}$-ray radiography and micro-computed tomography $(\mu \mathrm{CT})$, have been applied to directly visualize and quantify microvascular morphology in animals. ${ }^{101,102}$ Currently, these methods require excision and processing of the tissue of interest and lack the ability to visualize vessels of less than $20 \mu \mathrm{m}$ in diameter. Similarly, the resolution of MRI does not allow direct visualization of individual microvessels. However, an in vivo MRI-based method, i.e., magnetic resonance vessel size imaging (MR-VSI), ${ }^{103,104}$ has been developed that yields values related to microvessel density and radius. Studies have shown that MR-VSI displays a systematic overestimation of these morphological measures with a large variation between the different studies (see table 3 of Chapter 5 and references within). The large variation may be attributed to differences in experimental setup and data analysis. The resulting non-physiological values can therefore not be used for absolute quantification. Nevertheless, with MR-VSI the angiogenic rim of tumors may be discriminated from the less vascularized core. Therefore, MR-VSI may allow assessment of the spatial distribution of the microvessel density and radius on a voxel-by-voxel basis. This method is insensitive to vessel orientation and displays the 
average microvessel density and radius per voxel (voxel volume of approximately $0.1 \mu \mathrm{m}^{3}$ ). Using optical techniques, morphologic parameters such as fractional blood volume, microvessel radius, and microvessel orientation, may be quantified with a sub-micrometer resolution, although these techniques are confined to superficial observations due to the limited tissue penetration depth of light. ${ }^{105-107}$

The increased endothelial permeability of neo-vasculature offers an additional opportunity for visualization. In that case, intravascular contrast agents are able to move out of the vessel compartment into the interstitial space surrounding the neo-vasculature. Quantification of the extravasation rate provides a measure for the endothelial permeability and, hence, angiogenic activity and may be assessed with MRI, ${ }^{108}$ ultrasound, ${ }^{109}$ and optical techniques. ${ }^{110}$

The endothelium of neo-vasculature displays angiogenic activity, i.e., (over-) expresses biologically functional epitopes. The most widely used epitopes for molecular imaging of angiogenesis are the $\alpha_{v} \beta_{3}$ integrin and the aminopeptidase CD13 (Figure 1). The $\alpha_{v} \beta_{3}$ integrin has been successfully targeted with RGD-conjugated contrast agents for MRI of angiogenic activity in atherosclerosis and cancer. ${ }^{11-113}$ Mulder et al. developed bi-modal liposomes to visualize angiogenic endothelial cells with in vivo MRI and subsequent ex vivo fluorescence microscopy. ${ }^{111}$ In addition, Cai et al. employed whole-body in vivo optical imaging to assess angiogenic in subcutaneous tumors. ${ }^{114}$ The ligand for CD13, NGR, was initially used for targeted therapy of anti-cancer drugs ${ }^{115}$ and later for optical molecular imaging of angiogenic activity in tumors ${ }^{116}$ and after myocardial infarction. ${ }^{117}$ The tripeptide NGR has not been used for molecular imaging of angiogenesis in atherosclerosis.

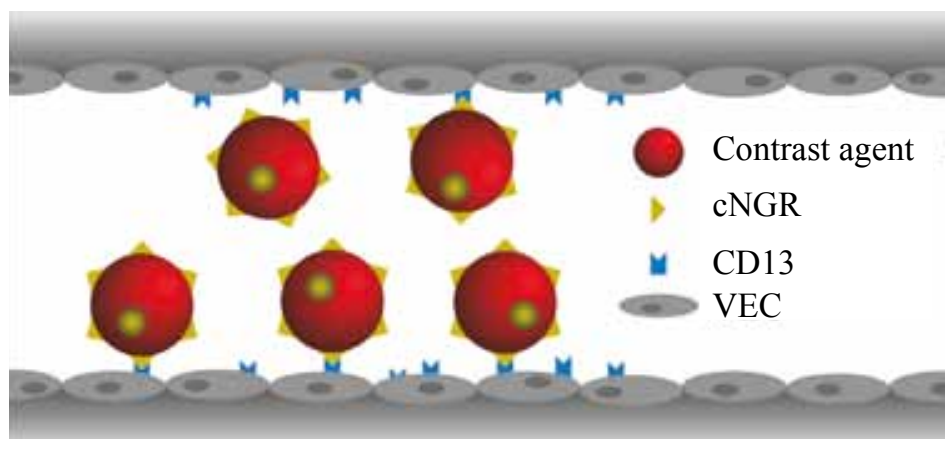

Figure 1 Molecular imaging of angiogenic endothelial cells lining the vessel wall. The angiogenesis marker CD13, expressed by vascular endothelial cells (VECS), is targeted via the blood flow by a contrast agent bound to the CD13 ligand cyclic NGR (cNGR).

\section{Two-photon laser scanning microscopy (TPLSM) of neo-vasculature and angiogenesis}

\section{Basic principles of two-photon laser scanning microscopy}

In 1990, Denk et al. described TPLSM, ${ }^{118}$ an optical technique with three-dimensional resolution. The main physical principle of TPLSM was predicted by Maria Göppert-Mayer in 1929 and involves the near-simultaneous (within $10^{-18} \mathrm{~s}$ ) absorption of two near-infrared (NIR) photons (wavelength about $800 \mathrm{~nm}$ ) by a fluorophore to reach the excited state (Figure 2). ${ }^{119}$ In contrast, in single-photon excited fluorescence microscopy the excited state is reached by absorption of a single photon (wavelength: $350-650 \mathrm{~nm}$ ).

In general, the efficiency of two-photon excitation is low. Therefore, high intensity lasers and high numerical aperture (NA) objective lenses are required to ensure spatiotemporal overlap of ample NIR 


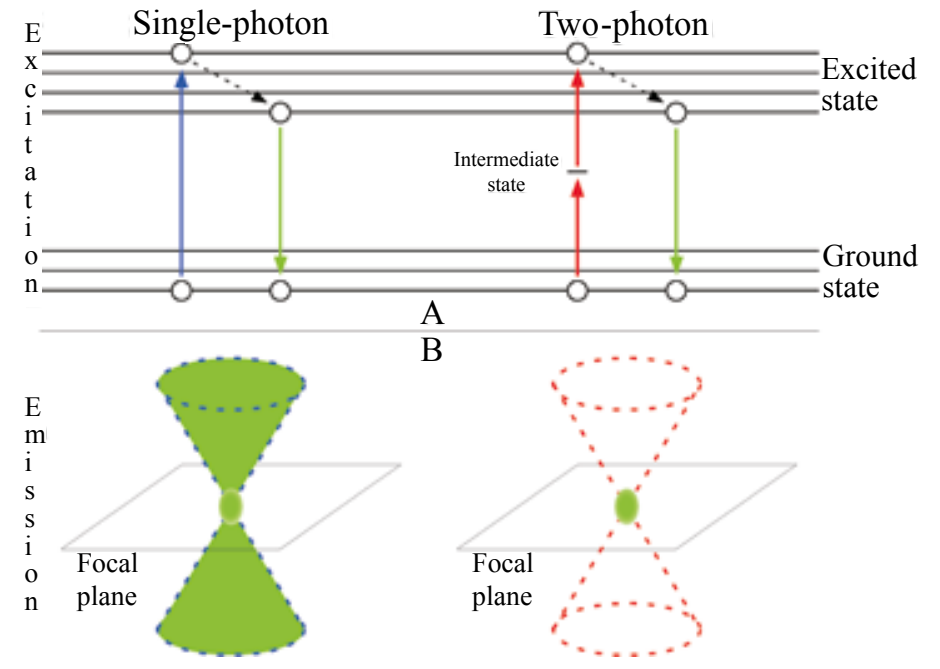

Figure 2 A) Jablonksi diagram. For simplicity, the vibrational transitions have been omitted. Electron $(O)$ transitions during single- and two-photon excitation (left and right panel, respectively) and subsequent fluorescence emission. B) In single-photon excitation fluorescence occurs within the whole cone of illumination and contributes to the image (left panel); in two-photon excitation fluorescence is restricted to the focal zone and detected light originates from the focal plane only (right panel).

photons and cause excitation. Continuous wave lasers are not suitable since continuous laser illumination with the required high intensity causes photodamage and -bleaching due to concentration of the excitation light in the focal point. In mode-locked, pulsed lasers the high peak power of the pulses suffices for two-photon excitation, but the average output power is lower, thereby decreasing photodamage and -bleaching. Mode-locked lasers refer to laser systems that operate at a limited range of output wavelengths, usually $700-1000 \mathrm{~nm} .{ }^{120}$ The phase between these frequencies is fixed such that inference between them causes a standing wave between the mirrors in the laser cavity, resulting in a train of light pulses of which the repetition rate depends on the distance between the laser cavity end mirrors and the speed of light. ${ }^{121}$ During TPLSM experiments described in chapters 4, 5, and 6, the laser was tuned around a center wavelength of $800 \mathrm{~nm}$ and had a pulse repetition rate of $82.5 \mathrm{MHz}$ and a pulse width of $140 \mathrm{fs}$.

The probability of two-photon excitation is confined to a volume of $0.1-1 \mu \mathrm{m}^{3}$ centered about the focal point ${ }^{122}$ and decreases with the fourth power of distance from that focal point. ${ }^{123}$ Thus in TPLSM, fluorescence emission originates exclusively from the focal zone, which, combined with reduced scattering and out-of-focus absorption of NIR photons, enables optical sectioning deep in biological tissue without affecting its integrity. ${ }^{124,125}$ The use of NIR excitation limits photodamage as long as a critical threshold, which depends on potential fluorophore phototoxicity, tissue, and laser power, is not exceeded. ${ }^{126,127}$ Fluorescence intensity in TPLSM depends on the square of the excitation power; however, two-photon photobleaching is associated with higher-order photon interactions, implying that photobleaching increases highly non-linear with increasing laser power. ${ }^{128}$ Whereas in confocal fluorescence microscopy pinholes are used to reject out-offocus contributions, pinholes are not required in TPLSM. However, pinholes do increase spatial resolution in TPLSM, albeit at the cost of a severe reduction in signal-to-noise ratio (SNR). ${ }^{129}$

In theory, the spatial resolution of TPLSM is approximately $70 \%$ of that of CLSM due to the longer-wavelength photons. ${ }^{130}$ However, the effective (practical) resolution depends on the SNR and contrast of the sample. Therefore, the spatial resolution of TPLSM deteriorates far less than that of CLSM when tissue penetration depth is increased (Figure 3). ${ }^{131}$ Thus, in superficial layers, CLSM is to be preferred, whereas TPLSM is ideal for imaging deeper in intact tissue. 

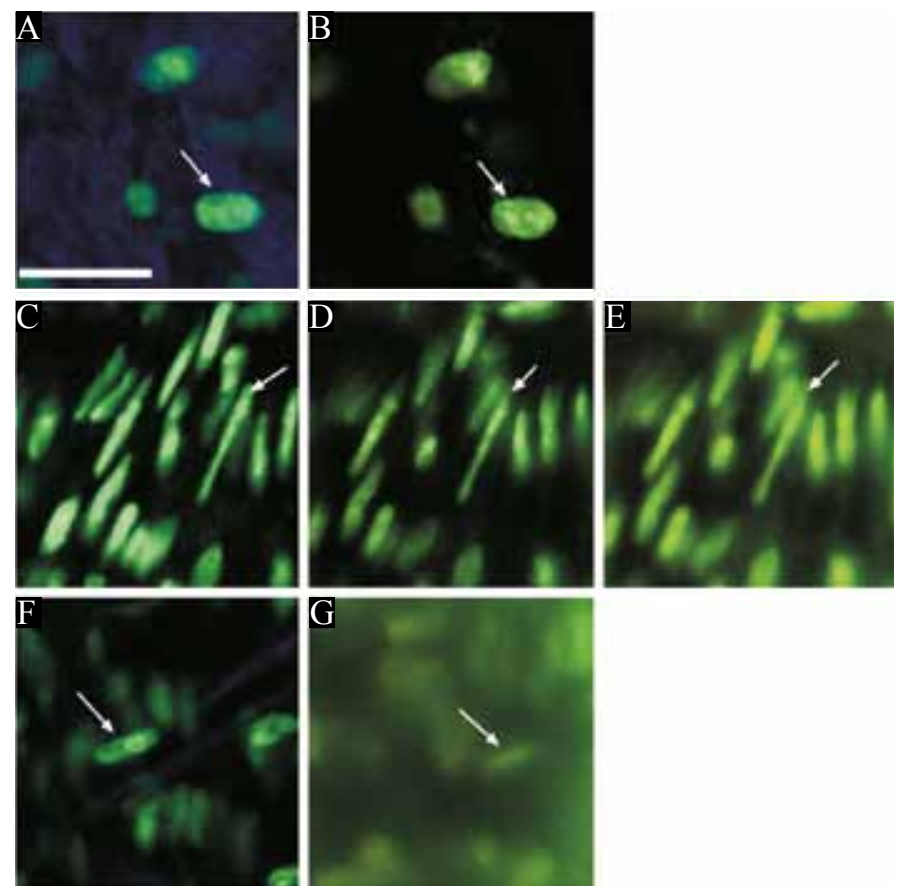

Figure 3 Effect of penetration depth on the effective spatial resolution obtained with TPLSM (A, C, F) and CLSM (B, D, E, G). TPLSM and CLSM were applied to a mouse carotid artery, which was embedded in agarose gel. Cell nuclei of the artery were labeled with SYTO13 (green). Images are obtained from the tunica adventitia ( $A-B, 15 \mu \mathrm{m}$ depth), the tunica media (C-E, $40 \mu \mathrm{m}$ depth), and the tunica intima $(F-G, 80 \mu \mathrm{m}$ depth). Due to out-of-focus fluorescence in CLSM, the effective resolution deteriorates far more with increasing depths as compared with TPLSM. Confocal images obtained with optimal pinhole settings, ${ }^{131}$ except for $E$ in which the pinholes were fully open. Bar indicates $20 \mu \mathrm{m}$. Figure is adapted from $^{131}$ and used with permission from $S$. Karger AG, Basel Germany.

\section{Two-photon laser scanning microscopy for visualization and} quantification of (micro-) vascular characteristics

TPLSM offers a high spatial resolution with limited effect on tissue integrity. However, inherent fluorescence from tissue, i.e., autofluorescence, is generally not sufficient to provide adequate contrast. With fluorophore-conjugated antibodies and other specific fluorophores, molecular expression patterns, cells, and vascular structures can be discriminated, including inflammation and apoptosis related adhesion molecules, ${ }^{132-134}$ the endothelial glycocalyx, and elastin and collagen fibers. ${ }^{131,135,136}$ In addition, fluorescent labeling of blood-borne macromolecules, e.g., serum albumin, allows in vivo quantification of perfusion and diffusion in tumors ${ }^{62,137,138}$ and vascular dynamics in the brain cortex and tumors ${ }^{139-142}$ at depths of over 200 $\mu \mathrm{m} .{ }^{105}$ Moreover, TPLSM may be used for in vivo quantification of vascular morphology, e.g., volume density of angiogenic vessels. ${ }^{143}$

Optical systems are characterized by a point spread function (PSF) that describes the response to a point source and, hence, is a measure of the resolving power of the optical system. However, the PSF causes anisotropic deformation of components in the acquired (threedimensional) datasets (Figure 4). Quantification of vessel diameters and volumes requires restoration of the acquired anisotropic dataset. Therefore, blind and non-blind deconvolution methods have been developed. Blind deconvolution is an iterative procedure during which the initial PSF is estimated based on configurations of the optical system (Figure 5), e.g., magnification, emission wavelength, refractive index, and signal-to-noise ratio, whereas non-blind deconvolution refers to deconvolution using an experimentally obtained PSF. Recently, deconvolution methods were developed with a static and adaptive depth-dependent PSF to correct for decreased intensity and axial resolution with increasing depths, respectively. ${ }^{144,145}$ In this thesis commercially available deconvolution software was utilized to perform straightforward blind deconvolution. 


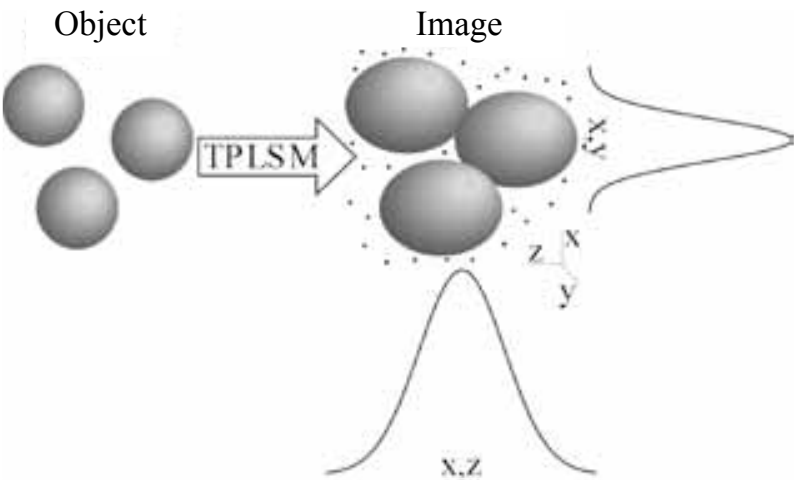

Figure 4 Transformation in optical imaging (optical axis parallel to z-axis). Due to the point spread function (see text) of the TPLSM setup, which has different lateral $(x, y)$ and axial $(z)$ dimensions, spheres are visualized as spheroids.

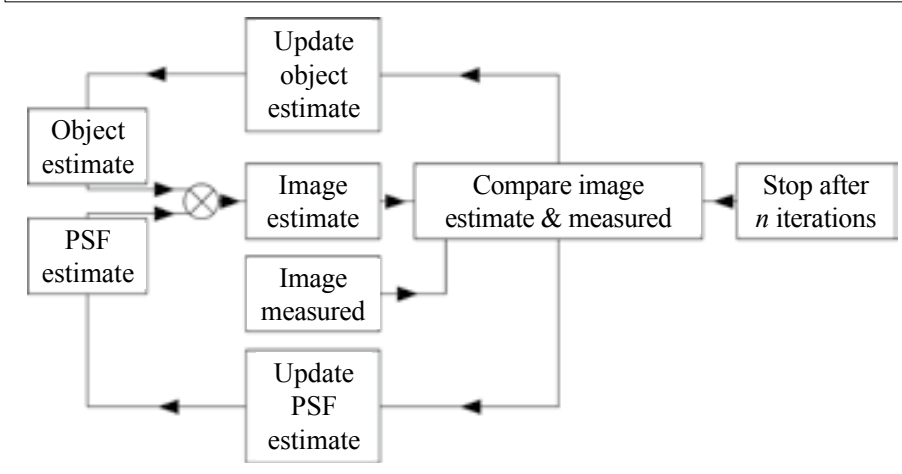

Figure 5 Schematic representation of blind deconvolution. The initial PSF estimate is based on parameters of the optical system, e.g., magnification, emission wavelength, refractive index, and signal-to-noise ratio. Image estimates are obtained by convolution of the object estimate with the PSF estimate. Deconvolution is performed $n$ times.

\section{Two-photon laser scanning microscopy as complementary high-resolution method}

The routinely used in vivo (molecular) imaging modalities, e.g., MRI, positron emission tomography (PET), and computed tomography $(\mathrm{CT})$, offer a limited spatial resolution. Hence, these methods may fail to discriminate between contrast agents that specifically bind to (angiogenic) endothelial cells and contrast agents that have extravasated from the blood into the perivascular interstitial space. TPLSM offers a sub-micrometer spatial resolution and thus allows visualization and quantification of contrast agent binding and extravasation. Furthermore, immunohistological slices are often associated with cutting artifacts. In contrast, TPLSM allows imaging in intact, unprocessed tissue. However, TPLSM offers a penetration depth limited to several hundreds of micrometers, which inhibits whole-body imaging. The limited sampling volume requires adequate sampling of the tissue of interest to obtain reliable information. 


\section{References}

1. Carmeliet P. Mechanisms of angiogenesis and arteriogenesis. Nat Med 2000;6:389-95. 2. Folkman J. Angiogenesis in cancer, vascular, rheumatoid and other disease. Nat Med 1995;1:27-31.

3. Fong GH. Mechanisms of adaptive angiogenesis to tissue hypoxia. Angiogenesis 2008;11:121-40.

4. Ushio-Fukai M, Alexander RW. Reactive oxygen species as mediators of angiogenesis signaling: role of $N A D(P) H$ oxidase. Mol Cell Biochem 2004;264:85-97.

5. Kim CH, Cho YS, Chun YS, Park JW, Kim MS. Early expression of myocardial HIFlalpha in response to mechanical stresses: regulation by stretch-activated channels and the phosphatidylinositol 3-kinase signaling pathway. Circ Res 2002;90:E25-33.

6. Costa C, Incio J, Soares R. Angiogenesis and chronic inflammation: cause or consequence? Angiogenesis 2007;10:149-66.

7. Sluimer JC, Gasc JM, van Wanroij JL, et al. Hypoxia, hypoxia-inducible transcription factor, and macrophages in human atherosclerotic plaques are correlated with intraplaque angiogenesis. J Am Coll Cardiol 2008;51:1258-65.

8. Balasubramanian SP, Brown NJ, Reed MW. Role of genetic polymorphisms in tumour angiogenesis. Br J Cancer 2002;87:1057-65.

9. Bellon G, Martiny L, Robinet A. Matrix metalloproteinases and matrikines in angiogenesis. Crit Rev Oncol Hematol 2004;49:203-20.

10. Cooke JP, Losordo DW. Nitric oxide and angiogenesis. Circulation 2002;105:2133-5. 11. Dvorak HF, Nagy JA, Feng D, Brown LF, Dvorak AM. Vascular permeability factor/vascular endothelial growth factor and the significance of microvascular hyperpermeability in angiogenesis. Curr Top Microbiol Immunol 1999;237:97-132.

12. Gerhardt H, Betsholtz C. Endothelial-pericyte interactions in angiogenesis. Cell Tissue Res 2003;314:15-23.

13. Jain RK. Molecular regulation of vessel maturation. Nat Med 2003;9:685-93.

14. Birner P, Gatterbauer B, Oberhuber G, et al. Expression of hypoxia-inducible factor-1 alpha in oligodendrogliomas: its impact on prognosis and on neoangiogenesis. Cancer 2001;92:165-71.

15. Zagzag D, Zhong H, Scalzitti JM, Laughner E, Simons JW, Semenza GL. Expression of hypoxia-inducible factor lalpha in brain tumors: association with angiogenesis, invasion, and progression. Cancer 2000;88:2606-18.

16. Lando D, Peet DJ, Gorman JJ, Whelan DA, Whitelaw ML, Bruick RK. FIH-1 is an asparaginyl hydroxylase enzyme that regulates the transcriptional activity of hypoxiainducible factor. Genes Dev 2002;16:1466-71.

17. Li J, Post M, Volk R, et al. PR39, a peptide regulator of angiogenesis. Nat Med 2000;6:49-55.
18. Ravi R, Mookerjee B, Bhujwalla ZM, et al. Regulation of tumor angiogenesis by p53induced degradation of hypoxia-inducible factor 1 alpha. Genes Dev 2000;14:34-44.

19. Groulx I, Lee S. Oxygen-dependent ubiquitination and degradation of hypoxiainducible factor requires nuclear-cytoplasmic trafficking of the von Hippel-Lindau tumor suppressor protein. Mol Cell Biol 2002;22:5319-36.

20. Semenza GL. HIF-1 and mechanisms of hypoxia sensing. Curr Opin Cell Biol 2001; $13: 167-71$.

21. Semenza GL. Targeting HIF-1 for cancer therapy. Nat Rev Cancer 2003;3:721-32. 22. Carmeliet P, Dor Y, Herbert JM, et al. Role of HIF-1alpha in hypoxia-mediated apoptosis, cell proliferation and tumour angiogenesis. Nature 1998;394:485-90.

23. Pouyssegur J, Dayan F, Mazure NM. Hypoxia signalling in cancer and approaches to enforce tumour regression. Nature 2006;441:437-43.

24. Pugh CW, Ratcliffe PJ. Regulation of angiogenesis by hypoxia: role of the HIF system. Nat Med 2003;9:677-84.

25. Blouin CC, Page EL, Soucy GM, Richard DE. Hypoxic gene activation by lipopolysaccharide in macrophages: implication of hypoxia-inducible factor 1 alpha. Blood 2004;103:1124-30.

26. Winner M, Koong AC, Rendon BE, Zundel W, Mitchell RA. Amplification of tumor hypoxic responses by macrophage migration inhibitory factor-dependent hypoxiainducible factor stabilization. Cancer Res 2007;67:186-93.

27. Gerald D, Berra E, Frapart YM, et al. JunD reduces tumor angiogenesis by protecting cells from oxidative stress. Cell 2004;118:781-94.

28. Yang C, Mwaikambo BR, Zhu T, et al. Lymphocytic microparticles inhibit angiogenesis by stimulating oxidative stress and negatively regulating VEGF-induced pathways. Am J Physiol Regul Integr Comp Physiol 2008;294:R467-76.

29. Libby P, Ridker PM, Maseri A. Inflammation and atherosclerosis. Circulation 2002;105:1135-43.

30. Chatzizisis YS, Coskun AU, Jonas M, Edelman ER, Feldman CL, Stone PH. Role of endothelial shear stress in the natural history of coronary atherosclerosis and vascular remodeling: molecular, cellular, and vascular behavior. J Am Coll Cardiol 2007;49:2379-93.

31. Homma S, Troxclair DA, Zieske AW, Malcom GT, Strong JP. Histological topographical comparisons of atherosclerosis progression in juveniles and young adults. Atherosclerosis 2008;197:791-8.

32. Huxley VH, Williams DA. Role of a glycocalyx on coronary arteriole permeability to proteins: evidence from enzyme treatments. Am J Physiol Heart Circ Physiol 2000;278:H1177-85.

33. Björnheden T, Levin M, Evaldsson M, Wiklund O. Evidence of hypoxic areas within the arterial wall in vivo. Arterioscler Thromb Vasc Biol 1999;19:870-6. 
34. Sluimer JC, Gasc JM, Van Wanroij JL, et al. Hypoxia in murine plaque macrophages overrides the effect of LysMcre/HIFlalpha and PHDI deficiency on HIF protein expression and murine atherosclerosis. Submitted.

35. Higashida T, Kanno H, Nakano M, Funakoshi K, Yamamoto I. Expression of hypoxia-inducible angiogenic proteins (hypoxia-inducible factor-1alpha, vascular endothelial growth factor, and E26 transformation-specific-1) and plaque hemorrhage in human carotid atherosclerosis. J Neurosurg 2008;109:83-91.

36. Fleiner M, Kummer M, Mirlacher M, et al. Arterial neovascularization and inflammation in vulnerable patients: early and late signs of symptomatic atherosclerosis. Circulation 2004;110:2843-50.

37. Gössl M, Versari D, Mannheim D, Ritman EL, Lerman LO, Lerman A. Increased spatial vasa vasorum density in the proximal LAD in hypercholesterolemia--implications for vulnerable plaque-development. Atherosclerosis 2007;192:246-52.

38. Kumamoto M, Nakashima Y, Sueishi K. Intimal neovascularization in human coronary atherosclerosis: its origin and pathophysiological significance. Hum Pathol 1995;26:450-6.

39. Galili O, Herrmann J, Woodrum J, Sattler KJ, Lerman LO, Lerman A. Adventitial vasa vasorum heterogeneity among different vascular beds. J Vasc Surg 2004;40:529-35.

40. Herrmann J, Lerman LO, Rodriguez-Porcel M, et al. Coronary vasa vasorum neovascularization precedes epicardial endothelial dysfunction in experimental hypercholesterolemia. Cardiovasc Res 2001;51:762-6.

41. Kwon HM, Sangiorgi G, Ritman EL, et al. Enhanced coronary vasa vasorum neovascularization in experimental hypercholesterolemia. J Clin Invest 1998;101:1551-6. 42. Khurana R, Zhuang Z, Bhardwaj S, et al. Angiogenesis-dependent and independent phases of intimal hyperplasia. Circulation 2004;110:2436-43.

43. Milei J, Parodi JC, Alonso GF, Barone A, Grana D, Matturri L. Carotid rupture and intraplaque hemorrhage: immunophenotype and role of cells involved. Am Heart J 1998;136:1096-105.

44. Virmani R, Narula J, Farb A. When neoangiogenesis ricochets. Am Heart J 1998;136:937-9.

45. Libby P, Schonbeck U. Drilling for oxygen: angiogenesis involves proteolysis of the extracellular matrix. Circ Res 2001;89:195-7.

46. de Boer OJ, van der Wal AC, Teeling P, Becker AE. Leucocyte recruitment in rupture prone regions of lipid-rich plaques: a prominent role for neovascularization? Cardiovasc Res 1999;41:443-9.

47. Jeziorska M, Woolley DE. Local neovascularization and cellular composition within vulnerable regions of atherosclerotic plaques of human carotid arteries. J Pathol 1999;188:189-96.

48. Sukhova GK, Schonbeck U, Rabkin E, et al. Evidence for increased collagenolysis by interstitial collagenases-1 and -3 in vulnerable human atheromatous plaques. Circulation 1999;99:2503-9.

49. Moreno PR, Purushothaman KR, Fuster V, et al. Plaque neovascularization is increased in ruptured atherosclerotic lesions of human aorta: implications for plaque vulnerability. Circulation 2004;110:2032-8.

50. Virmani R, Kolodgie FD, Burke AP, et al. Atherosclerotic plaque progression and vulnerability to rupture: angiogenesis as a source of intraplaque hemorrhage. Arterioscler Thromb Vasc Biol 2005;25:2054-61.

51. Daugherty A. Mouse models of atherosclerosis. Am J Med Sci 2002;323:3-10.

52. Kiefer CR, McKenney JB, Trainor JF, Snyder LM. Maturation-dependent acquired coronary structural alterations and atherogenesis in the Dahl sodium-sensitive hypertensive rat. Circulation 2002;106:2486-90.

53. Ohashi $\mathrm{R}, \mathrm{Mu} \mathrm{H}$, Yao Q, Chen C. Cellular and molecular mechanisms of atherosclerosis with mouse models. Trends Cardiovasc Med 2004;14:187-90.

54. Taylor JM, Fan J. Transgenic rabbit models for the study of atherosclerosis. Front Biosci 1997;2:d298-308.

55. Yanni AE. The laboratory rabbit: an animal model of atherosclerosis research. Lab Anim 2004;38:246-56.

56. Ishibashi S, Brown MS, Goldstein JL, Gerard RD, Hammer RE, Herz J. Hypercholesterolemia in low density lipoprotein receptor knockout mice and its reversal by adenovirus-mediated gene delivery. J Clin Invest 1993;92:883-93.

57. Wouters K, Shiri-Sverdlov R, van Gorp PJ, van Bilsen M, Hofker MH. Understanding hyperlipidemia and atherosclerosis: lessons from genetically modified apoe and ldlr mice. Clin Chem Lab Med 2005;43:470-9.

58. Zhang SH, Reddick RL, Piedrahita JA, Maeda N. Spontaneous hypercholesterolemia and arterial lesions in mice lacking apolipoprotein E. Science 1992;258:468-71.

59. Veniant MM, Withycombe S, Young SG. Lipoprotein size and atherosclerosis susceptibility in Apoe(-/-) and Ldlr(-/-) mice. Arterioscler Thromb Vasc Biol 2001;21:1567-70.

60. Ishibashi S, Herz J, Maeda N, Goldstein JL, Brown MS. The two-receptor model of lipoprotein clearance: tests of the hypothesis in "knockout" mice lacking the low density lipoprotein receptor, apolipoprotein E, or both proteins. Proc Natl Acad Sci U S A 1994;91:4431-5.

61. Witting PK, Pettersson K, Ostlund-Lindqvist AM, Westerlund C, Eriksson AW, Stocker R. Inhibition by a coantioxidant of aortic lipoprotein lipid peroxidation and atherosclerosis in apolipoprotein $E$ and low density lipoprotein receptor gene double knockout mice. Faseb J 1999;13:667-75.

62. Braun A, Trigatti BL, Post MJ, et al. Loss of SR-BI expression leads to the early onset of occlusive atherosclerotic coronary artery disease, spontaneous myocardial 
infarctions, severe cardiac dysfunction, and premature death in apolipoprotein E-deficient mice. Circ Res 2002;90:270-6.

63. Kuhlencordt PJ, Gyurko R, Han F, et al. Accelerated atherosclerosis, aortic aneurysm formation, and ischemic heart disease in apolipoprotein E/endothelial nitric oxide synthase double-knockout mice. Circulation 2001;104:448-54.

64. Falk E, Schwartz SM, Galis ZS, Rosenfeld ME. Putative murine models of plaque rupture. Arterioscler Thromb Vasc Biol 2007;27:969-72.

65. Schwartz SM, Galis ZS, Rosenfeld ME, Falk E. Plaque rupture in humans and mice. Arterioscler Thromb Vasc Biol 2007;27:705-13.

66. Johnson J, Carson K, Williams H, et al. Plaque rupture after short periods of fat feeding in the apolipoprotein E-knockout mouse: model characterization and effects of pravastatin treatment. Circulation 2005;111:1422-30.

67. Johnson JL, Jackson CL. Atherosclerotic plaque rupture in the apolipoprotein E knockout mouse. Atherosclerosis 2001;154:399-406.

68. von der Thüsen JH, van Vlijmen BJ, Hoeben RC, et al. Induction of atherosclerotic plaque rupture in apolipoprotein E-/- mice after adenovirus-mediated transfer of p53. Circulation 2002;105:2064-70.

69. Williams H, Johnson JL, Carson KG, Jackson CL. Characteristics of intact and ruptured atherosclerotic plaques in brachiocephalic arteries of apolipoprotein $E$ knockout mice. Arterioscler Thromb Vasc Biol 2002;22:788-92.

70. Jackson CL, Bennett MR, Biessen EA, Johnson JL, Krams R. Assessment of unstable atherosclerosis in mice. Arterioscler Thromb Vasc Biol 2007;27:714-20.

71. Virmani R, Kolodgie FD, Burke AP, Farb A, Schwartz SM. Lessons from sudden coronary death: a comprehensivemorphological classification scheme for atherosclerotic lesions. Arterioscler Thromb Vasc Biol 2000;20:1262-75.

72. Hanahan D, Weinberg RA. The hallmarks of cancer. Cell 2000;100:57-70.

73. Vogelstein B, Kinzler KW. The multistep nature of cancer. Trends Genet 1993;9:138-41.

74. Futreal PA, Coin L, Marshall M, et al. A census of human cancer genes. Nat Rev Cancer 2004:4:177-83.

75. Poulsen HE, Prieme H, Loft S. Role of oxidative DNA damage in cancer initiation and promotion. Eur J Cancer Prev 1998;7:9-16.

76. Tricker AR, Preussmann R. Chemical food contaminants in the initiation of cancer Proc Nutr Soc 1990;49:133-44.

77. Hahn WC, Counter CM, Lundberg AS, Beijersbergen RL, Brooks MW, Weinberg RA Creation of human tumour cells with defined genetic elements. Nature 1999;400:464-8.

78. Rajendran JG, Wilson DC, Conrad EU, et al. [(18)F]FMISO and [(18)F]FDG PET imaging in soft tissue sarcomas: correlation of hypoxia, metabolism and VEGF expression. Eur J Nucl Med Mol Imaging 2003;30:695-704.

79. Torres Filho IP, Leunig M, Yuan F, Intaglietta M, Jain RK. Noninvasive measurement of microvascular and interstitial oxygen profiles in a human tumor in SCID mice. Proc Natl Acad Sci U S A 1994;91:2081-5.

80. Harada H, Xie X, Itasaka S, et al. Diameter of tumor blood vessels is a good parameter to estimate HIF-1-active regions in solid tumors. Biochem Biophys Res Commun 2008;373:533-8.

81. Gimbrone MA, Jr., Leapman SB, Cotran RS, Folkman J. Tumor dormancy in vivo by prevention of neovascularization. J Exp Med 1972;136:261-76.

82. Li XF, Carlin S, Urano M, Russell J, Ling CC, O’Donoghue JA. Visualization of hypoxia in microscopic tumors by immunofluorescent microscopy. Cancer Res 2007;67:7646-53.

83. Bremnes RM, Camps C, Sirera R. Angiogenesis in non-small cell lung cancer: the prognostic impact of neoangiogenesis and the cytokines VEGF and bFGF in tumours and blood. Lung Cancer 2006;51:143-58.

84. Kakeji Y, Maehara Y, Sumiyoshi Y, Oda S, Emi Y. Angiogenesis as a target for gastric cancer. Surgery 2002;131:S48-54.

85. Nicholson B, Theodorescu D. Angiogenesis and prostate cancer tumor growth. J Cell Biochem 2004;91:125-50.

86. Ribatti D, Marimpietri D, Pastorino F, et al. Angiogenesis in neuroblastoma. Ann N Y Acad Sci 2004;1028:133-42.

87. Schneider BP, Miller KD. Angiogenesis of breast cancer. J Clin Oncol 2005;23:1782-90. 88. Cristi E, Perrone G, Toscano G, et al. Tumour proliferation, angiogenesis, and ploidy status in human colon cancer. J Clin Pathol 2005;58:1170-4.

89. Kaspar M, Trachsel E, Neri D. The antibody-mediated targeted delivery of interleukin-15 and GM-CSF to the tumor neovasculature inhibits tumor growth and metastasis. Cancer Res 2007;67:4940-8.

90. Ogawa T, Takayama K, Takakura N, Kitano S, Ueno H. Anti-tumor angiogenesis therapy using soluble receptors: enhanced inhibition of tumor growth when soluble fibroblast growth factor receptor-1 is used with soluble vascular endothelial growth factor receptor Cancer Gene Ther 2002:9:633-40.

91. Zhang J, Lu A, Beech D, Jiang B, Lu Y. Suppression of breast cancer metastasis through the inhibition of VEGF-mediated tumor angiogenesis. Cancer Ther 2007;5:273-286.

92. Jain RK. Normalization of tumor vasculature: an emerging concept in antiangiogenic therapy. Science 2005;307:58-62.

93. Taguchi E, Nakamura K, Miura T, Shibuya M, Isoe T. Anti-tumor activity and tumor vessel normalization by the vascular endothelial growth factor receptor tyrosine kinase inhibitor KRN951 in a rat peritoneal disseminated tumor model. Cancer Sci 2008;99:623-30.

94. Hlatky L, Hahnfeldt P, Folkman J. Clinical application of antiangiogenic therapy: microvessel density, what it does and doesn't tell us. J Natl Cancer Inst 2002;94:883-93. 
95. Demirkesen C, Buyukpinarbasili N, Ramazanoglu R, Oguz O, Mandel NM, Kaner $\mathrm{G}$. The correlation of angiogenesis with metastasis in primary cutaneous melanoma: a comparative analysis of microvessel density, expression of vascular endothelial growth factor and basic fibroblastic growth factor. Pathology 2006;38:132-7.

96. Dewan MZ, Terunuma H, Ahmed S, et al. Natural killer cells in breast cancer cell growth and metastasis in SCID mice. Biomed Pharmacother 2005;59 Suppl 2:S375-9.

97. Kelland LR. Of mice and men: values and liabilities of the athymic nude mouse model in anticancer drug development. Eur J Cancer 2004;40:827-36.

98. Cameron MD, Schmidt EE, Kerkvliet N, et al. Temporal progression of metastasis in lung: cell survival, dormancy, and location dependence of metastatic in-efficiency. Cancer Res 2000;60:2541-6.

99. Hiraga T, Myoui A, Choi ME, Yoshikawa H, Yoneda T. Stimulation of cyclooxygenase-2 expression by bone-derived transforming growth factor-beta enhances bone metastases in breast cancer. Cancer Res 2006;66:2067-73.

100. Li XF, Kinuya S, Yokoyama K, et al. Benefits of combined radioimmunotherapy and anti-angiogenic therapy in a liver metastasis model of human colon cancer cells. Eur J Nucl Med Mol Imaging 2002;29:1669-74.

101. Langheinrich AC, Michniewicz A, Sedding DG, et al. Correlation of vasa vasorum neovascularization and plaque progression in aortas of apolipoprotein E(-/-)/low-density lipoprotein(-/-) double knockout mice. Arterioscler Thromb Vasc Biol 2006;26:347-52.

102. Maehara N. Experimental microcomputed tomography study of the $3 D$ microangioarchitecture of tumors. Eur Radiol 2003;13:1559-65.

103. Kiselev VG, Strecker R, Ziyeh S, Speck O, Hennig J. Vessel size imaging in humans. Magn Reson Med 2005;53:553-63.

104. Troprès I, Lamalle $\mathrm{L}$, Peoc'h $\mathrm{M}$, et al. In vivo assessment of tumoral angiogenesis. Magn Reson Med 2004;51:533-41.

105. Brown EB, Campbell RB, Tsuzuki Y, et al. In vivo measurement of gene expression, angiogenesis and physiological function in tumors using multiphoton laser scanning microscopy. Nat Med 2001;7:864-8.

106. Leunig M, Yuan F, Menger MD, et al. Angiogenesis, microvascular architecture, microhemodynamics, and interstitial fluid pressure during early growth of human adenocarcinoma LS174T in SCID mice. Cancer Res 1992;52:6553-60.

107. Yang M, Baranov E, Li XM, et al. Whole-body and intravital optical imaging of angiogenesis in orthotopically implanted tumors. Proc Natl Acad Sci U S A 2001;98:2616-21.

108. de Lussanet QG, Langereis S, Beets-Tan RG, et al. Dynamic contrast-enhance MR imaging kinetic parameters and molecular weight of dendritic contrast agents in tumor angiogenesis in mice. Radiology 2005;235:65-72.

109. Goossen TE, de la Rosette JJ, Hulsbergen-van de Kaa CA, van Leenders GJ,
Wijkstra H. The value of dynamic contrast enhanced power Doppler ultrasound imaging in the localization of prostate cancer. Eur Urol 2003;43:124-31.

110. Yuan F, Dellian M, Fukumura D, et al. Vascular permeability in a human tumor xenograft: molecular size dependence and cutoff size. Cancer Res 1995;55:3752-6.

111. Mulder WJ, Strijkers GJ, Habets JW, et al. MR molecular imaging and fluorescence microscopy for identification of activated tumor endothelium using a bimodal lipidic nanoparticle. Faseb J 2005;19:2008-10.

112. Winter PM, Caruthers SD, Kassner A, et al. Molecular imaging of angiogenesis in nascent Vx-2 rabbit tumors using a novel alpha(nu)beta3-targeted nanoparticle and 1.5 tesla magnetic resonance imaging. Cancer Res 2003;63:5838-43.

113. Winter PM, Morawski AM, Caruthers SD, et al. Molecular imaging of angiogenesis in early-stage atherosclerosis with alpha(v)beta3-integrin-targeted nanoparticles. Circulation 2003;108:2270-4

114. Cai W, Shin DW, Chen K, et al. Peptide-labeled near-infrared quantum dots for imaging tumor vasculature in living subjects. Nano Lett 2006;6:669-76.

115. Curnis F, Sacchi A, Borgna L, Magni F, Gasparri A, Corti A. Enhancement of tumor necrosis factor alpha antitumor immunotherapeutic properties by targeted delivery to aminopeptidase N (CD13). Nat Biotechnol 2000;18:1185-90.

116. von Wallbrunn A, Waldeck J, Höltke $C$, et al. In vivo optical imaging of CD13/ $A P N$-expression in tumor xenografts. Journal of Biomedical Optics 2008;13:011007.

117. Buehler A, van Zandvoort MA, Stelt BJ, et al. $c N G R$ : a novel homing sequence for CD13/APN targeted molecular imaging of murine cardiac angiogenesis in vivo. Arterioscler Thromb Vasc Biol 2006;26:2681-7.

118. Denk W, Strickler JH, Webb WW. Two-photon laser scanning fluorescence microscopy. Science 1990;248:73-6.

119. Göppert-Mayer M. Über die Wahrscheinlichkeit des Zusamenwirkens zweier Lichquanten in einem Elementarakt. Naturwissenschaften 1929;17:932.

120. Zipfel WR, Williams RM, Webb WW. Nonlinear magic: multiphoton microscopy in the biosciences. Nat Biotechnol 2003;21:1369-77.

121. Hopkins JM, Sibbett W. Ultrashort-pulse lasers: big payoffs in a flash. Sci Am 2000;283:72-9.

122. French T, So PT, Dong CY, Berland KM, Gratton E. Fluorescence lifetime imaging techniques for microscopy. Methods Cell Biol 1998;56:277-304.

123. Diaspro A, Robello M. Two-photon excitation of fluorescence for three-dimensional optical imaging of biological structures. J Photochem Photobiol B 2000;55:1-8.

124. Helmchen F, Denk W. Deep tissue two-photon microscopy. Nat Methods 2005;2:932-40.

125. Hopt A, Neher E. Highly nonlinear photodamage in two-photon fluorescence microscopy. Biophys J 2001;80:2029-36. 
126. König K. Multiphoton microscopy in life sciences. J Microsc 2000;200:83-104. 127. Squirrell JM, Wokosin DL, White JG, Bavister BD. Long-term two-photon fluorescence imaging of mammalian embryos without compromising viability. Nat Biotechnol 1999;17:763-7.

128. Patterson GH, Piston DW. Photobleaching in two-photon excitation microscopy. Biophys J 2000;78:2159-62.

129. Gauderon R, Lukins $\mathrm{PB}$, Sheppard CJ. Effect of a confocal pinhole in two-photon microscopy. Microsc Res Tech 1999;47:210-4.

130. Gu M, Sheppard CJR. Comparison of three-dimensional imaging properties between two-photon and single-photon fluorescence microscopy. J. Microsc 1995;177:128-137.

131. van Zandvoort MA, Engels W, Douma K, et al. Two-photon microscopy for imaging of the (atherosclerotic) vascular wall: a proof of concept study. J Vasc Res 2004;41:54-63.

132. Ferrara DE, Weiss D, Carnell PH, et al. Quantitative $3 D$ fluorescence technique for the analysis of en face preparations of arterial walls using quantum dot nanocrystals and two-photon excitation laser scanning microscopy. Am J Physiol Regul Integr Comp Physiol 2006;290:R114-23.

133. Megens RT, oude Egbrink MG, Merkx M, Slaaf DW, van Zandvoort MA. Twophoton microscopy on vital carotid arteries: imaging the relationship between collagen and inflammatory cells in atherosclerotic plaques. J Biomed Opt 2008;13:044022.

134. Prinzen L, Miserus RJ, Dirksen A, et al. Optical and magnetic resonance imaging of cell death and platelet activation using annexin a5-functionalized quantum dots. Nano Lett 2007;7:93-100.

135. Megens RT, oude Egbrink MG, Cleutjens JP, et al. Imaging collagen in intact viable healthy and atherosclerotic arteries using fluorescently labeled CNA35 and twophoton laser scanning microscopy. Mol Imaging 2007;6:247-60.

136. Megens RT, Reitsma S, Schiffers $\mathrm{PH}$, et al. Two-photon microscopy of vital murine elastic and muscular arteries. Combined structural and functional imaging with subcellular resolution. J Vasc Res 2007;44:87-98.

137. Alexandrakis G, Brown EB, Tong RT, et al. Two-photon fluorescence correlation microscopy reveals the two-phase nature of transport in tumors. Nat Med 2004;10:203-7. 138. Reyes-Aldasoro CC, Wilson I, Prise VE, et al. Estimation of apparent tumor vascular permeability from multiphoton fluorescence microscopic images of $P 22$ rat sarcomas in vivo. Microcirculation 2008;15:65-79.

139. Nimmagadda A, Park HP, Prado R, Ginsberg MD. Albumin therapy improves local vascular dynamics in a rat model of primary microvascular thrombosis: a two-photon laser-scanning microscopy study. Stroke 2008;39:198-204.

140. Park HP, Nimmagadda A, DeFazio RA, Busto R, Prado R, Ginsberg MD. Albumin therapy augments the effect of thrombolysis on local vascular dynamics in a rat model of arteriolar thrombosis: a two-photon laser-scanning microscopy study. Stroke $2008 \cdot 39 \cdot 1556-62$
141. Serduc R, Verant P, Vial JC, et al. In vivo two-photon microscopy study of shortterm effects of microbeam irradiation on normal mouse brain microvasculature. Int $\mathrm{J}$ Radiat Oncol Biol Phys 2006;64:1519-27.

142. Tozer GM, Ameer-Beg SM, Baker J, et al. Intravital imaging of tumour vascular networks using multi-photon fluorescence microscopy. Adv Drug Deliv Rev 2005;57:135-52.

143. Padera TP, Stoll BR, So PT, Jain RK. Conventional and high-speed intravital multiphoton laser scanning microscopy of microvasculature, lymphatics, and leukocyteendothelial interactions. Mol Imaging 2002;1:9-15.

144. Shaevitz JW, Fletcher DA. Enhanced three-dimensional deconvolution microscopy using a measured depth-varying point-spread function. J Opt Soc Am A Opt Image Sci Vis 2007;24:2622-7.

145. von Tiedemann M, Fridberger A, Ulfendahl M, Tomo I, Boutet de Monvel J. Image adaptive point-spread function estimation and deconvolution for in vivo confocal microscopy. Microsc Res Tech 2006;69:10-20 


\title{
Chapter 3
}

\section{Nanoparticles for optical molecular imaging of atherosclerosis}

\author{
Kim Douma*,Lenneke Prinzen*, DickW. Slaaf, Chris P.M. Reutelingsperger, \\ Erik A.L. Biessen, Tilman M. Hackeng, Mark J. Post \\ and Marc A.M.J. van Zandvoort
}

* Authors have contributed equally

Small 2009;5(5):544-557 


\begin{abstract}
Molecular imaging contributes to future personalized medicine dedicated to treat cardiovascular disease, the leading cause of mortality in industrialized countries. Endoscope-compatible optical imaging techniques would offer a stand-alone alternative and high spatial resolution validation technique to the clinically accepted imaging techniques in the (intravascular) assessment of vulnerable atherosclerotic lesions, which are predisposed to initiate acute clinical events. Efficient optical visualization of molecular epitopes specific for vulnerable atherosclerotic lesions requires targeting of high quality optical contrast-enhancing particles. In this review, we provide an overview of both current optical nanoparticles and targeting ligands for optical molecular imaging of atherosclerotic lesions and speculate on their applicability in the clinical setting.
\end{abstract}




\section{Introduction}

Cardiovascular disease is the leading cause of death in industrialized countries and places a social and financial burden on Western society by contributing strongly to acute clinical events, such as myocardial infarction. Myocardial infarction typically results from exposure of the plaque's thrombogenic content to hte blood upon rupture. It would be of great clinical relevance to non-invasively assess atherosclerotic plaques in the pre-symptomatic phase, including detection of vulnerable plaques and intraplaque hemorrhage, and to classify the plaque's stage of development, thus allowing stratification of patientsat-risk. Assessment of atherogenesis in the early stage of development would direct early treatment to impede this process. The majority of current clinical imaging platforms, including X-ray angiography and computed tomography (CT), focus on post-symptomatic detection of morphological alterations of the arterial wall that affect the lumen diameter. However, the assessment of plaque extent is obscured by outward remodeling and does not provide direct information on plaque vulnerability. Therefore, molecular imaging strategies are being developed for non-invasive diagnosis of coronary artery disease at various stages. Most of these strategies are based on recognizing the stage-specific expression of molecules that allow binding of ligand-conjugated nanoparticles (NPs), ${ }^{1}$ which can be detected with non-invasive clinical imaging platforms such as magnetic resonance imaging (MRI), radionuclide-based imaging (positron emission tomography, PET), single photon emission computed tomography (SPECT), CT and ultrasound (US). The routine application of NPs is still far ahead, but it is an actively evolving field of research with encouraging results that hold promise for future clinical use.

Feasibility of molecular imaging studies is based on progress made in three scientific fields: (1) non-invasive imaging platforms, (2) molecular epitope recognition and ligand identification, and (3) design of high quality contrast agents. As far as the latter is concerned, significant progress is being made in the design of contrast-enhancing NPs for molecular imaging, ${ }^{2-5}$ enabling detection of these NPs with clinical imaging platforms, including MRI and PET/SPECT. However, these imaging platforms have either limited sensitivity or low spatial resolution and therefore lack the ability to detect sparsely expressed molecular epitopes. Moreover, discrimination between specific and non-specific binding or even between bound and circulating NPs is often difficult. In contrast, optical techniques combine high sensitivity with high spatial resolution ${ }^{6}$ and therefore have gained considerable attention as techniques that allow (sub-) cellular localization of targeted hybrid NPs with additional luminescent properties.

In this review, we explore the feasibility of optical imaging techniques in combination with NPs to visualize and identify vulnerable plaques and discuss the potential clinical applications. Common for all optical imaging techniques is the limited penetration depth, which ranges from sub-millimeter to several centimeters. Penetration depth depends on tissue type, as each type has different absorbance and scattering properties, which depend on composition and density. In order to reduce tissue absorbance, excitation and emission light should match the optical window, which is usually in the $700-1200 \mathrm{~nm}$ range. ${ }^{7}$ Below $650 \mathrm{~nm}$, absorbance of light by hemoglobin increases, while water absorbs light above $1200 \mathrm{~nm}$. Scattering of light may cause an additional reduction in penetration depth. In plaque tissue, cholesterol esters and calcifications are known to scatter light more than other tissue components. Scattering is also wavelength determined and may partially be resolved using long wavelength excitation light and near infrared (NIR) NPs.

Several optical imaging techniques are discussed. Two-photon laser scanning microscopy (TPLSM) allows fluorescence imaging at larger penetration depths than single-photon techniques, such as confocal microscopy. Optical coherence tomography (OCT) is the 
optical equivalent of ultrasound, in which the backscatter of emitted light is captured into an image. Raman micro-spectroscopy (RMS) uses the vibration of chemical bonds to identify molecular composition. In photoacoustic tomography (PAT) light is converted into acoustic signals. These techniques will be discussed more extensively in the next paragraph. This review further provides an overview of the physicochemical properties of five optical NPs that have been utilized in in vitro and in vivo studies. Additionally, various possible targeting strategies are provided that ensure homing of the presented NPs to (vulnerable) atherosclerotic lesions. Subsequently, multi-modal NPs are presented that enable (sequential) visualization of pathological processes with complementary imaging platforms in. Finally, we consider the clinical perspectives of the presented optical NPs.

\section{Optical imaging platforms for cardiovascular research}

Optical imaging techniques offer a spatial resolution superior to conventional clinical imaging platforms and enable simultaneous visualization of multiple molecular epitopes. With optical imaging techniques, contrast can be generated by detecting (differences in) fluorophore emission spectra (fluorescence microscopy and derivatives), fluorescence lifetime (fluorescence lifetime imaging, FLIM), polarization (polarization microscopy), molecular resonances (RMS), backscattering (OCT) or photoacoustic waves (PAT). Due to the limited penetration depth of light, non-invasive whole-body animal luminescence imaging is confined to superficial or subcutaneous events, whereas exposure of tissue is mandatory in other situations, for example atherosclerosis. However, with progress made in (near) real-time endoscope-compatible microscopic systems, including multi-photon laser scanning microscopy (MPLSM), ${ }^{8,9} \mathrm{RMS},{ }^{10}$ OCT, ${ }^{11,12}$ and PAT, ${ }^{13}$ state-of-the-art intravascular and real-time optical examination of the morphology of atherosclerotic plaques is within reach. Additionally, targeted optical NPs would allow assessment of the molecular expression patterns of these lesions (see Table 1 for the specifications of the optical imaging platforms).

TPLSM is the most frequently encountered version of MPLSM and is based on the non-linear absorption of two NIR photons, ${ }^{14}$ i.e., photons with wavelengths ranging $700-1000 \mathrm{~nm}$. The probability of excitation depends on the spatial and temporal overlap of two NIR photons at the excitable molecule. Even then absorption cross sections are extremely small and consequently excitation only occurs effectively at the objective's focal zone, the probability rapidly decreasing away from focus. Absence of out-of-focus absorption and emission allows optical slicing and additionally limits photobleaching and -damage, allowing vital imaging of intact tissue. Furthermore, NIR photons have a wavelength approximately double that of traditional fluorescence microscopy and are thus less scattered, resulting in increased penetration depths up to $250 \mu \mathrm{m}$, the exact value strongly depending on tissue absorbance and scattering properties. In cardiovascular research, TPLSM has primarily been applied ex vivo, ${ }^{15-17}$ but in vivo applications are within reach due to recent developments in imaging speed and optical detection efficiency.

RMS is based on detecting vibrational alterations of chemical bonds in molecules upon interaction with monochromatic light and hence provides detailed information on the molecular composition of tissue. For example, ex vivo RMS allows quantification of cholesterol content in arterial walls ${ }^{18}$ and recognition of atherosclerotic vasculature. ${ }^{19,20}$ Furthermore, in vivo studies have shown that RMS is suitable for characterizing arterial wall composition ${ }^{10}$ and is applicable in molecular imaging of tumors. ${ }^{21}$

OCT utilizes the echo time delay and intensity of backscattered light to create cross-sectional images of sub-surface tissue structures. The penetration depth 10-fold larger than that of TPLSM, whereas the spatial resolution is 10 -fold lower. OCT allows ex vivo intravascular 
imaging and characterization of plaque morphology $\mathrm{y}^{22-24}$ and in vivo visualization of vulnerable atherosclerotic plaques in mice ${ }^{25}$ and morphology in human coronary atherosclerotic plaques. ${ }^{26,27}$

In PAT, ultrasonic sources are generated by absorption of pulsed light. Though the application of PAT to cardiovascular disease is in its infancy, PAT allows vascular imaging in vivo with $^{28,29}$ and without ${ }^{30,31}$ exogenous contrast agents. More interestingly, with intravascular PAT atherosclerotic plaques can be identified and characterized $e x$ vivo, ${ }^{32,33}$ which holds great promise for in vivo applications.

Taken together, RMS and OCT allow in vivo assessment of the molecular and structural changes of the atherosclerotic arterial wall. Examples of the in vivo application of TPLSM and PAT in visualizing atherosclerosis are currently unavailable in scientific literature. However, various ex vivo applications have shown their feasibility in atherosclerosis research. Optical NPs, targeted towards molecular epitopes specifically expressed in each stage of plaque development, will increase the sensitivity in the microscopic evaluation of the plaque's stage of development.

\section{Optical nanoparticles for cardiovascular research}

For in vivo molecular imaging, optical NPs require good physicochemical properties for efficient optical detection and functionalization by targeting ligands. In addition to NPsize and shape, modifications in surface structure, e.g., by altering surface charge and attachment of bio-molecules, affect the pharmacokinetics. ${ }^{34}$ Numerous covalent, amphiphilic and electrostatic strategies have been developed to coat optical NPs and adapt circulation halflife, organ accumulation and excretion pathways. However, these coatings may affect luminescence properties, either by increasing ${ }^{35}$ or decreasing ${ }^{36}$ the NP's brightness. We refer to Niemeyer ${ }^{37}$ for additional information on these surface modifications.
Table 1 Optical imaging platforms suitable for intravascular applications.

\begin{tabular}{|c|c|c|c|c|c|}
\hline \multirow{2}{*}{$\begin{array}{l}\begin{array}{l}\text { Optical } \\
\text { platform }\end{array} \\
\text { TPLSM }\end{array}$} & \multirow{2}{*}{$\begin{array}{l}\text { Contrast } \\
\text { Spectral }\end{array}$} & \multirow{2}{*}{$\begin{array}{l}\begin{array}{l}\text { Penetration } \\
\text { depth }[\mathrm{a}]\end{array} \\
\sim 250[\mu \mathrm{m}]\end{array}$} & \multicolumn{2}{|c|}{$\begin{array}{l}\text { Spatial } \\
\text { resolution }[\mu \mathrm{m}]\end{array}$} & \multirow{2}{*}{$\begin{array}{l}\text { Temporal } \\
\text { resolution }[\mathrm{fps}][\mathrm{b}] \\
\text { up to } 50\end{array}$} \\
\hline & & & Axial & $<1$ & \\
\hline & & & Lateral & $<1$ & \\
\hline \multirow[t]{2}{*}{ OCT } & \multirow{2}{*}{$\begin{array}{l}\text { Echo delay \& } \\
\text { backscatter }\end{array}$} & \multirow[t]{2}{*}{$1-2[\mathrm{~mm}]$} & Axial & $\sim 20$ & 30 \\
\hline & & & Lateral & $2-4$ & \\
\hline \multirow[t]{2}{*}{ RMS } & \multirow{2}{*}{$\begin{array}{l}\text { Molecular } \\
\text { resonance }\end{array}$} & \multirow[t]{2}{*}{$450[\mu \mathrm{m}]$} & Axial & - & 1 \\
\hline & & & Lateral & 25 & \\
\hline \multirow[t]{2}{*}{ PAT } & \multirow{2}{*}{$\begin{array}{l}\text { Laser-induced } \\
\text { ultrasound }\end{array}$} & \multirow[t]{2}{*}{ several $[\mathrm{cm}]$} & Axial & 25 & 1 \\
\hline & & & Lateral & 100 & \\
\hline
\end{tabular}

[a] Penetration depth: maximal depth from which an adequate signal may be acquired.

[b] Temporal resolution: maximal frame-rate (in frames per second, fps) that may be attained.

The optical NPs described here are relatively new (see Figure 1 for graphical representations and Table 2 for physicochemical properties), but some have already been tested in vivo in preclinical disease models. Note that the physicochemical properties in Table 2 apply to water-soluble optical NPs without targeting ligands. Quantum dots (QDs) and gold NPs (AuNPs) have proven extremely useful in molecular imaging with optical methods, including TPLSM, OCT and PAT, but presumably have limitations with respect to long term biocompatibility. Three recently synthesized NPs, diamond (DNP), carbon (CNP) and silica (SNP), theoretically have a better biocompatibility and have been tested in vitro for imaging purposes and were shown to have characteristics highly suitable for in vivo optical imaging. The physical principles behind luminescence from QDs, AuNPs and CNPs are beyond the scope of this paper. Therefore light emitted by these NPs is simply referred to as luminescence. 


\section{Quantum dots}

Quantum dots (QDs) are nanometer-sized, semiconductor crystals (Figure 1A) that offer superior photophysical properties over organic dyes, ${ }^{38,39}$ including high quantum yields, ${ }^{40}$ broad excitation spectra and narrow emission spectra and high photostability (Table 2). ${ }^{41,42}$

Importantly, they allow efficient two-photon excitation, which together with the aforementioned advantageous properties makes them suitable for TPLSM imaging deep in scattering tissue. Moreover, the size-dependent emission wavelength allows simultaneous visualization of differently sized QDs with a single-wavelength excitation source. ${ }^{43}$ The photophysical properties of QDs are strongly dependent on regularity in core structure and size-distribution and their synthesis therefore requires stringent conditions. ${ }^{44,45}$ The QD quantum yield can reach $70 \%$ by encapsulating the QD core with an inorganic shell to obtain core/shell QDs. ${ }^{46,47}$ The organic shell furthermore reduces desorption and subsequent oxidation of the toxic core components. ${ }^{48}$ Moreover, additional organic coating of core/shell QDs provides both water-solubility and increased core/ shell stability, ${ }^{35}$ which are required for in vivo applications.

In mice, QDs are generally cleared from the blood by accumulation in organs of the reticuloendothelial system and in some cases also the kidneys, ${ }^{49,50}$ although this varies depending on the surface chemistry and ligands attached. However, QDs are usually not excreted through urine or feces, ${ }^{50,51}$ even for months after intravascular administration, and are therefore assumed to reside in these organs. Hence, accumulated QDs may eventually degrade chemically and release cytotoxic components and are therefore considered to be clinically unsafe. Therefore, several methods were recently developed to produce QDs that are composed of non-toxic components, ${ }^{52,53}$ are encapsulated in a silica-shell to increase biocompatibility, ${ }^{54}$ and are cleared by the kidneys. ${ }^{49}$ These new developments will potentiate the use of QD in future clinical applications. ${ }^{55}$
Targeted QDs are obtained by covalently binding ligands to the shell-surface ${ }^{56}$ or via non-covalent strategies, ${ }^{57}$ including the streptavidin-biotin bond. ${ }^{58}$ The latter is frequently used in biomedical research. Thus far, QDs have been applied to cancer research in animals, including sentinel node mapping ${ }^{59,60}$ and in vivo molecular imaging of tumors. ${ }^{57,61}$ The application of(targeted) QDs to cardiovascular research is advancing. QDs have been used to visualize ex vivo the expression of the oxLDL receptor CD36, ${ }^{62}$ vascular adhesion molecule-1 (VCAM-1) and intracellular adhesion molecule-1 (ICAM-1), ${ }^{63}$ the angiogenic marker CD13, ${ }^{15}$ and phosphatedylserine (PS) exposing cells. ${ }^{64}$ Recently, ICAM-, VCAM-, as well as platelet endothelial cell adhesion molecule (PECAM-) conjugated QDs have been used for simultaneous targeting and imaging of the endothelial phenotype in retinal vasculature. ${ }^{65}$ In addition, the proteolytic activity of matrix metalloproteinases (MMPs) in atherosclerotic plaques, contributing to a mechanically unstable phenotype, may be visualized using QDbased biosensors, ${ }^{66}$ which were successfully applied in vivo in tumors. ${ }^{67}$ However, the approaches mentioned above require external excitation, often implying exposure of the tissue of interest. By chemical excitation of infrared emitting QDs via bio-luminescence resonance energy transfer (BRET), ${ }^{68}$ true non-invasive optical imaging may be realized.

The examples above show that QDs are highly suitable for optical imaging in cardiovascular research. However, besides optical properties, local contrast-enhancing effects of targeted NPs depend on ligand-receptor interactions. Various studies have shown that QDs allow quantification of ligand-receptor binding kinetics ${ }^{69}$ and monitoring of receptor-mediated endocytosis. ${ }^{41,58}$ Therefore, QDs may be applicable to in vivo probing of binding affinity and subsequent processing of ligands specific for atherosclerosis-related molecular epitopes. 


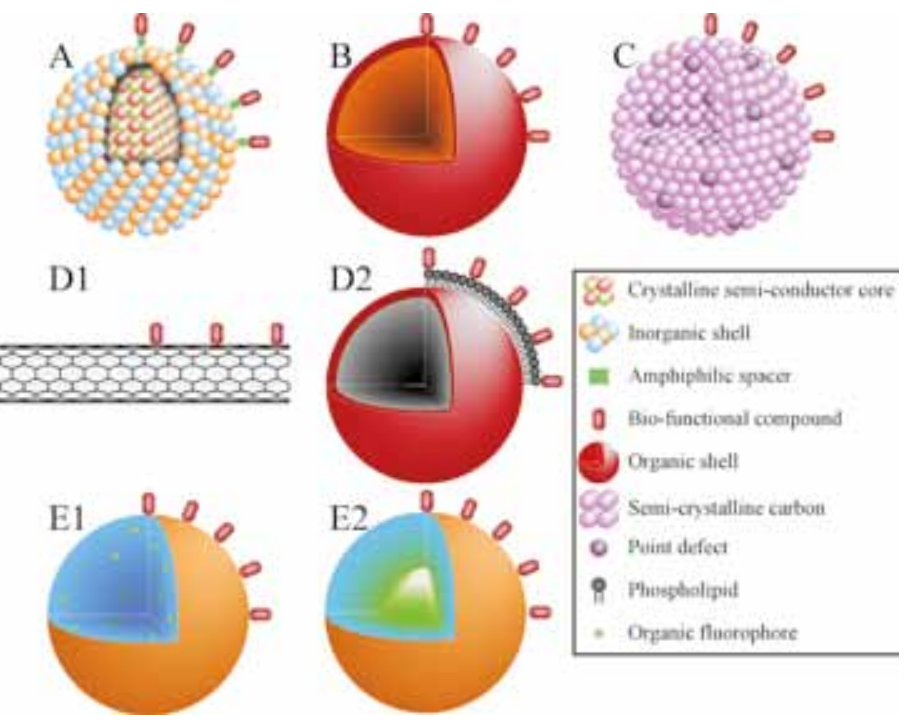

Figure 1 Schematic overview of the composition of A) quantum dot, B) gold nanoparticle, C) diamond nanoparticle, D1) carbon nanotube, D2) carbon dot (C-Dot), E1) silica nanoparticle with encapsulated organic fluorophores, E2) silica nanoparticle with fluorescent core. Several chemical methods for surface binding of bio-active compounds are mentioned in the text. See Table 2 for spatial dimensions.

\section{Gold nanoparticles}

Gold particles are used extensively in electron microscopy ${ }^{70}$ However, recent progress in synthesis of gold nanoparticles (AuNPs, Figure 1B) has yielded highly luminescent NPs with emissions ranging from $400-1200 \mathrm{~nm}^{71,72}$ This NIR emission makes them suitable for optical imaging of biological tissues, since tissue absorption at these wavelengths is limited. AuNPs require an adequate protecting and stabilizing organic shell for their luminescence and display relatively narrow excitation and broad emission spectra with quantum yields up to $40 \% .{ }^{71}$ Similar to QDs, the emission spectra of AuNPs are sizedependent. ${ }^{73}$ Moreover, AuNPs are strongly luminescent upon twophoton absorption ${ }^{74}$ and may display specific surface scattering ${ }^{75}$ indicating that AuNPs can be visualized by both TPLSM and OCT. Furthermore, excitation with NIR photons induces ultrasonic waves, which allow detection with PAT (see Table 2).

In vitro, organically stabilized AuNPs are internalized via endocytosis ${ }^{76,77}$ without affecting cell viability. ${ }^{77,78}$ In vivo, AuNPs predominantly accumulate in the liver and spleen of mice, ${ }^{79}$ do not initiate (hepatic) toxicity, ${ }^{80}$ and are slowly excreted via the feces. ${ }^{81}$ AuNPs are clinically approved for treatment of rheumatoid $\operatorname{arthritis}^{82,83}$ and are considered safe $^{84}$ although several studies showed a correlation between AuNP therapy and lung disease. ${ }^{85,86}$

Covalent attachment of amine ${ }^{87}$ and thiol ${ }^{88}$ groups to the AuNP surface allow functionalization with amino acids ${ }^{89}$ and proteins ${ }^{90}$ for targeted delivery, e.g., to atherosclerosis-related markers. Moreover, direct capping of the AuNP surface with certain amino acids yields stable, water-dispersible and functionalized particles. ${ }^{89,91}$

Agglutination of AuNPs enhances their detection with reflectance microscopy, including $\mathrm{OCT},{ }^{92}$ allowing in vitro visualization of cancer cells. $^{75,76}$ This phenomenon can be exploited in molecular imaging since surface-expressed markers spatially coincide, thereby bringing targeted AuNPs in close contact with each other. Additionally, TPLSM allows visualization of non-targeted AuNPs in vivo ${ }^{93}$ and identification of AuNP-labeled cancer cells in tissue phantoms targeted by AuNPs. ${ }^{94}$

\section{Diamond nanoparticles}

Diamond nanoparticles (DNPs) represent a potentially ideal optical label, combining efficient scattering properties (i.e., they can be used for OCT),${ }^{95}$ bright and photostable fluorescence, ${ }^{96}$ low cytotoxicity, ${ }^{97}$ and chemical stability (Table 2). Fluorescence arises from so-called 
point defects (Figure 1C), ${ }^{98}$ initiated by high-energy irradiation..$^{99}$ Each of the point defects has a fluorescence brightness comparable to a single organic fluorophore, enabling detection of individual DNPs by fluorescence microscopy, ${ }^{97}$ including TPLSM. ${ }^{100}$ However, current DNPs have broad emission spectra, ${ }^{96}$ which significantly hampers multi-color imaging. For functionalization, DNPs are chemically modified to yield carboxylated DNPs for the covalent attachment of bioactive ligands. ${ }^{96,101}$ Recent progress in the dispersion of DNPs in aqueous media has facilitated their use in physiological solutions. ${ }^{102}$

Preliminary results yield DNPs non-toxic in vitro ${ }^{97}$ as well as in vivo. ${ }^{103}$ Long term follow-up studies on DNP toxicity, however, are currently lacking. The favorable photophysical and potential pharmacodynamic characteristics of DNPs show great promise for biological applications, yet preclinical research on DNPs is still in its infancy. In vitro, DNPs were shown to enable single-particle tracking ${ }^{96}$ and detection of growth hormone receptor expression. ${ }^{101}$

\section{Carbon nanoparticles}

Carbon nanoparticles (CNPs), which include carbon nanotubes (CNTs, Figure 1D1) and carbon dots (or C-Dots, ${ }^{104}$ Figure 1D2), may offer a less cytotoxic alternative to the aforementioned quantum dots. CNTs and C-Dots are photostable, ${ }^{104,105}$ but display relatively broad - excitation wavelength dependent - emission spectra (Table 2). ${ }^{105,106}$ Therefore, in contrast to QDs, multi-color TPLSM imaging of CNPs in tissue is limited. Non-aggregated CNTs display an inherent NIR luminescence with a tube-length dependent quantum yield, ${ }^{107}$ reaching values up to $10 \% .{ }^{108} \mathrm{C}$-Dots, however, require a large surface-to-volume ratio and surface stabilization with organic polymers, such as $\mathrm{PEG}_{1500}$, to become luminescent. ${ }^{105}$ Several strategies were developed to obtain individualized and hydrophilic CNTs, including non-covalent functionalization with proteins, ${ }^{109}$ dendrimers ${ }^{110}$ and phospholipids. ${ }^{111}$
CNPs are internalized via endocytosis in vitro, ${ }^{105,112}$ but both CNTs and C-Dots display no acute toxicity. ${ }^{104,113}$ However, longterm effects of CNPs on cell viability strongly depend on surfacebound (bio-) molecules and dose $\mathrm{e}^{12,114}$ and traces of metal catalysts used during synthesis. ${ }^{113}$ In addition, CNTs may penetrate the nuclear membrane physically ${ }^{115}$ and elicit DNA damage through ROS generation. ${ }^{116}$ After intravenous administration of CNTs, no pathological abnormalities were found in the liver, kidneys and other organs. ${ }^{117}$ In rodents, CNTs are cleared by the kidneys, ${ }^{118}$ whereas excretion routes of C-Dots are currently unknown. CNPs may be functionalized for molecular imaging by coating with ligand-bound phospholipids ${ }^{119}$ and amino-terminated dendrimers. ${ }^{110}$

Until now, few studies have utilized CNPs for in vivo optical imaging. Nevertheless, the NIR and Raman signals from CNTs were detected in the blood pool of Drosphilia melanogaster ${ }^{106}$ and in subcutaneously implanted tumors in mice, ${ }^{21}$ respectively. These preliminary results indicate the potential of TPLSM in visualizing CNPs in biological tissue.

\section{Silica nanoparticles}

Fluorescent silica nanoparticles (SNPs) are synthesized by trapping fluorophores in a mesoporous silica matrix (Figure 1E1 and 1E2). The spectral properties thus depend on the entrapped fluorophores and can therefore not be specified. The quantum yield has an optimum since both a low concentration and too high concentration (inducing self-quenching ${ }^{120}$ ) will affect SNP brightness. ${ }^{121}$ The brightness of dye-doped SNPs (Figure 1E1) additionally suffers from dye-leakage from the silica pores, hampering accurate assessment of the spatial distribution of SNPs by optical imaging modalities. Leakage can be reduced by covalent ${ }^{42}$ or electrostatic interactions ${ }^{120}$ between the fluorophore and the silica precursors, by increasing the size of the dye molecule, ${ }^{120}$ or by stabilizing the fluorophore-doped silica core 
with a dye-free silica shell (Figure 1E2). ${ }^{42,120}$ Core/shell SNPs exhibit a relatively high brightness, but still display an approximately 3 -fold lower luminescence intensity than QDs. ${ }^{42}$

Reactive silica precursors enable chemical modifications of the SNP surface. For example, maleimide and iodoacetyl groups can be introduced ${ }^{122}$ and amino groups ${ }^{123}$ can be ionized to enable (covalent) attachment of bioactive ligands.

In vitro experiments show cytotoxic responses to SNPs. Upon internalization by endocytosis, ${ }^{124}$ SNPs impair proliferative activity, stimulate the release of the inflammation marker interleukin-8, and reduce cell viability in vitro in a dose- and time-dependent manner. ${ }^{125-127}$ In mice, however, intravenous administration of colloidal core/shell SNPs at biologically relevant concentrations do not induce acute or chronic responses, even 60 days post-injection. ${ }^{128}$

Several in vitro fluorescence microscopy studies have shown that SNPs allow peripheral labeling of cancer cells by targeting folate receptors. ${ }^{42,129}$ In addition, antibody-conjugated SNPs allow multi-target monitoring of bacteria species. ${ }^{130}$

Table 2 Physicochemical properties of water-soluble non-targeted nanoparticles for optical molecular imaging.

\begin{tabular}{|c|c|c|c|c|c|c|}
\hline & \multirow{2}{*}{ Quantum Dot } & \multirow{2}{*}{ Gold } & \multirow{2}{*}{ Diamond } & \multicolumn{2}{|c|}{ Carbon } & \multirow{2}{*}{ Silica } \\
\hline & & & & Dot & Tube & \\
\hline Quantum yield & $<70 \%{ }^{46,47,131}$ & $<40 \%{ }^{71}$ & $\sim 50 \%{ }^{96}$ & $\sim 10 \%{ }^{105}$ & $<10 \%{ }^{108,132}$ & $\begin{array}{l}\text { Fluorophore \& } \\
\text { concentration } \\
\text { dependent }\end{array}$ \\
\hline $\begin{array}{l}\text { Fluorescence } \\
\text { excitation spectrum } \\
{[\mathrm{nm}]}\end{array}$ & $>200[\mathrm{a}]$ & $300 \sim 450^{71}[\mathrm{a}]$ & $450 \sim 550^{97,133,134}[\mathrm{a}]$ & $450 \sim 650^{105}[\mathrm{a}]$ & Unknown & $\begin{array}{l}\text { Fluorophore } \\
\text { dependent }\end{array}$ \\
\hline $\begin{array}{l}\text { Fluorescence emission } \\
\text { spectrum [nm] }\end{array}$ & $\sim 30[\mathrm{~b}]$ & $\sim 60[\mathrm{~b}]$ & $\sim 100^{96,133}[\mathrm{~b}]$ & $\sim 100^{105}[\mathrm{~b}]$ & $\sim 500^{106,114,117}[\mathrm{a}]$ & $\begin{array}{l}\text { Fluorophore } \\
\text { dependent }\end{array}$ \\
\hline $\begin{array}{l}\text { Hydrodynamic } \\
\text { diameter }[\mathrm{nm}]\end{array}$ & $<20$ & $1-50$ & $35-100$ & $<5$ & $\begin{array}{c}\sim 1 \mathrm{~nm}(\varnothing) \\
<500 \text { (length) }\end{array}$ & $\sim 15$ \\
\hline Blood clearance & $\begin{array}{l}\text { Predominantly } \\
\text { spleen and liver }\end{array}$ & $\begin{array}{l}\text { Predominantly } \\
\text { spleen and liver }\end{array}$ & Unknown & Unknown & Kidneys & $\begin{array}{l}\text { Spleen, liver, and } \\
\text { lung } 128\end{array}$ \\
\hline Excretion & None & Slowly via feces ${ }^{81}$ & Unknown & Unknown & Urine $^{118}$ & Urine and feces ${ }^{135}$ \\
\hline Optical platform & TPLSM & $\begin{array}{l}\text { TPLSM } \\
\text { OCT } \\
\text { PAT }\end{array}$ & $\begin{array}{l}\text { TPLSM } \\
\text { OCT }\end{array}$ & TPLSM & TPLSM & TPLSM \\
\hline
\end{tabular}

[a] Total bandwidth

[b] Full-width-at-half-maximum 


\section{Detection of optical nanoparticles}

For efficient detection, optical NPs should have favorable luminescence properties, i.e., high quantum yield, broad excitation spectrum and narrow emission spectrum that matches the optical window of tissue. The presented optical NPs share the ability to be detected with TPLSM (Table 1). However, the $250 \mu \mathrm{m}$ penetration depth of TPLSM in biological tissue restricts its clinical application to early atherosclerotic lesions. The penetration depth of OCT and PAT are 1 and 2 orders larger, respectively, and may therefore be preferred over TPLSM when greater depths should be attained, i.e., intraplaque visualization of developed lesions.

\section{Targeting nanoparticles to atherosclerotic lesions}

The application of molecular imaging in assessing vulnerable atherosclerotic plaques is a challenging task, since these plaques are highly complex and constantly evolving structures. Consequently, these lesions display numerous molecular targets, expressed either at the endothelial surface or subendothelially by cells and extracellular matrix in the vascular wall.

The American Heart Association (AHA) has recognized six states of plaque development in humans (Figure 2), divided in precursor and advanced types. Precursor lesions (types I, II, III) are asymptomatic and do not narrow the lumen; ${ }^{136}$ whereas advanced lesions (types IV, V, VI) are hemodynamically and clinically more relevant since they may lead to ischemic complications. ${ }^{137}$ Type I plaques are characterized by endothelial activation, which is accompanied by luminal expression of various adhesion molecules; ${ }^{138}$ these include intercellular (ICAM), vascular (VCAM), and platelet endothelial (PECAM) cell adhesion molecules, and the lectin-like oxLDL receptor LOX-1. These adhesion molecules initiate the accumulation of macrophages and lipids in the vascular wall, causing gradual progression to type II lesions. Type III lesions contain extracellular lipid and apoptotic cells and typically show extracellular matrixdegrading enzymes, such as matrix metalloproteinases (MMPs) and cathepsins. ${ }^{138}$ In type IV lesions the necrotic core develops, as large amounts of extracellular lipid accumulate in the intima. Capillaries surround the lipid core, mostly in the shoulder of the plaque, and calcifications may also be present. Macrophages, foam cells, and lymphocytes are mainly present in the periphery of the lesion, most notably in the shoulders of the plaque. Type V lesions develop when the subendothelial layer grows into more collagen-rich tissue, forming the fibrous cap. More and larger capillaries are present in these lesions. Type VI lesions closely resemble type IV and V lesions, but have had disruptions of the lesion surface, hematoma or hemorrhages, with subsequent thrombus formation. It is important to stress that vulnerable plaques do not necessarily coincide with rupture-prone plaques. More accurately, vulnerable plaques are at risk for thrombotic complications and consequent rapid progression of plaque instability, as was proposed by Naghavi et al. ${ }^{139}$

Each stage of plaque development displays specific features, such as inflammation, activated endothelium, accumulated lipid and macrophages, collagen-rich fibrous cap, angiogenic activity, apoptosis and thrombi. Each of these features is associated with specific molecular targets that may be used for molecular imaging. Available targets and corresponding ligands, which have been used in clinical and pre-clinical studies, are mentioned in Table 3. The NPs in Table 3 include both optical and non-optical NPs. The ligands mentioned in Table 3 can be combined with the optical NPs mentioned earlier, to generate particles for specific and highresolution visualization of vulnerable plaques using (endoscopebased) optical imaging techniques. Optical techniques described in Table 3 either require exposure of the tissue of interest or served as 


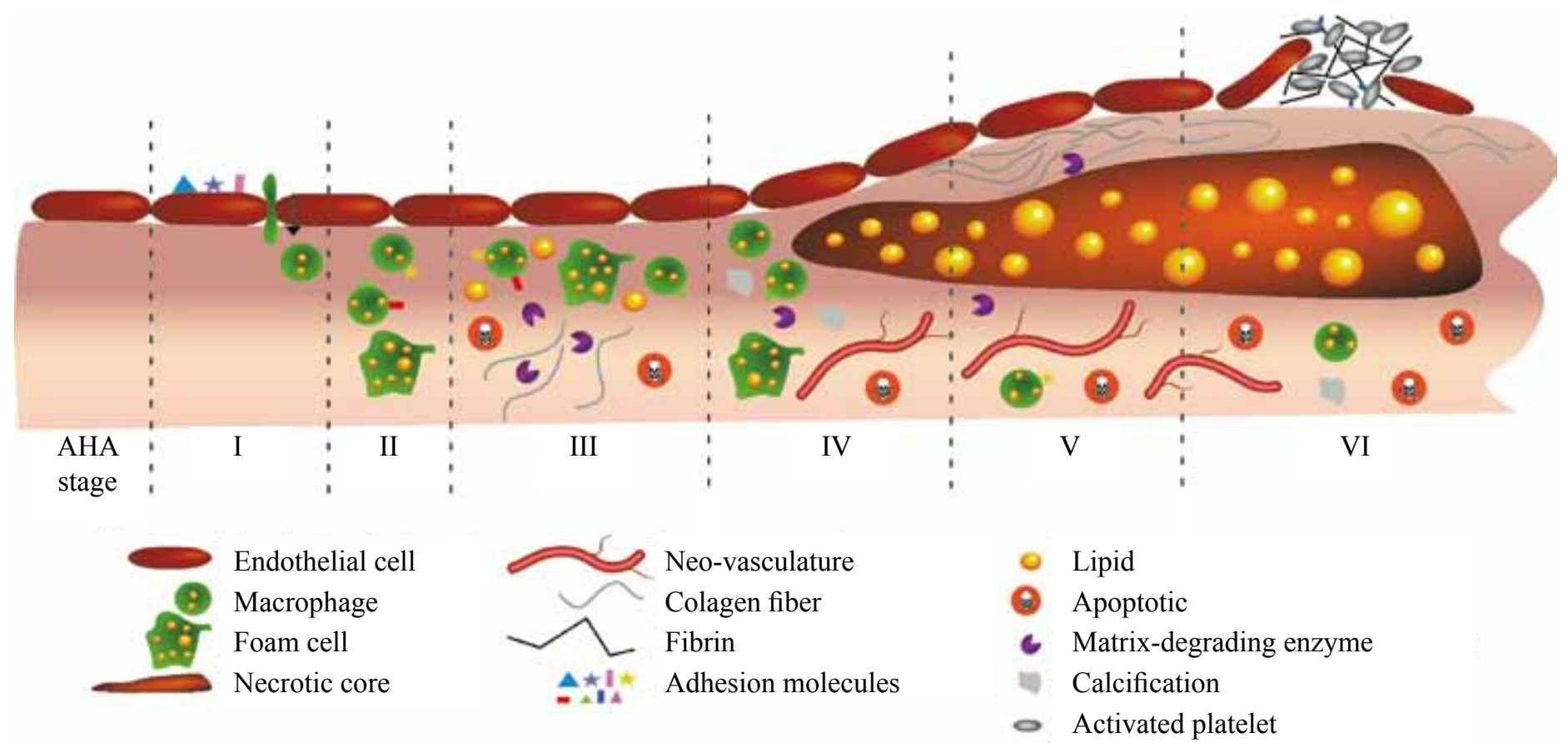

Figure 2 Schematic representation of human plaque progression. The different types of plaque morphology are not necessarily successive and not all plaques progress to ruptured plaques (AHA type VI).

an ex vivo validation tool. Optical imaging techniques are currently being developed that would allow in vivo endoscopy-based imaging.

A distinction should be made between luminal (e.g., CD13) ${ }^{15,140}$ and sub-endothelial targets (e.g., apoptotic cells in atherosclerotic plaques $\left.^{141}\right)$. For sub-endothelial targets the hydrodynamic size of the NP should be considered, as the particle has to translocate through the endothelial layer. Furthermore, the permeability of the endothelium should be taken into account, as plaque endothelium is more permeable than healthy endothelium, allowing translocation of larger NPs. In advanced plaques, NPs may also reach the intraplaque targets through the vasa vasorum, an adventitial vascular network that often expands into the lesion during plaque growth. 
Chapter 3

Table 3 Molecular targets utilized in in vivo studies for stage-specific visualization of plaque progression.

\begin{tabular}{|c|c|c|c|c|c|c|}
\hline $\begin{array}{l}\text { AHA } \\
\text { stage }\end{array}$ & Characteristic & $\begin{array}{l}\text { Molecular target } \\
\text { (location) }\end{array}$ & Ligand & NP & Imaging modality & Reference \\
\hline \multirow[t]{7}{*}{ I } & $\begin{array}{l}\text { Activated endothe- } \\
\text { lium }\end{array}$ & $\begin{array}{l}\text { VCAM-1 } \\
\text { (luminal) }\end{array}$ & $\begin{array}{l}\text { Peptide sequence (not } \\
\text { specified) }\end{array}$ & ${ }^{123} \mathrm{I}$ or ${ }^{99 \mathrm{~m}} \mathrm{Tc}$ & Nuclear & 142 \\
\hline & & $\begin{array}{l}\text { VCAM-1 } \\
\text { (luminal) }\end{array}$ & Antibodies & $\begin{array}{l}\text { Magneto-optical nano- } \\
\text { particles }\end{array}$ & Optical & 143 \\
\hline & & & & Microbubbles & Ultrasound & 144 \\
\hline & & & & Iron oxide particles & MRI & 145 \\
\hline & & $\begin{array}{l}\text { VCAM-1 } \\
\text { (luminal) }\end{array}$ & $\begin{array}{l}\text { Peptide sequence } \\
\text { VHSPNKK }\end{array}$ & Magnetofluorescent NPs & Optical and MRI & 146 \\
\hline & & $\begin{array}{l}\text { VCAM-1 } \\
\text { (luminal) }\end{array}$ & $\begin{array}{l}\text { Peptide sequence } \\
\text { VHPKQHR }\end{array}$ & Magnetofluorescent NPs & Optical and MRI & 147 \\
\hline & & $\begin{array}{l}\text { P-selectin } \\
\text { (luminal) }\end{array}$ & Antibodies & $\begin{array}{l}\text { Iron oxide NPs } \\
\text { Microbubbles }\end{array}$ & $\begin{array}{l}\text { MRI } \\
\text { Ultrasound }\end{array}$ & $\begin{array}{l}148 \\
149\end{array}$ \\
\hline \multirow[t]{5}{*}{ II/III } & $\begin{array}{l}\text { Macrophages/ } \\
\text { Inflammation }\end{array}$ & $\begin{array}{l}\text { MMPs } \\
\text { (sub-endothelial) }\end{array}$ & $\begin{array}{l}\text { Peptide sequence } \\
\text { GGPRQITAG }\end{array}$ & Near infrared probe & Optical & 150 \\
\hline & & $\begin{array}{l}\text { Cathepsin K } \\
\text { (sub-endothelial) }\end{array}$ & $\begin{array}{l}\text { Peptide sequence } \\
\text { GHPGGPQKC }\end{array}$ & Near infrared probe & Optical & 151 \\
\hline & & $\begin{array}{l}\text { Macrophage Scaven- } \\
\text { ger Receptor (CD204) } \\
\text { (sub-endothelial) }\end{array}$ & Antibodies & Immunomicelles & Optical and MRI & 152 \\
\hline & & $\begin{array}{l}\text { P2 receptors or } \\
\text { adenosine nucleotide } \\
\text { receptors } \\
\text { (sub-endothelial) }\end{array}$ & Adenosine nucleotides & ${ }^{18} \mathrm{~F}$ & Nuclear & 153 \\
\hline & & $\begin{array}{l}\text { Glucose transporters } \\
\text { (sub-endothelial) }\end{array}$ & FDG & ${ }^{18} \mathrm{~F}$ & Nuclear & 154,155 \\
\hline III & Apoptosis & $\begin{array}{l}\text { Cell surface expressed } \\
\text { phosphatedylserine } \\
\text { (sub-endothelial) }\end{array}$ & Annexin A5 & $\begin{array}{l}{ }^{99 \mathrm{~m}} \mathrm{Tc} \\
\text { Iron oxide NPs } \\
\text { Paramagnetic QDs }\end{array}$ & $\begin{array}{l}\text { Nuclear } \\
\text { MRI } \\
\text { Optical and MRI }\end{array}$ & $\begin{array}{l}141,156,157 \\
158 \\
64\end{array}$ \\
\hline
\end{tabular}




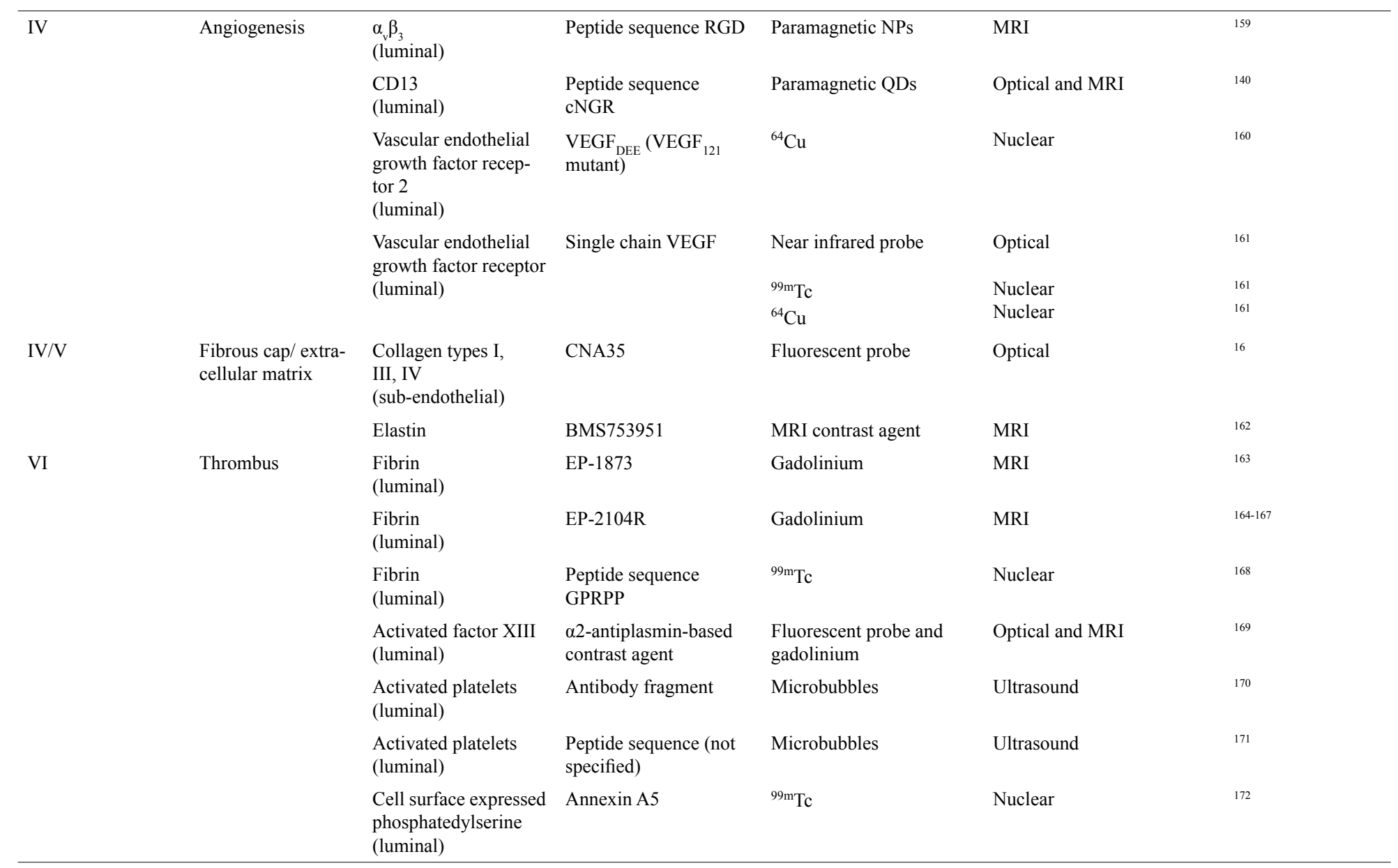




\section{Hybrid nanoparticles for multimodal imaging}

Clinically approved imaging techniques allow non-invasive evaluation of the localization of targeted contrast enhancing NPs, yet lack the sensitivity and resolution to prove target specificity. Therefore, high spatial resolution validation of non-invasive molecular imaging is mandatory and requires NPs suitable for multimodal imaging. Hybrid NPs can be detected by optical imaging methods as well as by non-invasive clinical imaging methods. These hybrid NPs may also be linked to the ligands in Table 3, for imaging of atherosclerosis-related molecular markers. In such a set up, a combination of non-invasive imaging for macroscopic detection, followed by invasive optical imaging, allows determination of distribution and exact location. Hybrid NPs developed so far mostly include MRI and fluorescent labels. Of the hybrid NPs currently available, few have been applied in vivo.

Hybrid lipidic structures, such as liposomes and micelles, are composed of natural amphiphilic lipids and are therefore highly biocompatible. They can be easily formulated and adjusted for various purposes. The maximum payload of added moieties, e.g., ligand or contrast agent, depends on the liposome's size, but may be thousands per liposome. The size of liposomes often exceeds $100 \mathrm{~nm}$, which is large compared to the optical NPs presented in Table 2. In recent decades, though, liposomes have been investigated extensively as drug carriers ${ }^{173,174}$ and two liposomal cytostatic formulations have been approved for clinical use so far. ${ }^{175}$ Incorporation of contrast agents allows their application in imaging purposes, e.g., for in vivo MRI detection of intimal thickening. ${ }^{176}$ When contrast agents with different functionalities are incorporated in the lipid bilayer, dual detection with for instance MRI and fluorescence microscopy is enabled. Hybrid liposomes have been developed to specifically target and visualize the expression of E-selectin ${ }^{177}$ and apoptotic cells. ${ }^{178} \alpha_{v} \beta_{3}$ targeted liposomes with surface-conjugated RGD have been used to detect angiogenic activity in tumors ${ }^{179}$ and in atherosclerotic plaques ${ }^{159}$ by in vivo MRI and subsequent ex vivo validation with fluorescence microscopy. ${ }^{179}$ Bimodal micelles targeting the macrophage scavenger receptor (MSR) by surfacebound anti-MSR antibodies allow visualization of macrophageuptake in atherosclerotic plaques of mice with in vivo MRI, and by ex vivo fluorescence microscopy. ${ }^{180}$

QDs may serve as a highly luminescent scaffold for MR probes, PET/SPECT tracers and CT contrast agents to produce multi-modal imaging probes. The payload of additional contrast agents or ligands is estimated to be 10 - 30 per QD. QDs provided with a paramagnetic lipid-coating were applied to MR and optical visualization of $\alpha_{v} \beta_{3}$ expression on the membranes of activated HUVECs ${ }^{181}$ or for PS exposure of apoptotic cells. ${ }^{182}$ A different approach was chosen through silica-coated QDs with a hydrophobic phase between the QD surface and the silica-shell ${ }^{183}$ in order to incorporate hydrophobic contrast agents. The drawback of this approach is the rather tedious and stringent synthesis protocol to produce monodisperse NPs containing a single QD. The time-consuming synthesis makes these particles less suitable for PET/SPECT applications, due to decay of radioactive tracers.

A more flexible scaffold is provided by streptavidin-coated QDs, since the QD-surface can easily be functionalized by biotinylated moieties, including ligands and non-optical imaging probes. To further increase detectability, dendritic wedges with 8 DTPA or DOTA compounds were developed to incorporate paramagnetic gadolinium or radioactive PET/SPECT tracers, respectively. ${ }^{184}$ Utilizing these dendritic structures, paramagnetic QDs were successfully applied for MR and optical imaging of apoptosis ex vivo using Annexin A5. ${ }^{64}$ Moreover, cyclic Cys-Asn-Gly-Arg-Cys (cNGR-) coupled QDs were successfully utilized for in vivo optical detection of angiogenic activity after myocardial infarction. ${ }^{15}$ Recently, a bimodal cNGR- 
coupled QD with a dendritic gadolinium wedge was shown to enable the detection of angiogenic activity in tumor-bearing mice by in vivo MRI and ex vivo TPLSM. ${ }^{140}$ A different type of hybrid NP is a QD containing a shell doped with paramagnetic manganese. ${ }^{185}$ This NP was shown to be taken up by macrophages in vitro as shown by MRI and optical methods.

The mesoporous matrix of silica NPs and coatings allows the incorporation of probes with different functionality. By coating a luminescent ruthenium core with a silylated Gd complex, bimodal NPs were obtained for efficient luminescent and paramagnetic labeling of monocytes in vitro, ${ }^{186}$ with the potential to extrapolate this to in vivo visualization of leukocyte accumulation in atherosclerotic plaques. Also, gadolinium oxide cores may be covered by a fluorophore-containing silica layer. ${ }^{187}$ In contrast to the previously discussed NPs, these PEGylated NPs were excreted mainly via the kidney when intravenously injected in mice, as visualized in vivo with both fluorescence imaging and MRI. In addition, magnetite $\left(\mathrm{Fe}_{3} \mathrm{O}_{4}\right)$ can be coated with a silica shell, containing luminescent iridium, in order to visualize their passive ingestion in vitro. ${ }^{188}$

In contrast to gadolinium, superparamagnetic compounds, such as iron oxide generate negative contrast with MRI. Several different iron oxide-based multi-modal nanoparticles have been developed, but only few have been applied in vivo so far. Magnetite particles to which NIR fluorophores were conjugated, ${ }^{189}$ were used to load macrophages for in vivo imaging applications. In addition, iron oxide particles covered with a phospholipidic layer containing fluorophores were developed to specifically visualize apoptotic cells in vitro. ${ }^{178}$ Also so-called nanosponges were developed in which the magnetic and luminescent characteristics of their components are maintained. ${ }^{190}$ The in vivo experience with iron oxide based hybrids is still limited. Small ( $3 \mathrm{~nm}$ ) iron oxide NPs coated with fluorescent cyanine 5.5, allowed visualization of atherosclerotic lesions in mice with in vivo MRI and ex vivo fluorescence microscopy, ${ }^{191}$ apparently by virtue of their macrophages uptake. These results have promising implications for non-invasive assessment of inflammation, and vulnerability to rupture, of an atherosclerotic plaque.

Also, conjugtation of CNT to iron oxide nanoparticles resulted in a bimodal NP allowing visualization of the in vitro uptake by macrophages with MRI and optical techniques. ${ }^{192}$ To increase biocompatibility, this NP was encapsulated in DNA.

\section{Summary and outlook}

In this paper, optical and hybrid contrast enhancing NPs were described that have been applied to in vitro and in vivo animal studies. As such, these particles may play a role in confirming (sub-) cellular localization following non-invasive imaging in animal models. In the future, NPs may be applied clinically in conjunction with optical imaging techniques, due to fast developments in this field. Ideal NPs for optical molecular imaging in clinical use should bear the following characteristics: (1) highly luminescent upon irradiation, (2) high binding affinity and specificity for the target, (3) resistant to chemical degradation and (4) cleared via kidney or liver upon intravenous injection to prevent organ accumulation. It should be kept in mind that the in vivo targeting behavior, as well as the level of toxicity, of the NPs highly depend on geometrical (i.e., NP size), biophysical (i.e., the availability of the target and hemodynamic forces), chemical (i.e., NP stability), and biological (i.e., ligand-target affinity and excretion pathway) parameters. As such, a thorough quantitative analysis of the in vivo bio-distribution and pharmacokinetics of each individual construct (i.e., NP and applied surface modifications) should be performed and should result in a well defined and uniform safety and efficacy profile prior to clinical use. 
The relatively narrow emission spectra of QDs and AuNPs offer a valuable contribution to the research of complex and multi-factorial diseases, including atherosclerosis, since multiple molecular targets may be visualized simultaneously. However, the current commercially available QDs consist of heavy metals such as cadmium, and are therefore not likely to be suitable for clinical use, despite encapsulation of the core. CNPs offer a potentially non-toxic alternative to QDs, but display a low quantum yield and broad emission spectrum, both hampering multi-color imaging in vivo. AuNPs, DNPs and SNPs combine high luminescence with a non-toxic potential in vivo, although it is not yet known whether DNPs are excretable. Therefore, based on current knowledge on toxicity and optical properties of the presented NPs, AuNPs and SNPs are the most promising NPs for clinical use in optical molecular imaging of atherosclerosis. The use of AuNPs is clinically approved in treatment of rheumatoid arthritis, ${ }^{82,83}$ however, both AuNPs and SNPs have been poorly characterized for in vivo imaging applications at this moment.

Many of the presented optical NPs hold a dual-purpose character, i.e., they may be used as contrast agent in optical imaging as well as therapeutic agent to specifically disrupt processes that contribute to plaque formation and destabilization. These processes include MMP expression by macrophages and angiogenic expansion of the vasa vasorum that penetrate the plaque. The use of optical NPs as therapeutic agent is still in initial phase of development, but several approaches can be recognized. First, surface binding or encapsulation of photosensitizers may employ QDs and SNPs, respectively, for targeted photodynamic therapy (PDT) of atherosclerotic lesions. ${ }^{193-199}$ In PDT, (indirect) illumination of the photosensitizers induces local formation of reactive oxygen species, which stimulates apoptosis of the surrounding cells. Second, AuNPs ${ }^{200}$ and CNTs ${ }^{119}$ convert absorbed radiation into heat ${ }^{200}$ and hence may allow directed photothermal destruction of cells ${ }^{76}$ to which these NPs were targeted. This technique is referred to as photothermal therapy (PTT). Third, AuNPs, ${ }^{201,202}$ CNTs, ${ }^{119}$ and SNPs ${ }^{123}$ may serve as scaffold for targeted gene therapy or, in the case of SNPs, may be filled with chemotherapeutic drugs ${ }^{203}$ to attenuate the progression of atherosclerotic lesions.

Research committed to finding the most suitable target, as well as the accompanying ligand for the assessment of vulnerable atherosclerotic plaques, has increased tremendously in recent years. Molecular targets used in molecular imaging and therapy of tumors show great resemblance to the targets expressed in atherosclerotic plaques, including inflammation, ${ }^{204}$ proteolytic activity, ${ }^{205,206}$ neovascularization, ${ }^{207,208}$ and apoptosis. ${ }^{209,210}$ Although both pathologies have different origins and progressions, the shared molecular markers may aid in the development and testing of ligands for specific targeting of NPs towards vulnerable plaques, as research committed to targeted tumor treatment is more advanced than targeted atherosclerotic plaque therapy.

In conclusion, current optical techniques and associated nanoparticles are promising for their application in high-resolution and high-sensitivity stand-alone imaging platforms as well as complementary techniques to clinically accepted imaging modalities. 


\section{References}

1. Wickline SA, Neubauer AM, Winter PM, Caruthers SD, Lanza GM. Molecular imaging and therapy of atherosclerosis with targeted nanoparticles. J Magn Reson Imaging 2007;25:667-80.

2. Caruthers SD, Wickline SA, Lanza GM. Nanotechnological applications in medicine. Curr Opin Biotechnol 2007.

3. Muller RH, Keck CM. Challenges and solutions for the delivery of biotech drugs - a review of drug nanocrystal technology and lipid nanoparticles. J Biotechnol 2004;113:151-70.

4. Ozkan M. Quantum dots and other nanoparticles: what can they offer to drug discovery? Drug Discov Today 2004;9:1065-71.

5. Wagner V, Dullaart A, Bock AK, Zweck A. The emerging nanomedicine landscape. Nat Biotechnol 2006;24:1211-7.

6. Cai W, Chen X. Nanoplatforms for targeted molecular imaging in living subjects. Small 2007;3:1840-54.

7. Anderson RR, Parrish JA. The optics of human skin. J Invest Dermatol 1981;77:13-9.

8. Jung JC, Schnitzer MJ. Multiphoton endoscopy. Opt Lett 2003;28:902-4.

9. König K, Ehlers A, Riemann I, Schenkl S, Buckle R, Kaatz M. Clinical twophoton microendoscopy. Microsc Res Tech 2007;70:398-402.

10. Buschman HP, Marple ET, Wach ML, et al. In vivo determination of the molecular composition of artery wall by intravascular Raman spectroscopy. Anal Chem 2000;72:3771-5.

11. Fujimoto JG. Optical coherence tomography for ultrahigh resolution in vivo imaging. Nat Biotechnol 2003;21:1361-7.

12. Tearney GJ, Brezinski ME, Bouma BE, et al. In vivo endoscopic optical biopsy with optical coherence tomography. Science 1997;276:2037-9.

13. Sethuraman S, Aglyamov SR, Amirian JH, Smalling RW, Emelianov SY. Intravascular photoacoustic imaging using an IVUS imaging catheter. IEEE Trans Ultrason Ferroelectr Freq Control 2007;54:978-86.

14. Denk W, Strickler JH, Webb WW. Two-photon laser scanning fluorescence microscopy. Science 1990;248:73-6.

15. Buehler A, van Zandvoort MA, Stelt BJ, et al. $c N G R$ : A novel homing sequence for CD13/APN targeted molecular imaging of murine cardiac angiogenesis in vivo. Arterioscler Thromb Vasc Biol 2006;26:2681-2687.

16. Megens RT, oude Egbrink MG, Cleutjens JP, et al. Imaging collagen in intact viable healthy and atherosclerotic arteries using fluorescently labeled CNA35 and two-photon laser scanning microscopy. Mol Imaging 2007;6:247-60.

17. Zoumi A, Lu X, Kassab GS, Tromberg BJ. Imaging coronary artery microstructure using second-harmonic and two-photon fuorescence microscopy. Biophys $\mathrm{J}$ 2004;87:2778-86.

18. Römer TJ, Brennan JF, 3rd, Schut TC, et al. Raman spectroscopy for quantifying cholesterol in intact coronary artery wall. Atherosclerosis 1998;141:117-24.

19. Buschman HP, Deinum G, Motz JT, et al. Raman microspectroscopy of human coronary atherosclerosis: biochemical assessment of cellular and extracellular morphologic structures in situ. Cardiovasc Pathol 2001;10:69-82.

20. Buschman HP, Motz JT, Deinum G, et al. Diagnosis of human coronary atherosclerosis by morphology-based Raman spectroscopy. Cardiovasc Pathol 2001;10:59-68

21. Keren S, Zavaleta C, Cheng Z, de la Zerda A, Gheysens O, Gambhir SS. Noninvasive molecular imaging of small living subjects using Raman spectroscopy. Proc Natl Acad Sci U S A 2008;105:5844-9.

22. Brezinski ME, Tearney GJ, Bouma BE, et al. Imaging of coronary artery microstructure (in vitro) with optical coherence tomography. Am J Cardiol 1996;77:92-3

23. Brezinski ME, Tearney GJ, Bouma BE, et al. Optical coherence tomography for optical biopsy. Properties and demonstration of vascular pathology. Circulation 1996;93:1206-13.

24. Yabushita H, Bouma BE, Houser SL, et al. Characterization of human atherosclerosis by optical coherence tomography. Circulation 2002;106:1640-5.

25. Cilingiroglu M, Oh JH, Sugunan $\mathrm{B}$, et al. Detection of vulnerable plaque in a murine model of atherosclerosis with optical coherence tomography. Catheter Cardiovasc Interv 2006;67:915-23.

26. Jang IK, Bouma BE, Kang DH, et al. Visualization of coronary atherosclerotic plaques in patients using optical coherence tomography: comparison with intravascular ultrasound. J Am Coll Cardiol 2002;39:604-9.

27. MacNeill $\mathrm{BD}$, Jang IK, Bouma $\mathrm{BE}$, et al. Focal and multi-focal plaque macrophage distributions in patients with acute and stable presentations of coronary artery disease. J Am Coll Cardiol 2004;44:972-9.

28. Wang D, He J, Rosenzweig N, Rosenzweig Z. Superparamagnetic $\mathrm{Fe}_{2} \mathrm{O}_{3}$ beadsCdSe/ZnS quantum dots core-shell nanocomposite particles for cell separation. Nano Lett. 2004;4:409-413.

29. Yang X, Skrabalak SE, Li ZY, Xia Y, Wang LV. Photoacoustic tomography of a rat cerebral cortex in vivo with au nanocages as an optical contrast agent. Nano Lett 2007; 7:3798-802

30. Wang X, Pang Y, Ku G, Xie X, Stoica G, Wang LV. Noninvasive laser-induced photoacoustic tomography for structural and functional in vivo imaging of the brain. Nat Biotechnol 2003;21:803-6. 
31. Zemp RJ, Bitton R, Li ML, Shung KK, Stoica G, Wang LV. Photoacoustic imaging of the microvasculature with a high-frequency ultrasound array transducer. J Biomed Opt 2007;12:010501.

32. Sethuraman S, Amirian JH, Litovsky SH, Smalling RW, Emelianov SY. Ex vivo characterization of atherosclerosis using intravascular photoacoustic imaging. Opt Express 2007;15:16657-66.

33. Sethuraman S, Amirian JH, Litovsky SH, Smalling RW, Emelianov SY Spectroscopic intravascular photoacoustic imaging to differentiate atherosclerotic plaques. Opt Express 2008;16:3363-7.

34. Oberdörster G, Oberdörster E, Oberdörster J. Nanotoxicology: an emerging discipline evolving from studies of ultrafine particles. Environ Health Perspect 2005;113:823-39.

35. Kirchner C, Liedl T, Kudera S, et al. Cytotoxicity of colloidal CdSe and CdSe/ZnS nanoparticles. Nano Lett 2005;5:331-8.

36. Hartschuh A, Pedrosa HN, Novotny L, Krauss TD. Simultaneous fluorescence and Raman scattering from single carbon nanotubes. Science 2003;301:1354-6.

37. Niemeyer CM. Nanoparticles, proteins, and nucleic acids: biotechnolohy meets materials science. Angewandte Chemie International Edition 2001;40:4128-58.

38. Bruchez M, Jr., Moronne M, Gin P, Weiss S, Alivisatos AP. Semiconductor nanocrystals as fluorescent biological labels. Science 1998;281:2013-6.

39. Chan WC, Nie S. Quantum dot bioconjugates for ultrasensitive nonisotopic detection. Science 1998;281:2016-8.

40. Chan WC, Maxwell DJ, Gao X, Bailey RE, Han M, Nie S. Luminescent quantum dots for multiplexed biological detection and imaging. Curr Opin Biotechnol 2002; $13: 40-6$

41. Jaiswal JK, Mattoussi H, Mauro JM, Simon SM. Long-term multiple color imaging of live cells using quantum dot bioconjugates. Nat Biotechnol 2003;21:47-51.

42. Ow H, Larson DR, Srivastava M, Baird BA, Webb WW, Wiesner U. Bright and stable core-shell fluorescent silica nanoparticles. Nano Lett 2005;5:113-7.

43. Alivisatos AP. Semiconductor clusters, nanocrystals, and quantum dots. Science 1996;271:933-7.

44. Eychmuller A, Mews A, Weller H. A quantum dot quantum well: $\mathrm{CdS} / \mathrm{HgS} / \mathrm{CdS}$. Chemical Physics Letters 1993;208:59-62.

45. Murray CB, Norris DJ, Bawendi MG. Synthesis and characterization of nearly monodisperse $C d E$ ( $E=$ sulfur, selenium, tellurium) semiconductor nanocrystallites. J. Am. Chem. Soc. 1993;115:8706-15.

46. Hines MA, Guyot-Sionnest P. Synthesis and characterization of strongly luminescing ZnS-Capped CdSe nanocrystals. J. Phys. Chem. 1996;100:468-71.

47. Peng X, Schlamp MC, Kadavanich AV, Alivisatos AP. Epitaxial growth of highly luminescent CdSe/CdS core/shell nanocrystals with photostability and electronic accessibility. J. Am. Chem. Soc. 1997;119:7019-29.

48. Derfus AM, Chan WC, Bhatia SN. Probing the cytotoxicity of semiconductor quantum dots. Nano Lett. 2004;4:11-18.

49. Soo Choi H, Liu W, Misra P, et al. Renal clearance of quantum dots. Nat Biotech 2007;25:1165-70

50. Yang RS, Chang LW, Wu JP, et al. Persistent tissue kinetics and redistribution of nanoparticles, quantum dot 705, in mice: ICP-MS quantitative assessment. Environ Health Perspect 2007;115:1339-43.

51. Fischer HC, Liu L, Pang KS, Chan WC. Pharmacokinetics of nanoscale quantum dots: in vivo distribution, sequestration, and clearance in the rat. Advanced Functional Materials 2006;16:1299-1305.

52. Omura M, Tanaka A, Hirata M, et al. Testicular toxicity of gallium arsenide, indium arsenide, and arsenic oxide in rats by repetitive intratracheal instillation Fundamental and Applied Toxicology 1996;32:72-8.

53. Zimmer JP, Kim SW, Ohnishi S, Tanaka E, Frangioni JV, Bawendi MG. Size series of small indium arsenide-zinc selenide core-shell nanocrystals and their application to in vivo imaging. J. Am. Chem. Soc. 2006;128:2526-7.

54. Zhelev Z, Ohba H, Bakalova R. Single quantum dot-micelles coated with silica shell as potentially non-cytotoxic fluorescent cell tracers. J Am Chem Soc 2006;128:6324-5.

55. Cai W, Hsu A, Li Z-B, Chen X. Are quantum dots ready for in vivo imaging in human subjects? Nanoscale Research Letters 2007;2:265-81.

56. Cai W, Shin DW, Chen K, et al. Peptide-labeled near-infrared quantum dots for imaging tumor vasculature in living subjects. Nano Lett 2006;6:669-76.

57. Gao X, Cui Y, Levenson RM, Chung LW, Nie S. In vivo cancer targeting and imaging with semiconductor quantum dots. Nat Biotechnol 2004;22:969-76.

58. Cambi A, Lidke DS, Arndt-Jovin DJ, Figdor CG, Jovin TM. Ligand-conjugated quantum dots monitor antigen uptake and processing by dendritic cells. Nano Lett 2007;7:970-7.

59. Ballou B, Ernst LA, Andreko S, et al. Sentinel lymph node imaging using quantum dots in mouse tumor models. Bioconjug Chem 2007;18:389-96.

60. Kim S, Lim YT, Soltesz EG, et al. Near-infrared fluorescent type II quantum dots for sentinel lymph node mapping. Nat Biotechnol 2004;22:93-7.

61. Wu X, Liu H, Liu J, et al. Immunofluorescent labeling of cancer marker Her2 and other cellular targets with semiconductor quantum dots. Nat Biotech 2003;21:41-6.

62. Kahn E, Vejux A, Menetrier F, et al. Analysis of CD36 expression on human monocytic cells and atherosclerotic tissue sections with quantum dots: investigation by flow cytometry and spectral imaging microscopy. Anal Quant Cytol Histol 2006;28:14-26 
63. Suo J, Ferrara DE, Sorescu D, Guldberg RE, Taylor WR, Giddens DP. Hemodynamic shear stresses in mouse aortas: implications for atherogenesis. Arterioscler Thromb Vasc Biol 2007;27:346-51.

64. Prinzen L, Miserus RJ, Dirksen A, et al. Optical and magnetic resonance imaging of cell death and platelet activation using annexin a5-functionalized quantum dots. Nano Lett 2007;7:93-100.

65. Jayagopal A, Russ PK, Haselton FR. Surface engineering of quantum dots for in vivo vascular imaging. Bioconjug Chem 2007;18:1424-33.

66. Grecco HE, Lidke KA, Heintzmann R, et al. Ensemble and single particle photophysical properties (two-photon excitation, anisotropy, FRET, lifetime, spectral conversion) of commercial quantum dots in solution and in live cells. Microsc Res Tech 2004;65:169-79.

67. Weissleder R, Tung $\mathrm{CH}$, Mahmood U, Bogdanov A, Jr. In vivo imaging of tumors with protease-activated near-infrared fluorescent probes. Nat Biotechnol 1999; $17: 375-8$

68. So MK, Xu C, Loening AM, Gambhir SS, Rao J. Self-illuminating quantum dot conjugates for in vivo imaging. Nat Biotechnol 2006;24:339-43

69. Kampani K, Quann K, Ahuja J, Wigdahl B, Khan ZK, Jain P. A novel high throughput quantum dot-based fluorescence assay for quantitation of virus binding and attachment. Journal of Virological Methods 2007;141:125-32.

70. Horisberger M, Rosset J. Colloidal gold, a useful marker for transmission and scanning electron microscopy. J Histochem Cytochem 1977;25:295-305.

71. Zheng J, Petty JT, Dickson RM. High quantum yield blue emission from watersoluble Au8 nanodots. J Am Chem Soc 2003;125:7780-1.

72. Montalti M, Zaccheroni N, Prodi L, O’Reilly N, James SL. Enhanced sensitized NIR luminescence from gold nanoparticles via energy transfer from surface-bound fluorophores. J Am Chem Soc 2007;129:2418-9.

73. Alvarez MM, Khoury JT, Schaaff TG, Shafigullin MN, Vezmar I, Whetten RL. Optical absorption spectra of nanocrystal gold molecules. Journal of Physical Chemistry B 1997;101:3706-12.

74. Farrer RA, Butterfield FL, Chen VW, Fourkas JT. Highly efficient multiphotonabsorption-induced luminescence from gold nanoparticles. Nano Lett 2005;5:1139-42. 75. Chen J, Saeki F, Wiley BJ, et al. Gold nanocages: bioconjugation and their potential use as optical imaging contrast agents. Nano Lett 2005;5:473-7.

76. Huang X, El-Sayed IH, Qian W, El-Sayed MA. Cancer cell imaging and photothermal therapy in the near-infrared region by using gold nanorods. J Am Chem Soc 2006;128:2115-20.

77. Shukla R, Bansal V, Chaudhary M, Basu A, Bhonde RR, Sastry M. Biocompatibility of gold nanoparticles and their endocytotic fate inside the cellular compartment: a microscopic overview. Langmuir 2005;21:10644-54.

78. Tan WB, Zhang Y. Surface modification of gold and quantum dot nanoparticles with chitosan for bioapplications. J Biomed Mater Res A 2005;75:56-62.

79. Kim D, Park S, Lee JH, Jeong YY, Jon S. Antibiofouling polymer-coated gold nanoparticles as a contrast agent for in vivo $X$-ray computed tomography imaging. $\mathrm{J}$ Am Chem Soc 2007;129:7661-5.

80. Mukherjee P, Bhattacharya R, Wang P, et al. Antiangiogenic properties of gold nanoparticles. Clin Cancer Res 2005;11:3530-4.

81. Renaud G, Hamilton RL, Havel RJ. Hepatic metabolism of colloidal gold-lowdensity lipoprotein complexes in the rat: evidence for bulk excretion of lysosomal contents into bile. Hepatology 1989;9:380-92.

82. Rau R, Herborn G, Menninger H, Sangha O. Radiographic outcome after three years of patients with early erosive rheumatoid arthritis treated with intramuscular methotrexate or parenteral gold. Extension of a one-year double-blind study in 174 patients. Rheumatology (Oxford) 2002;41:196-204.

83. Wolfe F, Hawley DJ. The relationship between clinical activity and depression in rheumatoid arthritis. J Rheumatol 1993;20:2032-7.

84. Kvien TK, Zeidler HK, Hannonen P, et al. Long term efficacy and safety of cyclosporin versus parenteral gold in early rheumatoid arthritis: a three year study of radiographic progression, renal function, and arterial hypertension. Ann Rheum Dis 2002;61:511-6.

85. Hafejee A, Burke MJ. Acute pneumonitis starting 2 hours after intramuscular gold administration in a patient with rheumatoid arthritis. Ann Rheum Dis 2004;63:1525-6. 86. Hiramatsu K, Ishizuka H, Yamasaki M. Bronchiolar disease associated with gold compounds administration in a patient with rheumatoid arthritis. Mod Rheumatol 2005; 15:148-52.

87. Leff DV, Brandt L, Heath JR. Synthesis and characterization of hydrophobic, organically-soluble gold nanocrystals functionalized with primary amines. Langmuir 1996;12:4723-30.

88. Huang T, Murray RW. Visible luminescence of water-soluble monolayer-protected gold clusters. J. Phys. Chem. B 2001;105:12498-502.

89. Selvakannan P, Mandal S, Phadtare S, et al. Water-dispersible tryptophanprotected gold nanoparticles prepared by the spontaneous reduction of aqueous chloroaurate ions by the amino acid. J Colloid Interface Sci 2004;269:97-102.

90. Gole A, Dash C, Soman C, Sainkar SR, Rao M, Sastry M. On the preparation, characterization, and enzymatic activity of fungal protease-gold colloid bioconjugates. Bioconjug Chem 2001;12:684-90.

91. SelvakannanPR, MandalS, PhadtareS,PasrichaR, SastryM.Cappingofgoldnanoparticles by the amino acid lysine renders them water-dispersible. Langmuir 2003;19:3545-9. 
92. Sokolov K, Follen M, Aaron J, et al. Real-time vital optical imaging of precancer using anti-epidermal growth factor receptor antibodies conjugated to gold nanoparticles. Cancer Res 2003;63:1999-2004.

93. Wang $\mathrm{H}$, Huff TB, Zweifel DA, et al. In vitro and in vivo two-photon luminescence imaging of single gold nanorods. Proc Natl Acad Sci U S A 2005;102:15752-6.

94. Durr NJ, Larson T, Smith DK, Korgel BA, Sokolov K, Ben-Yakar A. Two-photon luminescence imaging of cancer cells using molecularly targeted gold nanorods. Nano Lett. 2007;7:941-5.

95. Colpin Y, Swan A, Zvyagin AV, Plakhotnik T. Imaging and sizing of diamond nanoparticles. Opt Lett 2006;31:625-7.

96. Fu CC, Lee HY, Chen K, et al. Characterization and application of single fluorescent nanodiamonds as cellular biomarkers. Proc Natl Acad Sci U S A 2007;104:727-32.

97. Yu SJ, Kang MW, Chang HC, Chen KM, Yu YC. Bright fluorescent nanodiamonds: no photobleaching and low cytotoxicity. J Am Chem Soc 2005;127:17604-5.

98. Beveratos A, Brouri R, Gacoin T, Poizat JP, Grangier P. Nonclassical radiation from diamond nanocrystals. Physical Review A 2001;64.

99. Brouri R, Beveratos A, Poizat JP, Grangier P. Photon antibunching in the fluorescence of individual color centers in diamond. Opt. Lett. 2000;25:1294-6.

100. Wee TL, Tzeng YK, Han CC, et al. Two-photon excited fluorescence of nitrogen-vacancy centers in proton-irradiated type Ib diamond. J Phys Chem A 2007;111:9379-86

101. Cheng CY, Perevedentseva E, Tu JS, et al. Direct and in vitro observation of growth hormone receptor molecules in A549 human lung epithelial cells by nanodiamond labeling. Applied Physics Letters 2007;90:163903.

102. Kruger A, Kataoka F, Ozawa M, et al. Unusually tight aggregation in detonation nanodiamond: Identification and disintegration. Carbon 2005;43:1722-30.

103. Bakowizc K, Mitura S. Biocompatibility of NCD. Journal of Wide Bandgap Materials 2002;9:261-72

104. Cao L, Wang X, Meziani MJ, et al. Carbon dots for multiphoton bioimaging. J Am Chem Soc 2007; 129:11318-9.

105. Sun YP, Zhou B, Lin Y, et al. Quantum-sized carbon dots for bright and colorful photoluminescence. J Am Chem Soc 2006;128:7756-7.

106. Leeuw TK, Reith RM, Simonette RA, et al. Single-walled carbon nanotubes in the intact organism: near-IR imaging and biocompatibility studies in Drosophila. Nano Lett 2007;7:2650-4.

107. Heller DA, Mayrhofer RM, Baik S, Grinkova YV, Usrey ML, Strano MS Concomitant length and diameter separation of single-walled carbon nanotubes. J Am Chem Soc 2004;126:14567-73.

108. Lefebvre J, Austing DG, Bond J, Finnie P. Photoluminescence imaging of suspended single-walled carbon nanotubes. Nano Lett. 2006;6:1603-1608.

109. Chen RJ, Bangsaruntip S, Drouvalakis KA, et al. Noncovalent functionalization of carbon nanotubes for highly specific electronic biosensors. Proc Natl Acad Sci U S A 2003;100:4984-9.

110. Campidelli S, Sooambar C, Lozano Diz E, Ehli C, Guldi DM, Prato M Dendrimer-functionalized single-wall carbon nanotubes: synthesis, characterization, and photoinduced electron transfer. J Am Chem Soc 2006;128:12544-52.

111. Wu Y, Hudson JS, Lu Q, et al. Coating single-walled carbon nanotubes with phospholipids. J. Phys. Chem. B 2006;110:2475-8.

112. Kam NW, Jessop TC, Wender P, Dai H. Nanotube molecular transporters: internalization of carbon nanotube-protein conjugates into mammalian cells. Journal of the American Society 2004;126:6850-1.

113. Pulskamp K, Diabate S, Krug HF. Carbon nanotubes show no sign of acute toxicity but induce intracellular reactive oxygen species in dependence on contaminants. Toxicol Lett 2007;168:58-74.

114. Cherukuri $\mathrm{P}$, Bachilo SM, Litovsky SH, Weisman RB. Near-infrared fluorescence microscopy of single-walled carbon nanotubes in phagocytic cells. J Am Chem Soc 2004; $126: 15638-9$

115. Monteiro-Riviere NA, Nemanich RJ, Inman AO, Wang YY, Riviere JE. Multi-walled carbon nanotube interactions with human epidermal keratinocytes. Toxicology Letters 2005;155:377-84.

116. Zhu L, Chang DW, Dai L, Hong Y. DNA damage induced by multiwalled carbon nanotubes in mouse embryonic stem cells. Nano Lett 2007;7:3592-7.

117. Cherukuri P, Gannon CJ, Leeuw TK, et al. Mammalian pharmacokinetics of carbon nanotubes using intrinsic near-infrared fluorescence. Proc Natl Acad Sci U S A 2006; 103:18882-6.

118. Singh R, Pantarotto D, Lacerda L, et al. Tissue biodistribution and blood clearance rates of intravenously administered carbon nanotube radiotracers. Proceedings of the National Academy of Sciences 2006;103:3357-62.

119. Kam NW, O'Connell M, Wisdom JA, Dai H. Carbon nanotubes as multifunctional biological transporters and near-infrared agents for selective cancer cell destruction. Proc Natl Acad Sci U S A 2005;102:11600-5.

120. Zhao X, Bagwe RP, Tan W. Development of organic-dye-doped silica nanoparticles in a reverse microemulsion. Adv Mater 2004;16:173-6.

121. Montalti M, Prodi L, Zaccheroni N, Zattoni A, Reschiglian P, Falini G. Energy transfer in fluorescent silica nanoparticles. Langmuir 2004;20:2989-91.

122. Mallik R, Wa C, Hage DS. Development of sulfhydryl-reactive silica for protein immobilization in high-performance affinity chromatography. Anal Chem 2007;79:1411-24 
123. Roy I, Ohulchanskyy TY, Bharali DJ, et al. Optical tracking of organically modified silica nanoparticles as DNA carriers: a nonviral, nanomedicine approach for gene delivery. Proc Natl Acad Sci U S A 2005;102:279-84.

124. Xing X, He X, Peng J, Wang K, Tan W. Uptake of silica-coated nanoparticles by HeLa cells. J Nanosci Nanotechnol 2005;5:1688-93.

125. Chang JS, Chang KL, Hwang DF, Kong ZL. In vitro cytotoxicitiy of silica nanoparticles at high concentrations strongly depends on the metabolic activity type of the cell line. Environ Sci Technol 2007;41:2064-8.

126. Jin Y, Kannan S, Wu M, Zhao JX. Toxicity of luminescent silica nanoparticles to living cells. Chem Res Toxicol 2007;20:1126-33.

127. Peters K, Unger RE, Kirkpatrick CJ, Gatti AM, Monari E. Effects of nano-scaled particles on endothelial cell function in vitro: studies on viability, proliferation and inflammation. J Mater Sci Mater Med 2004;15:321-5.

128. Choi J, Burns AA, Williams RM, et al. Core-shell silica nanoparticles as fluorescent labels for nanomedicine. J Biomed Opt 2007;12:064007.

129. Santra S, Liesenfeld B, Dutta D, et al. Folate conjugated fluorescent silica nanoparticles for labeling neoplastic cells. J Nanosci Nanotechnol 2005;5:899-904.

130. Wang L, Zhao W, O'Donoghue MB, Tan W. Fluorescent nanoparticles for multiplexed bacteria monitoring. Bioconjug Chem 2007;18:297-301.

131. Dabbousi BO, Rodriguez-Viejo J, Mikulec FV, et al. (CdSe)ZnS core-shell quantum dots: synthesis and characterization of a size series of highly luminescent nanocrystallites. J. Phys. Chem. B 1997;101:9463-75.

132. O'Connell MJ, Bachilo SM, Huffman $\mathrm{CB}$, et al. Band gap fluorescence from individual single-walled carbon nanotubes. Science 2002;297:593-6.

133. Chang H-C, Chen K. Nanodiamond as a possible carrier for extended red emission. The Astrophysical journal 2006;639:L63-L66.

134. Treaussart F, Jacques V, Wu E, Gacoin T, Grangier P, Roch J-F. Photoluminescence of single colour defects in 50nm diamond nanocrystals. Physica B 2006;376-7.

135. Barbé C, Bartlett J, Kong L, et al. Silica particles: A novel drug delivery system. Advanced Materials 2004; 16:1959-66.

136. Stary $\mathrm{HC}$, Chandler $\mathrm{AB}$, Glagov $\mathrm{S}$, et al. A definition of initial, fatty streak, and intermediate lesions of atherosclerosis. A report from the committee on vascular lesions of the council on arteriosclerosis, american heart association. Circulation 1994;89:2462-78.

137. Stary HC, Chandler AB, Dinsmore RE, et al. A definition of advanced types of atherosclerotic lesions and a histological classification of atherosclerosis : a report from the committee on vascular lesions of the council on arteriosclerosis, american heart association. Circulation 1995;92:1355-74.

138. Sanz J, Fayad ZA. Imaging of atherosclerotic cardiovascular disease. Nature 2008;451:953-7.
139. Naghavi M, Libby P, Falk E, et al. From vulnerable plaque to vulnerable patient: a call for new definitions and risk assessment strategies: part I. Circulation 2003; 108:1664-72.

140. Oostendorp M, Douma $\mathrm{K}$, Hackeng TM, et al. In vivo T1 and T2 effects of paramagnetic quantum dot based contrast agents for molecular magnetic resonance imaging. Proc Intl Soc Mag Reson Med 2008;16:1699.

141. Kietselaer BL, Reutelingsperger $\mathrm{CP}$, Heidendal GA, et al. Noninvasive detection of plaque instability with use of radiolabeled annexin A5 in patients with carotidartery atherosclerosis. N Engl J Med 2004;350:1472-3.

142. Broisat A, Riou LM, Ardisson V, et al. Molecular imaging of vascular cell adhesion molecule-1 expression in experimental atherosclerotic plaques with radiolabelled B2702-p. Eur J Nucl Med Mol Imaging 2007;34:830-40.

143. Tsourkas A, Shinde-Patil VR, Kelly KA, et al. In vivo imaging of activated endothelium using an anti-VCAM-1 magnetooptical probe. Bioconjug Chem 2005; $16: 576-81$

144. Kaufmann BA, Sanders JM, Davis C, et al. Molecular imaging of inflammation in atherosclerosis with targeted ultrasound detection of vascular cell adhesion molecule-1. Circulation 2007;116:276-84.

145. McAteer MA, Sibson NR, von Zur Muhlen C, et al. In vivo magnetic resonance imaging of acute brain inflammation using microparticles of iron oxide. Nat Med 2007; $13: 1253-8$.

146. Kelly KA, Allport JR, Tsourkas A, Shinde-Patil VR, Josephson L, Weissleder R. Detection of vascular adhesion molecule-1 expression using a novel multimodal nanoparticle. Circ Res 2005;96:327-36.

147. Nahrendorf M, Jaffer FA, Kelly KA, et al. Noninvasive vascular cell adhesion molecule-1 imaging identifies inflammatory activation of cells in atherosclerosis. Circulation 2006;114:1504-11.

148. McAteer MA, Schneider JE, Ali ZA, et al. Magnetic resonance imaging of endothelial adhesion molecules in mouse atherosclerosis using dual-targeted microparticles of iron oxide. Arterioscler Thromb Vasc Biol 2008;28:77-83.

149. Rychak JJ, Lindner JR, Ley K, Klibanov AL. Deformable gas-filled microbubbles targeted to P-selectin. J Control Release 2006;114:288-99.

150. Deguchi JO, Aikawa $\mathrm{M}$, Tung $\mathrm{CH}$, et al. Inflammation in atherosclerosis: visualizing matrix metalloproteinase action in macrophages in vivo. Circulation 2006;114:55-62.

151. Jaffer FA, Kim DE, Quinti L, et al. Optical visualization of cathepsin K activity in atherosclerosis with a novel, protease-activatable fluorescence sensor. Circulation 2007;115:2292-8

152. Amirbekian V, Lipinski MJ, Briley-Saebo KC, et al. Detecting and assessing 
macrophages in vivo to evaluate atherosclerosis noninvasively using molecular MRI. Proc Natl Acad Sci U S A 2007;104:961-6.

153. Elmaleh DR, Fischman AJ, Tawakol A, et al. Detection of inflamed atherosclerotic lesions with diadenosine-5',5'”-P1,P4-tetraphosphate (Ap4A) and positron-emission tomography. Proc Natl Acad Sci U S A 2006;103:15992-6.

154. Tawakol A, Migrino RQ, Bashian GG, et al. In vivo $18 F$-fluorodeoxyglucose positron emission tomography imaging provides a noninvasive measure of carotid plaque inflammation in patients. J Am Coll Cardiol 2006;48:1818-24.

155. Zhang Z, Machac J, Helft G, et al. Non-invasive imaging of atherosclerotic plaque macrophage in a rabbit model with F-18 FDG PET: a histopathological correlation. BMC Nucl Med 2006;6:3.

156. Isobe $\mathrm{S}$, Tsimikas $\mathrm{S}$, Zhou $\mathrm{J}$, et al. Noninvasive imaging of atherosclerotic lesions in apolipoprotein E-deficient and low-density-lipoprotein receptor-deficient mice with annexin A5. J Nucl Med 2006;47:1497-505.

157. Kolodgie FD, Petrov A, Virmani R, et al. Targeting of apoptotic macrophages and experimental atheroma with radiolabeled annexin $V$ : a technique with potential for noninvasive imaging of vulnerable plaque. Circulation 2003;108:3134-9.

158. Smith BR, Heverhagen J, Knopp M, et al. Localization to atherosclerotic plaque and biodistribution of biochemically derivatized superparamagnetic iron oxide nanoparticles (SPIONs) contrast particles for magnetic resonance imaging (MRI). Biomed Microdevices 2007;9:719-27.

159. Winter PM, Morawski AM, Caruthers SD, et al. Molecular imaging of angiogenesis in early-stage atherosclerosis with alpha(v)beta3-integrin-targeted nanoparticles. Circulation 2003;108:2270-4.

160. Wang $\mathrm{H}$, Cai W, Chen K, et al. A new PET tracer specific for vascular endothelial growth factor receptor 2. European Journal of Nuclear Medicine and Molecula Imaging 2007;34:2001-10.

161. Backer MV, Levashova Z, Patel V, et al. Molecular imaging of VEGF receptors in angiogenic vasculature with single-chain VEGF-based probes. Nat Med 2007; 13:504-9.

162. von Bary C, Preissel A, Spuentrup E, et al. Molecular MRI of vascular remodeling in a swine model of coronary injury using an elastin-binding contrast agent. Proc Intl Soc Mag Reson Med 2008;16:321.

163. Botnar RM, Perez AS, Witte $\mathrm{S}$, et al. In vivo molecular imaging of acute and subacute thrombosis using a fibrin-binding magnetic resonance imaging contrast agent. Circulation 2004;109:2023-9.

164. Spuentrup E, Buecker A, Katoh M, et al. Molecular magnetic resonance imaging of coronary thrombosis and pulmonary emboli with a novel fibrin-targeted contrast agent. Circulation 2005;111:1377-82.
165. Spuentrup E, Fausten B, Kinzel S, et al. Molecular magnetic resonance imaging of atrial clots in a swine model. Circulation 2005;112:396-9.

166. Spuentrup E, Katoh M, Buecker A, et al. Molecular MR imaging of human thrombi in a swine model of pulmonary embolism using a fibrin-specific contrast agent. Invest Radiol 2007;42:586-95.

167. Stracke CP, Katoh M, Wiethoff AJ, Parsons EC, Spangenberg P, Spuntrup E. Molecular MRI of cerebral venous sinus thrombosis using a new fibrin-specific MR contrast agent. Stroke 2007;38:1476-81.

168. Aruva MR, Daviau J, Sharma SS, Thakur ML. Imaging thromboembolism with fibrin-avid 99mTc-peptide: evaluation in swine. J Nucl Med 2006;47:155-62.

169. Miserus RJ, Prinzen L, Herias MV, et al. In vivo MR imaging of acute thrombus formation using a bimodal contrast agent. Proc Intl Soc Mag Reson Med 2008; 16:22.

170. Alonso A, Della Martina A, Stroick M, et al. Molecular imaging of human thrombus with novel abciximab immunobubbles and ultrasound. Stroke 2007;38:1508-14.

171. Wang B, Zang WJ, Wang M, et al. Prolonging the ultrasound signal enhancement from thrombi using targeted microbubbles based on sulfur-hexafluoride-filled gas. Acad Radiol 2006;13:428-33.

172. Sarda-Mantel L, Coutard M, Rouzet F, et al. $99 m T c$-annexin-V functional imaging of luminal thrombus activity in abdominal aortic aneurysms. Arterioscler Thromb Vasc Biol 2006;26:2153-9.

173. Adrian JE, Kamps JA, Poelstra K, Scherphof GL, Meijer DK, Kaneda Y. Delivery of viral vectors to hepatic stellate cells in fibrotic livers using HVJ envelopes fused with targeted liposomes. J Drug Target 2007;15:75-82.

174. Rensen PC, Gras JC, Lindfors EK, et al. Selective targeting of liposmes to macrophages using a ligand with high affinity for the macrophage scavenger receptor class A. Curr Drug Discov Technol 2006;3:135-44.

175. Zamboni WC. Concept and clinical evaluation of carrier-mediated anticancer agents. Oncologist 2008;13:248-60.

176. Mulder WJ, Douma K, Koning GA, et al. Liposome-enhanced MRI of neointimal lesions in the ApoE-KO mouse. Magn Reson Med 2006;55:1170-4.

177. Mulder WJ, Strijkers GJ, Griffioen AW, et al. A liposomal system for contrastenhanced magnetic resonance imaging of molecular targets. Bioconjug Chem 2004;15:799-806.

178. van Tilborg GA, Mulder WJ, Deckers N, et al. Annexin A5-functionalized bimodal lipid-based contrast agents for the detection of apoptosis. Bioconjug Chem 2006; 17:741-9.

179. Mulder WJ, Strijkers GJ, Habets JW, et al. MR molecular imaging and fluorescence microscopy for identification of activated tumor endothelium using a 
bimodal lipidic nanoparticle. FASEB J. 2005:05-4145

180. Mulder WJ, Strijkers GJ, Briley-Saboe KC, et al. Molecular imaging of macrophages in atherosclerotic plaques using bimodal PEG-micelles. Magn Reson Med 2007;58:1164-70.

181. Mulder WJ, Koole R, Brandwijk RJ, et al. Quantum dots with a paramagnetic coating as a bimodal molecular imaging probe. Nano Lett 2006;6:1-6.

182. van Tilborg GA, Mulder WJ, Chin PT, et al. Annexin A5-conjugated quantum dots with a paramagnetic lipidic coating for the multimodal detection of apoptotic cells. Bioconjug Chem 2006;17:865-8.

183. Bakalova R, Zhelev Z, Aoki I, Ohba H, Imai Y, Kanno I. Silica-shelled single quantum dot micelles as imaging probes with dual or multimodality. Anal Chem 2006;78:5925-32.

184. Dirksen A, Meijer EW, Adriaens W, Hackeng TM. Strategy for the synthesis of multivalent peptide-based nonsymmetric dendrimers by native chemical ligation. Chem Commun (Camb) 2006:1667-9.

185. Wang S, Jarrett BR, Kauzlarich SM, Louie AY. Core/shell quantum dots with high relaxivity and photoluminescence for multimodality imaging. J Am Chem Soc 2007;129:3848-56.

186. Rieter WJ, Kim JS, Taylor KM, et al. Hybrid silica nanoparticles for multimodal imaging. Angew Chem Int Ed Engl 2007;46:3680-2.

187. Bridot JL, Faure AC, Laurent S, et al. Hybrid gadolinium oxide nanoparticles: multimodal contrast agents for in vivo imaging. J Am Chem Soc 2007;129:5076-84. 188. Lai CW, Wang $\mathrm{YH}$, Lai $\mathrm{CH}$, et al. Iridium-complex-functionalized $\mathrm{Fe}_{3} \mathrm{O}_{4} / \mathrm{SiO}_{2}$ core/shell nanoparticles: a facile three-in-one system in magnetic resonance imaging, luminescence imaging, and photodynamic therapy. Small 2008;4:218-24.

189. Lisy MR, Hartung A, Lang C, et al. Fluorescent bacterial magnetic nanoparticles as bimodal contrast agents. Invest Radiol 2007;42:235-41.

190. Gu H, Zheng R, Liu H, Zhang X, Xu B. Direct synthesis of a bimodal nanosponge based on FePt and ZnS. Small 2005;1:402-6.

191. Jaffer FA, Nahrendorf M, Sosnovik D, Kelly KA, Aikawa E, Weissleder R. Cellular imaging of inflammation in atherosclerosis using magnetofluorescent nanomaterials. Mol Imaging 2006;5:85-92.

192. Choi JH, Nguyen FT, Barone PW, et al. Multimodal biomedical imaging with asymmetric single-walled carbon nanotube/iron oxide nanoparticle complexes. Nano Lett 2007;7:861-7.

193. Amemiya $\mathrm{T}$, Nakajima $\mathrm{H}$, Katoh $\mathrm{T}$, Rakue $\mathrm{H}$, Miyagi $\mathrm{M}$, Ibukiyama $\mathrm{C}$. Photodynamic therapy of atherosclerosis using YAG-OPO laser and Porfimer sodium, and comparison with using argon-dye laser. Jpn Circ J 1999;63:288-95.

194. Chen Z, Woodburn KW, Shi C, Adelman DC, Rogers C, Simon DI. Photodynamic therapy with motexafin lutetium induces redox-sensitive apoptosis of vascular cells. Arterioscler Thromb Vasc Biol 2001;21:759-764.

195. Chou TM, Woodburn KW, Cheong WF, et al. Photodynamic therapy: applications in atherosclerotic vascular disease with motexafin lutetium. Catheter Cardiovasc Interv 2002;57:387-94.

196. Kim S, Ohulchanskyy TY, Pudavar HE, Pandey RK, Prasad PN. Organically modified silica nanoparticles co-encapsulating photosensitizing drug and aggregation-enhanced two-photon absorbing fluorescent dye aggregates for twophoton photodynamic therapy. J Am Chem Soc 2007;129:2669-75.

197. Overhaus M, Heckenkamp J, Kossodo S, Leszczynski D, LaMuraglia GM. Photodynamic therapy generates a matrix barrier to invasive vascular cell migration. Circ Res 2000;86:334-40.

198. Rockson SG, Lorenz DP, Cheong WF, Woodburn KW. Photoangioplasty: an emerging clinical cardiovascular role for photodynamic therapy. Circulation 2000;102:591-6.

199. Wakamatsu T, Saito T, Hayashi J, Takeichi T, Kitamoto K, Aizawa K. Long-term inhibition of intimal hyperplasia using vascular photodynamic therapy in ballooninjured carotid arteries. Med Mol Morphol 2005;38:225-32.

200. Link S, El-Sayed MA. Shape and size dependence of radiative, non-radiative and photothermal properties of gold nanocrystals. International Reviews in Physical Chemistry 2000;19:409-53.

201. Gibson JD, Khanal BP, Zubarev ER. Paclitaxel-functionalized gold nanoparticles. J Am Chem Soc 2007;129:11653-61.

202. Paciotti GF, Myer L, Weinreich $\mathrm{D}$, et al. Colloidal gold: a novel nanoparticle vector for tumor directed drug delivery. Drug Deliv 2004;11:169-83.

203. Shimada M, Natsugoe S, Aikou T. Enhanced efficacy of Bleomycin adsorbed on silica particles against lymph node metastasis derived from a transplanted tumor. Anticancer Res 1995;15:109-15.

204. Vallabhajosula S. (18)F-labeled positron emission tomographic radiopharmaceuticals in oncology: an overview of radiochemistry and mechanisms of tumor localization. Semin Nucl Med 2007;37:400-19.

205. Alencar H, Funovics MA, Figueiredo J, Sawaya H, Weissleder R, Mahmood U. Colonic adenocarcinomas: near-infrared microcatheter imaging of smart probes for early detection--study in mice. Radiology 2007;244:232-8.

206. Bremer $\mathrm{C}$, Tung $\mathrm{CH}$, Weissleder R. Molecular imaging of MMP expression and therapeutic MMP inhibition. Acad Radiol 2002;9 Suppl 2:S314-5.

207. Balestrieri ML, Napoli C. Novel challenges in exploring peptide ligands and corresponding tissue-specific endothelial receptors. Eur J Cancer 2007;43:1242-50. 208. Palmowski M, Huppert J, Ladewig G, et al. Molecular profiling of angiogenesis 


\section{Chapter 3}

with targeted ultrasound imaging: early assessment of antiangiogenic therapy effects. Mol Cancer Ther 2008;7:101-9.

209. Corsten MF, Hofstra L, Narula J, Reutelingsperger CP. Counting heads in the war against cancer: defining the role of annexin $A 5$ imaging in cancer treatment and surveillance. Cancer Res 2006;66:1255-60.

210. Thapa N, Kim S, So IS, et al. Discovery of a phosphatidylserine recognizing peptide and its Utility in molecular imaging of tumor apoptosis. J Cell Mol Med 2008;12:1649-60. 


\section{Chapter 4}

\section{High resolution vasa vasorum imaging in intact murine atherosclerotic arteries}

Kim Douma, Sylvia Heeneman, Tilman M. Hackeng,

M. Eline Kooi, Dick W. Slaaf, Mark J. Post, and Marc A.M.J. van Zandvoort

In preparation 


\begin{abstract}
Atherosclerotic plaques are associated with an increased density in vasa vasorum (VV), an adventitial plexus of microvessels. The VV potentially contribute to vulnerable plaque formation by providing conduits for inflammatory cells. Therefore, sensitive and highresolution visualization of the VV may aid in further understanding (vulnerable) plaque development. Vascular endothelial cells (VECs) in atherosclerotic $\mathrm{ApoE}^{-/-}$mice were labeled in vivo by intravenous injection of fluorescent CD31 antibody. To assess angiogenic activity, quantum dots (QDs) were targeted in vivo to CD13, expressed by angiogenic VECs, by binding cyclic Ans-Gly-Arg (cNGR) to the QD surface (cNGR-QDs). The aortic arch and abdominal aorta were embedded in agarose gel and observed with two-photon laser scanning microscopy (TPLSM). C57BL/6J mice served as control. VV were found in aortic abdominal bifurcations of 4 out of $5 \mathrm{ApoE}^{-/-}$mice, but not in other aortic segments. A single adventitial microvessel was observed in 2 control mice $(n=6)$. In the $\mathrm{ApoE}^{-/-}$mice, two groups of axial VV microvessels with different median diameter were recognized: $6.0 \mu \mathrm{m}(2.1-16.5 \mu \mathrm{m})$ and $22.7 \mu \mathrm{m}(16.6-43.8 \mu \mathrm{m})$. Microvessels, penetrating the media up to $60 \mu \mathrm{m}$, could be distinguished from axial VV and had a median diameter of $4.4 \mu \mathrm{m}(2.6-6.4 \mu \mathrm{m})$. cNGR-QDs colocalized with VV VECs in $30 \%$ of the axial VV of ApoE ${ }^{-/-}$mice, indicating angiogenic activity. We demonstrated visualization and $3 \mathrm{D}$ representation of in vivo fluorescently labeled $\mathrm{VV}$ associated with plaques and of angiogenic activity in excised, but intact aortic adventitia of $\mathrm{ApoE}^{-/}$mice. TPLSM may be employed to evaluate the mechanisms underlying destabilization of atherosclerotic lesions in longitudinal studies.
\end{abstract}




\section{Introduction}

In 1876, Köster suggested that (advanced) atherosclerotic lesions are associated with an increased density in vasa vasorum (VV), i.e., the adventitial plexus of microvessels providing the arterial wall with oxygen and nutrients and removing "waste" products. ${ }^{1}$ Ever since, a growing number of studies imply that both intraplaque vasculature and VV expansion enhance atherosclerotic plaque development. ${ }^{2,3}$ Experimental evidence that coronary VV expansion precedes plaque formation and endothelial dysfunction ${ }^{4,5}$ favors a regulating function of VV in plaque progression. Thus, VV contribute to plaque development and the observed expansion can be considered not merely a reaction to plaque progression. Intraplaque microvessels predominantly originate from $\mathrm{VV},{ }^{6}$ providing additional conduits for inflammatory cells to invade the plaque. ${ }^{7-9}$ These cells may affect the stability of the fibrous cap by releasing metalloproteinases (MMPs). ${ }^{10,11}$ Moreover, microvessels have been observed in the plaque shoulder, ${ }^{12}$ a location considered prone to rupture. ${ }^{3}$ Upon rupture, the plaque's thrombogenic contents is exposed to the blood, ${ }^{12}$ leading to acute cardiovascular events, including infarction, stroke, and critical limb ischemia.

Several studies have shown a correlation of VV density with plaque size ${ }^{13,14}$ and inflammatory content. ${ }^{15}$ However, evidence for a causative relation between VV and plaque vulnerability stems from studies with angiogenesis inhibitors in atherosclerotic mice with low VV density. ${ }^{16}$ The effect of anti-angiogenic therapy in these animals is stage-dependent and was shown to reduce macrophage accumulation, intimal vasculature, and plaque growth. ${ }^{15-17}$ These features likely contribute to plaque stabilization or regression. ${ }^{17}$ However, in an intervention study, statin treatment failed to affect VV density in hypercholesterolemic pigs, although the expression of key players in the angiogenic cascade and neo-vascularization such as hypoxia inducible factor- $1 \alpha$ (HIF-1 $\alpha$ ), vascular endothelial growth factor (VEGF), and MMPs was reduced. ${ }^{18}$ Conversely, VEGF promotes plaque progression and accumulation of inflammatory cells without increasing plaque vasculature in $\mathrm{ApoE}^{-/}$mice.$^{19}$ Hence, the causal relation between plaque neo-vascularization and stability remains to be elucidated. ${ }^{20}$

To gain better insight into the role of $\mathrm{VV}$ in plaque destabilization, assessment is required of morphological and functional alterations of the arterial wall, and microvessels therein, during lesion development and therapeutic interventions. Several approaches have been employed to visualize plaque microvasculature in animal models of atherosclerosis, including immunohistochemistry (IHC), ${ }^{3}$ micro-computed tomography $(\mu \mathrm{CT}),{ }^{14}$ magnetic resonance imaging (MRI), ${ }^{21,22}$ and intravascular ultrasound (IVUS). ${ }^{23}$ However, these methods require tissue processing and affect tissue integrity (IHC and $\mu \mathrm{CT}$ ) or lack the spatial resolution necessary to detect functional and structural properties of individual microvessels and to discriminate between angiogenic activity of the endothelial lining of the large vessel and VV endothelium (MRI and IVUS). We have demonstrated previously that two-photon laser scanning microscopy (TPLSM) allows detailed imaging of vessel wall structures with subcellular resolution in intact tissue. ${ }^{24-26}$ Therefore, in this study, TPLSM was applied to excised, but intact segments of the aortic arch and abdominal aorta from $\mathrm{ApoE}^{-/}$mice to visualize plaque-associated microvasculature, which was labeled in vivo by intravenous injection of FITC-conjugated anti-CD31 antibody ( $\alpha$ CD31-FITC). Moreover, highly luminescent quantum dots (QDs) were targeted in vivo to aminopeptidase N/CD13, which is overexpressed by angiogenic endothelium. ${ }^{27}$ 


\section{Materials and methods}

\section{Fluorescent probes and preparation of CD13-targeted quantum dots}

For in vivo fluorescent labeling of vascular endothelial cells (VECs), FITC-conjugated monoclonal rat anti-mouse $\alpha \mathrm{CD} 31(3.03 \mu \mathrm{mol} / \mathrm{L}$ stock solution; BD Biosciences Pharmingen, Alphen aan de Rijn, The Netherlands) was injected without modification. Unless otherwise indicated, prior to examination with TPLSM the excised vasculature was incubated ex vivo for 15 minutes with SYTO41 $(5 \mathrm{mmol} / \mathrm{L}$ stock solution; Invitrogen, Breda, The Netherlands), diluted to $1 \mu \mathrm{mol} / \mathrm{L}$ in Hanks Balanced Saline Solution(HBSS, pH 7.4, Invitrogen). SYTO41 is a vital DNA/RNA fluorescent probe that enables visualization of the nuclei of VECs, smooth muscle cells (SMCs), and fibroblasts. ${ }^{25}$

CD13-targeted quantum dots (QDs) were prepared as follows. Biotinylated cNGR was synthesized as described previously, lyophilized and stored at $-20{ }^{\circ} \mathrm{C} \cdot{ }^{24,28}$ QDs $(1 \mu \mathrm{mol} / \mathrm{L}$ stock solution, Invitrogen) are composed of a $\mathrm{CdSe}$ core with a $\mathrm{ZnS}$ shell to yield highly luminescent particles and covered with polyethyleneglycol-2000 for increased circulation half-life. Each QD holds 5 - 8 surface-conjugated streptavidin moieties to allow approximately 20 biotinylated cNGR moieties to bind. For each experiment, cNGR-QDs were prepared freshly by mixing $100 \mu \mathrm{L}$ of QD stock solution with freshly dissolved biotinylated cNGR in a molar ratio of 1:20 to a maximal volume of $140 \mu \mathrm{L}$.

\section{Animal model and vessel excision}

Animal experiments were carried out in accordance with institutional guidelines and were approved by the local animal welfare committee. Male ApoE ${ }^{-/}$mice $(n=5$, Charles River, Maasticht, The Netherlands) were fed a Western type diet ad libitum for 18 - 19 weeks to yield atherosclerotic lesions at predisposed sites of the vasculature. ${ }^{29}$ At the age of 22 - 23 weeks, the mice were anesthetized by a subcutaneous injection of $100 \mathrm{mg}$ ketamine and 20 mg xylazine per kg of mouse (Nimatek and Sedamun, respectively, Eurovet Animal Health, Bladel, The Netherlands). The tip from a $30 \mathrm{G}$ needle was removed from its plastic holder and placed in a 28 $\mathrm{mm}$ (inner diameter) polyethylene tube. The other end of the tubing was fitted to a $1 \mathrm{~mL}$ syringe by a $30 \mathrm{G}$ needle. Next, the left jugular vein was exposed and canulated and $80 \mu \mathrm{L} \alpha \mathrm{CD} 31-\mathrm{FITC}(\mathrm{n}=1)$ or $80 \mu \mathrm{L} \alpha \mathrm{CD} 31-\mathrm{FITC}$ and $140 \mu \mathrm{L}$ of cNGR-QDs $(\mathrm{n}=4)$ was gently administered. After 15 minutes of circulation, the diaphragm was cut and mice were bled to death. Subsequently, to expose the tunica adventitia, connective tissue was removed and the aortic arch and the thoracic and abdominal aorta were excised such that the tunica adventitia remained intact. The lumen of these aortic segments was flushed with HBSS after which the excised vasculature was placed in HBSS prior to examination with TPLSM. In the $\mathrm{ApoE}^{-/-}$mice two areas of interest were examined under a bright field microscope for the presence of atherosclerotic plaques: the aortic arch, including the base of the carotid arteries and the left subclavian artery, and the abdominal aorta bifurcation, including the base of the femoral arteries (Figure 2A). If plaques were present, the abluminal media and adventitia were screened systematically with TPLSM $5 \mathrm{~mm}$ distally and proximally from the plaque centre.

Male C57BL/6J wild type mice ( $\mathrm{n}=6$, aged 29 - 32 weeks) served as negative control. These mice are free of atherosclerotic lesions when fed normal chow. These mice received similar treatment as the $\mathrm{ApoE}^{-/}$mice and were intravenously injected with $\alpha$ CD31-FITC $(\mathrm{n}=3)$ or $\alpha \mathrm{CD} 31$-FITC and cNGR-QDs $(\mathrm{n}=$ 3). In $\mathrm{ApoE}^{-/-}$mice, vasa vasorum (VV) were found abluminal to plaques in the abdominal aorta bifurcation and not the aortic arch of ApoE $\mathrm{E}^{-/}$mice (see Results), therefore the abdominal aorta bifurcation of $\mathrm{C} 57 \mathrm{BL} / 6 \mathrm{~J}$ mice served as control tissue for the presence of $\mathrm{VV}$. 
Upon intravenous injection, QDs and $\alpha \mathrm{CD} 31$-FITC are cleared from the blood and accumulate in spleen and kidney. In order to determine whether the intravenous injection was successful, these organs were excised from each mouse and checked with TPLSM for the presence of cNGR-QDs and/or $\alpha \mathrm{CD} 31$-FITC.

\section{Two-photon laser scanning microscopy of the abdominal aorta}

After ex vivo labeling, the vascular segments were embedded in $2 \%$ (w/v) agarose gel (Invitrogen). TPLSM imaging was performed by using a Nikon Eclipse E600FN upright microscope (Tokyo, Japan), equipped with a Bio-Rad Radiance 2100MP imaging system and operated by Lasersharp2000 V6.0 software (Bio-Rad, Hemel Hempstead, UK). Fluorescent probes in tissues were excited by a Tsunami Ti:sapphire laser (Spectra-Physics, Mountain View, CA, USA), which was pumped by a Millennia Vs $5 \mathrm{~W}$ pump laser (Spectra-Physics) and mode-locked at $800 \mathrm{~nm}$, with a $82.5 \mathrm{MHz}$ repetition rate and $140 \mathrm{fs}$ pulse width. Tissues were observed through a water-dipping $60 \times$ fluor objective with a 1.00 numerical aperture (Nikon). Photomultiplier tubes (PMTs, Electron Tubes, Ruislip, UK) were used to collect fluorescence emission in three spectral regions: 420 - $470 \mathrm{~nm}$ (SYTO41 and autofluorescence), 520 - 560 $\mathrm{nm}(\alpha \mathrm{CD} 31-\mathrm{FITC})$ and $570-600 \mathrm{~nm}$ (cNGR-QDs). These spectral regions were tuned such that bleed-through of the fluorescent markers to adjacent PMTs was minimized. The as-obtained images, color-coded blue, green, and red, were subsequently merged into a single image. The in-plane pixel dwell-time was $11.8 \mu \mathrm{s}$, which together with Kalman averaging $(K=2)$ for reduced noise, resulted in an image acquisition speed of $0.16 \mathrm{~Hz}$. Field of view was $179 \times$ $179 \mu \mathrm{m}^{2}$ to which a $512 \times 512$ matrix was applied, resulting in 0.35 $\times 0.35 \mu \mathrm{m}^{2}$ sized pixels. In-depth scans were obtained by acquisition of consecutive images with a $1.05 \mu \mathrm{m}$ interplanar distance.

\section{Data analysis}

Data were analyzed with Image-Pro V6.2 (MediaCybernetics, Silver Spring, MD, USA) and ImageJ V1.37 software (NIH, Bethesda, MD, USA). Intraluminal diameters of the $\mathrm{VV}$ microvessels were measured in between bifurcations and presented as median (minimum - maximum).

\section{Results}

In all mice, the in vivo injection of $\alpha \mathrm{CD} 31-\mathrm{FITC}$ and/or cNGRQDs was successful as can be concluded from the presence of the respective fluorescence in kidney and splenic tissue (Figure 1). $\alpha \mathrm{CD} 31-\mathrm{FITC}$ allowed clear discrimination of vessels within these organs. Moreover, cNGR-QDs were typically observed inside the lumen of spleen (Figure 1B) and kidney vasculature (not shown).

\section{Luminal endothelium and adventitial microvessels in C57BL/6J mice}

The in vivo injection of $\alpha \mathrm{CD} 31-\mathrm{FITC}$ and subsequent ex vivo TPLSM observation of the embedded aortic segment allowed visualization of vascular endothelial cells (VECs) in the lumen of healthy aortic segments of control C57BL/6J mice (Figure 2B). Additional labeling of the nuclei of VECs, smooth muscle cells (SMCs), and fibroblasts with SYTO41 allowed orientation, i.e., discrimination between intima, media, and adventitia within the vascular wall (Figure 2B).

In two of the six control C57BL/6J mice a single adventitial $\mathrm{CD} 31$-positive $\left(\mathrm{CD} 31^{+}\right)$microvessel was found in the bifurcation of the abdominal aorta (not shown). Both microvessels (diameters 10.2 $\mu \mathrm{m}$ and $12.7 \mu \mathrm{m}$ ) were oriented axially without visible branches over their observed length $(\sim 300 \mu \mathrm{m})$. 

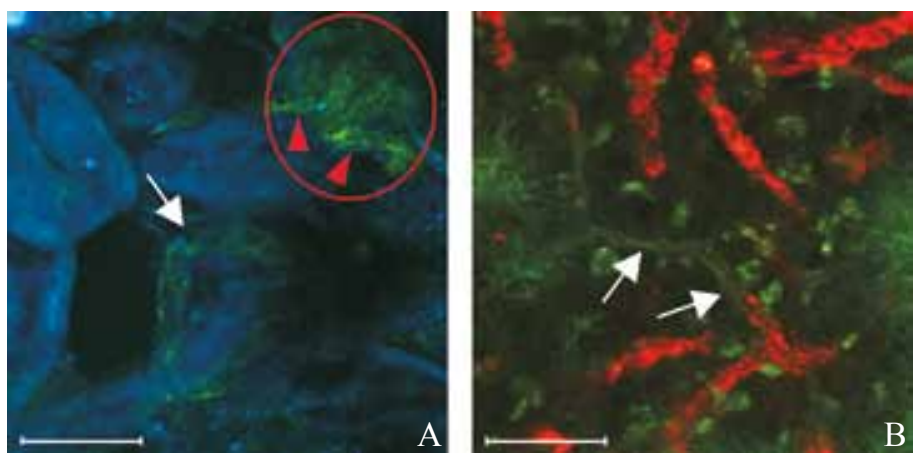

Figure 1 TPLSM images from C57BL/6J mice obtained from A) kidney and $B)$ spleen. The mice were injected solely with $\alpha C D 31-F I T C(A-B$, green) or co-injected with $c N G R-Q D s(B, r e d)$. The results indicate that the intravenous injection of $\alpha C D 31-F I T C$ and $c N G R-Q D$ s was successful. In both tissues, $\alpha C D 31-F I T C$ allowed detection of vasculature ( $A-B$, white arrows). In the kidneys, $C D 31^{+}$vasculature and glomeruli ( $A$, red ellipse), including afferent and efferent arterioles ( $A$, red arrowheads), could be discerned. Blue: autofluorescence of kidney tubuli. Bars indicate $50 \mu \mathrm{m}$.

Plaque-associated adventitial neo-vasculature in $\mathrm{ApoE}^{-/-}$mice Atherosclerotic lesions were present in the aortic arch, innominate artery, carotid and subclavian arteries, and bifurcation of the abdominal aorta of all $\mathrm{ApoE}^{-/-}$mice. In atherosclerotic arteries, VECs of the main artery could not be observed due to insufficient penetration depth of TPLSM in atherosclerotic lesions. ${ }^{30} \mathrm{CD} 31^{+}$vasa vasorum (VV) were observed in the adventitia of the abdominal aorta abluminal to the atherosclerotic lesions in 4 out of $5 \mathrm{ApoE}^{-/-}$mice (Figure 2C-E). However, VV were not observed in the adventitia abluminal to plaques in the aortic arch, innominate artery, base of the carotid arteries and subclavian arteries of $\mathrm{ApoE}^{-/-}$mice. In the aortic abdominal bifurcation, two groups of axially oriented VV microvessels could be clearly discriminated: one with a median diameter of $6.0 \mu \mathrm{m}(2.1-16.5 \mu \mathrm{m})$, which accounted for $\sim 80 \%$ of the axial microvessels, whereas the other group had a median diameter of $22.7 \mu \mathrm{m}(16.6-43.8 \mu \mathrm{m})$. In the latter population, individual endothelial cells could be discriminated by combined CD31 and SYTO41 labeling (Figure 2D). Furthermore, nuclear staining allowed visualization of cells closely associated to the VV (Figure 2E). These cells presumably represent pericytes.

In the adventitia of the abdominal bifurcation of 2 $\mathrm{ApoE}^{-/-}$mice, $\mathrm{VV}$ microvessels $(\mathrm{n}=3)$ with a median diameter of $4.4 \mu \mathrm{m}(2.6-6.4 \mu \mathrm{m})$ were found to originate from the small axial $\mathrm{VV}$ microvessels and could be followed penetrating the medial layer to a maximal depth of $\sim 60 \mu \mathrm{m}$, which excluded visualization of microvasculature inside atherosclerotic plaques, whereas the large axial VV microvessels did not display branching over their observed length $(\sim 500 \mu \mathrm{m})$.

\section{Angiogenic activity of adventitial neo-vasculature}

cNGR-QDs colocalized with $\alpha$ CD31-FITC on endothelial cells of the small axial VV microvessels abluminal to the atherosclerotic plaque in the abdominal bifurcation of $\mathrm{ApoE}^{-/-}$mice only $(\mathrm{n}=2$, Figure 3A-B). This accounted for $\sim 30 \%$ of the observed axial microvessels. This indicates the presence of angiogenic activity and the potential for angiogenic expansion. Figure 3B displays a three-dimensional reconstruction of 68 consecutive in-depth scans acquired from the adventitia of the abdominal bifurcation. Angiogenic sprouts, originating from $\mathrm{CD} 31^{+}$microvasculature, can clearly be observed (Figure 3B, arrows).

Atherosclerotic lesions are characterized by an increase in permeability of the endothelium covering the lesion. ${ }^{31}$ However, little is known about the permeability of VV that is associated with these lesions. ${ }^{32}$ In the present study, cNGR-QDs were found both colocalized with $\alpha \mathrm{CD} 31-\mathrm{FITC}$ and present outside the endothelial 

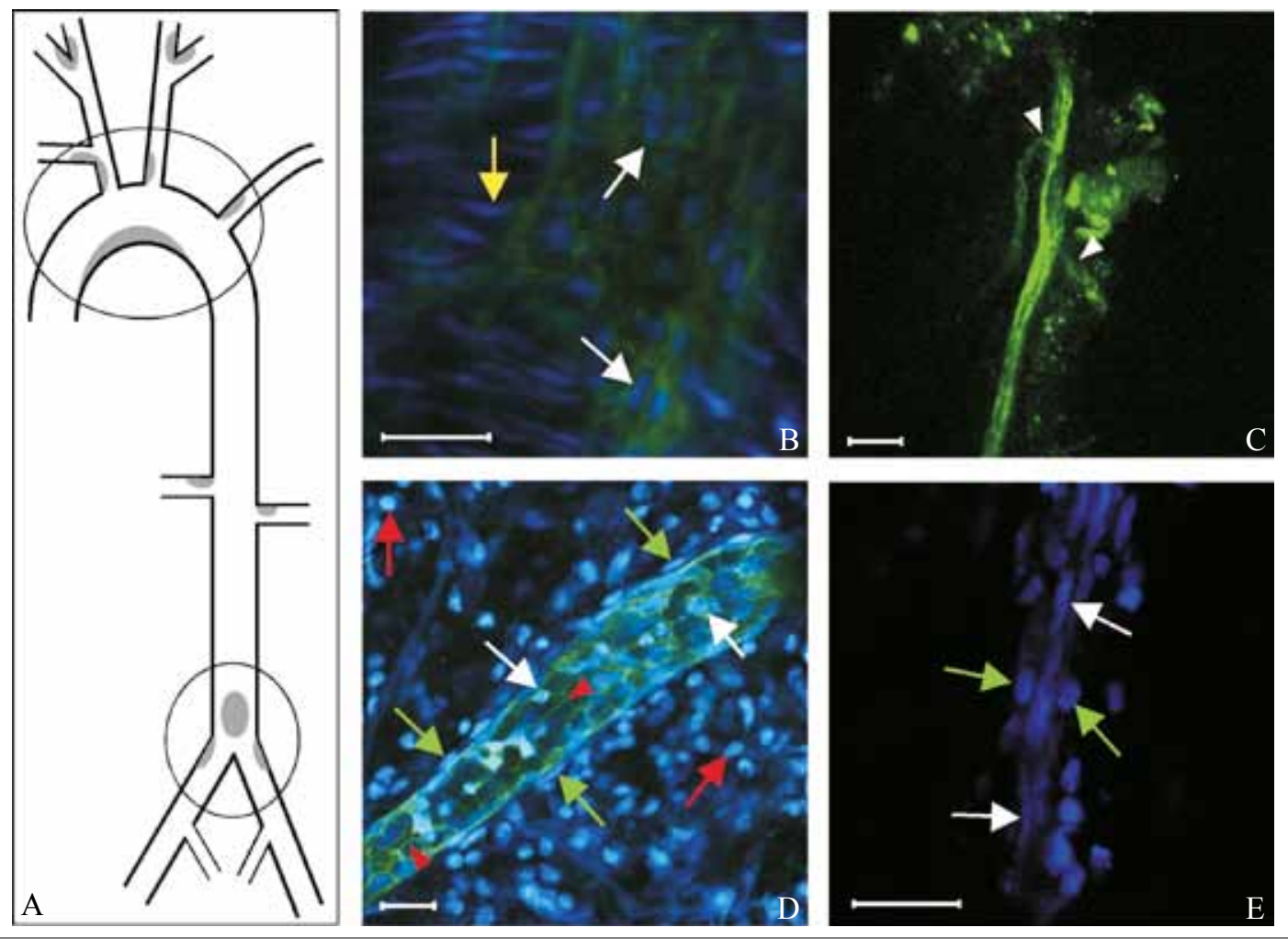

Figure 2 A) Schematic overview of the mouse aorta, ranging from the aortic root to the femoral arteries, including its main side-branches, i.e., left and right carotid arteries, left subclavian artery and renal and femoral arteries. Areas of interest are highlighted by grey ellipses. B-E) TPLSM images from control $C 57 B L / 6 \mathrm{~J}$ mice $(B)$ and ApoE-` mice (C-E) obtained at the abdominal bifurcation. In blue nuclei of cells: VECs (B, D and E, white arrows), SMCs (B, yellow arrow), fibroblasts ( $D$, red arrows), and presumably pericytes (D-E, green arrows). The green staining ( $\alpha C D 31-F I T C)$ surrounding the endothelial nuclei confirms the presence of endothelial cells. B) Intimal layer at abdominal bifurcation. C) Vasa vasorum microvessel (diameter $6.6 \mu \mathrm{m})$ with media-penetrating side branches (white arrowheads). D) Large vasa vasorum microvessel (diameter $34.8 \mu \mathrm{m}$ ) in the adventitial layer abluminal to the aortic plaque. Endothelial membranes can be distinguished (red arrowheads). E) Vasa vasorum microvessel (diameter $4.7 \mu \mathrm{m}$ ), abluminal to the aortic plaque, with closely associated cells that presumably represent pericytes. Bars indicate $25 \mu \mathrm{m}$. 
boundaries of the adventitial VV in one of the $\mathrm{ApoE}^{-/-}$mice (Figure $3 \mathrm{~B}$ ), which indeed indicates leaky endothelium. However, in all other $\mathrm{ApoE}^{-/-}$mice, cNGR-QDs were only found on the luminal side of $\mathrm{VV}$ endothelium, suggesting maturation of the observed microvessels and normal endothelial permeability.
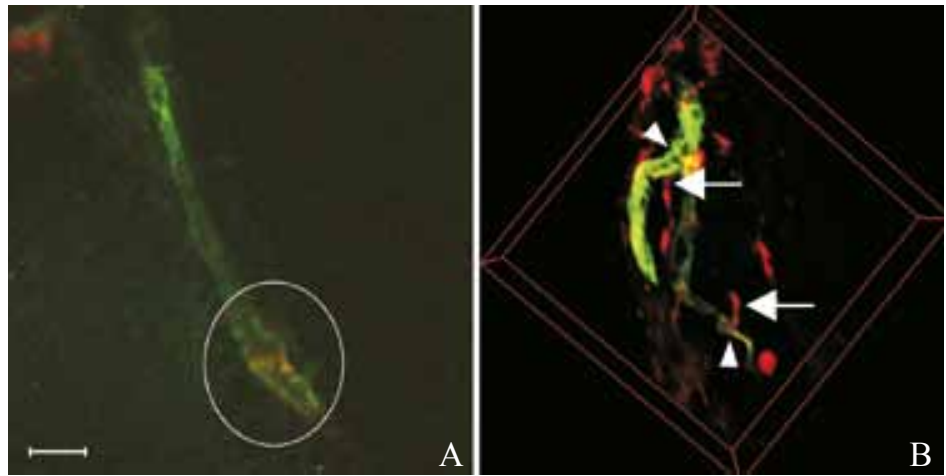

Figure $3 A$-B) TPLSM images obtained from the adventitia of the abdominal bifurcation of ApoE $E^{-/}$mice. A) Colocalization of cNGR-QDs (red) with $\alpha C D 31-F I T C$ (green) in adventitial microvasculature (diameter $6.3 \mu \mathrm{m}$ ) indicates the presence of angiogenic endothelial cells (ellipse). B) Three-dimensional reconstruction of a $200 \times 200 \times 70 \mu^{3}$ dataset shows the presence of angiogenic sprouts (arrows), branching off from nonangiogenic microvasculature (arrowheads), and extravasation beyond the luminal boundaries. Bar indicates $25 \mu \mathrm{m}$.

\section{Discussion}

This study shows the feasibility to visualize plaque-associated vasa vasorum (VV) and angiogenic activity thereof in the adventitia of excised, but intact abdominal aortic bifurcations of $\mathrm{ApoE}^{-/-}$mice after fluorescent labeling in vivo. Two-photon laser scanning microscopy (TPLSM) offered the ability to (1) image intact tissue without affecting its integrity, ${ }^{33}(2)$ determine size and distribution of VV microvessels, (3) follow microvessels penetrating the adventitia towards the medial layer (4) detect structural characteristics of the microvessels, e.g., presence of closely associated pericytes, and (5) detect angiogenic activity in adventitial microvasculature with cNGR as targeting ligand. The present results provide direct evidence on the presence of adventitial microvasculature abluminal from atherosclerotic plaques in the abdominal bifurcation and their angiogenic expansion.

The prevalence of VV in the abdominal bifurcation differed between control C57BL/6J and ApoE $\mathrm{E}^{-/}$mice. In two of the control mice a single adventitial microvessel was observed in the wall of the abdominal aortic bifuraction, whereas in 4 out of $5 \mathrm{ApoE}^{-/}$mice small microvascular networks, i.e., vasa vasorum, were observed in the plaque-associated adventitia of the abdominal aortic bifurcation only. These observations comply with Moulton et al., who obtained similar results in $\mathrm{ApoE}^{-/}$mice fed a high-cholesterol diet for 24 weeks. ${ }^{15}$ In the aortic arch, VV was not observed abluminal to plaques, which may be related to the extent of plaque size. In a more severe mouse model of atherosclerosis, i.e., ApoE ${ }^{-1-} / \mathrm{LDL}^{-/-}$mice with AHA type IV or higher atherosclerotic plaques, VV were observed in the aortic arch. ${ }^{13,14}$ Therefore, in future TPLSM experiments $\mathrm{ApoE}^{-/}$mice should be fed a Western type diet for a longer period to yield highly developed lesions. Due to practical incompatibility of histology with TPLSM, the observed atherosclerotic plaques could not be classified according to AHA standards. However, based on literature, the atherosclerotic lesions were estimated AHA type III. 
In contrast to standard immunohistochemical methods, the in vivo injection of contrast agent restricted the visualization of adventitial microvasculature to perfused (micro-) vessels. The minimal cylindrical diameter of mouse erythrocytes is reported to be about $2.65 \mu \mathrm{m},{ }^{34}$ which indicates that the diameter of the media-penetrating microvessels is large enough to be designated as functional. Although it is suggested that intraplaque vasculature and the expanding VV are hyperpermeable like tumor vasculature, ${ }^{22,32}$ cNGR-QDs were only once found beyond the endothelial microvascular boundaries, which accounts to approximately $7 \%$ of the total $\mathrm{VV}$ vasculature found in $\mathrm{ApoE}^{-/-}$mice and may be related to the relatively short blood circulation time. Therefore, further research is required to investigate hyperpermeability of the $\mathrm{VV}$ in a qualitative and quantitative manner. These results indicate that the in vivo injection of fluorophore-conjugated anti-CD31 antibody allows visualization of perfused adventitial microvasculature. However, if $\mathrm{CD} 31$-negative $\left(\mathrm{CD} 31^{-}\right)$microvasculature was present and/or the CD31-expression pattern of the observed microvessels was discontinuous, as is the case for human arteries, ${ }^{35}$ we may have underestimated the number of microvessels. Beside the moderately developed lesions mentioned above, the presence of CD31- VECs may also explain the controversial observation that $\mathrm{VV}$ were not detected in the aortic arch adventitia of ApoE $\mathrm{E}^{-/-}$mice, whereas Langheinrich et al. did. ${ }^{13}$ However, in that study the aorta was perfused with a radiopaque polymer, detecting both $\mathrm{CD} 31^{-}$and $\mathrm{CD} 31^{+} \mathrm{VV}$ with $\mu \mathrm{CT}$.

Winter et al. showed that targeting of the $\alpha_{v} \beta_{3}$-integrin, specific of angiogenic endothelium, allows visualization of angiogenic activity ${ }^{22}$ and is suitable for anti-angiogenic therapy, ${ }^{17}$ as assessed by in vivo magnetic resonance imaging (MRI) in a rabbit model of atherosclerosis. The current and previous studies ${ }^{24,26,36}$ suggest that targeting of CD13 by cNGR offers an alternative route in visualizing angiogenic activity. In addition, cNGR may be employed therapeutically, as was underscored by the reduction in tumor growth by cNGR-conjugated tissue necrotic factor- $\alpha(\mathrm{TNF}-\alpha),{ }^{37}$ to reduce plaque angiogenesis, decelerate plaque progression, and potentially prevent spontaneous plaque rupture.

A major point of discussion in current literature is the actual contribution of intraplaque vasculature to plaque destabilization. Current concepts are based on guilt-by-association evidence obtained from human endarterectomy specimen. ${ }^{12}$ Physiologically relevant animal models of spontaneous vulnerable plaque formation and rupture are currently limited or strongly debated and lack the correlation with the presence of intraplaque microvasculature. ${ }^{38-40}$ Further research is therefore required to assess a causative relation between intraplaque vasculature and plaque rupture. In this respect, TPLSM offers the ability to evaluate this putative causal relation. In a first attempt, we show here that TPLSM allows visualization of $\mathrm{VV}$ and, hence, may contribute to research that involves assessment of mechanisms underlying destabilization of atherosclerotic lesions. Penetration depth of TPLSM in atherosclerotic lesions, which in this study was limited to approximately $60 \mu \mathrm{m}$, may be increased by utilizing stable near-infrared fluorophores, adaptive optics, and pulsenarrowing protocols ${ }^{41}$ in order to enable visualization of intraplaque microvasculature. In addition, methods to quantify microvessel characteristics, e.g., microvessel functionality, permeability, and morphology would contribute to functional and longitudinal studies investigating the role of VV expansion and intraplaque vasculature in (vulnerable) atherosclerotic lesion formation.

In conclusion, this study indicates a higher plaqueassociated VV prevalence in the abdominal aorta bifurcation of ApoE ${ }^{-/}$mice than of control C57BL/6J mice. In other arterial segments, VV were absent in both $\mathrm{ApoE}^{-/}$and control mice. Moreover, the VV of $\mathrm{ApoE}^{-/-}$mice displayed angiogenic activity, as was assessed by CD13targeted cNGR-labeled quantum dots. TPLSM proved a feasible tool in visualizing the $\mathrm{VV}$ of intact arterial segments. 


\section{References}

1. Köster W. Endarteritis and arteritis. Berl Klin Wochenschr 1876;13:343-5.

2. Gössl M, Versari D, Mannheim D, Ritman EL, Lerman LO, Lerman A. Increased spatial vasa vasorum density in the proximal LAD in hypercholesterolemiaimplications for vulnerable plaque-development. Atherosclerosis 2007;192:246-52. 3. Moreno PR, Purushothaman KR, Fuster V, et al. Plaque neovascularization is increased in ruptured atherosclerotic lesions of human aorta: implications for plaque vulnerability. Circulation 2004;110:2032-8.

4. Herrmann J, Lerman LO, Rodriguez-Porcel M, et al. Coronary vasa vasorum neovascularization precedes epicardial endothelial dysfunction in experimental hypercholesterolemia. Cardiovasc Res 2001;51:762-6.

5. Kwon HM, Sangiorgi G, Ritman EL, et al. Enhanced coronary vasa vasorum neovascularization in experimental hypercholesterolemia. J Clin Invest 1998;101:1551-6. 6. Kumamoto M, Nakashima Y, Sueishi K. Intimal neovascularization in human coronary atherosclerosis: its origin and pathophysiological significance. Hum Pathol 1995;26:450-6.

7. de Boer OJ, van der Wal AC, Teeling P, Becker AE. Leucocyte recruitment in rupture prone regions of lipid-rich plaques: a prominent role for neovascularization? Cardiovasc Res 1999;41:443-9.

8. Jeziorska M, Woolley DE. Local neovascularization and cellular composition within vulnerable regions of atherosclerotic plaques of human carotid arteries. J Pathol 1999;188:189-96.

9. Moos MP, John N, Grabner R, et al. The lamina adventitia is the major site of immune cell accumulation in standard chow-fed apolipoprotein E-deficient mice. Arterioscler Thromb Vasc Biol 2005;25:2386-91.

10. Lendon CL, Davies MJ, Born GV, Richardson PD. Atherosclerotic plaque caps are locally weakened when macrophages density is increased. Atherosclerosis 1991;87:87-90.

11. van der Wal AC, Becker AE, van der Loos CM, Das PK. Site of intimal rupture or erosion of thrombosed coronary atherosclerotic plaques is characterized by an inflammatory process irrespective of the dominant plaque morphology. Circulation 1994;89:36-44

12. Virmani R, Kolodgie FD, Burke AP, et al. Atherosclerotic plaque progression and vulnerability to rupture angiogenesis as a source of intraplaque hemorrhage. Arterioscler Thromb Vasc Biol 2005;25:2054-61.

13. Langheinrich AC, Michniewicz A, Bohle RM, Ritman EL Vasa vasorum neovascularization and lesion distribution among different vascular beds in ApoE $E^{-1 /}$ $L D L^{-/}$double knockout mice. Atherosclerosis 2007;191:73-81.

14. Langheinrich AC, Michniewicz A, Sedding DG, et al. Correlation of vasa vasorum neovascularization and plaque progression in aortas of apolipoprotein E(-/-)/low-density lipoprotein(-/-) double knockout mice. Arterioscler Thromb Vasc Biol 2006;26:347-52. 15. Moulton KS, Vakili K, Zurakowski D, et al. Inhibition of plaque neovascularization reduces macrophage accumulation and progression of advanced atherosclerosis. Proc Natl Acad Sci U S A 2003;100:4736-41.

16. Moulton KS, Heller E, Konerding MA, Flynn E, Palinski W, Folkman J. Angiogenesis inhibitors endostatin or TNP-470 reduce intimal neovascularization and plaque growth in apolipoprotein E-deficient mice. Circulation 1999;99:1726-32.

17. Winter PM, Neubauer AM, Caruthers SD, et al. Endothelial alpha(v)beta 3 integrin-targeted fumagillin nanoparticles inhibit angiogenesis in atherosclerosis. Arterioscler Thromb Vasc Biol 2006;26:2103-9.

18. Wilson SH, Herrmann J, Lerman LO, et al. Simvastatin preserves the structure of coronary adventitial vasa vasorum in experimental hypercholesterolemia independent of lipid lowering. Circulation 2002;105:415-8.

19. Lucerna M, Zernecke A, de Nooijer R, et al. Vascular endothelial growth factor- $A$ induces plaque expansion in ApoE knock-out mice by promoting de novo leukocyte recruitment. Blood 2007;109:122-9.

20. Khurana R, Simons M, Martin JF, Zachary IC. Role of angiogenesis in cardiovascular disease: a critical appraisal. Circulation 2005;112:1813-24.

21. Calcagno C, Cornily JC, Hyafil F, et al. Detection of neovessels in atherosclerotic plaques of rabbits using dynamic contrast enhanced MRI and 18F-FDG PET. Arterioscler Thromb Vasc Biol 2008;28:1311-7.

22. Winter PM, Morawski AM, Caruthers SD, et al. Molecular imaging of angiogenesis in early-stage atherosclerosis with alpha(v)beta3-integrin-targeted nanoparticles. Circulation 2003;108:2270-4.

23. Goertz DE, Frijlink ME, Tempel D, et al. Contrast harmonic intravascular ultrasound: a feasibility study for vasa vasorum imaging. Invest Radiol 2006;41:631-8. 24. Buehler A, van Zandvoort MA, Stelt BJ, et al. cNGR: a novel homing sequence for CD13/APN targeted molecular imaging of murine cardiac angiogenesis in vivo. Arterioscler Thromb Vasc Biol 2006;26:2681-7.

25. Megens RT, Reitsma S, Schiffers $\mathrm{PH}$, et al. Two-photon microscopy of vital murine elastic and muscular arteries. Combined structural and functional imaging with subcellular resolution. J Vasc Res 2007;44:87-98.

26. Oostendorp M, Douma K, Hackeng TM, et al. Quantitative molecular magnetic resonance imaging of tumor angiogenesis using cNGR-labeled paramagnetic quantum dots. Cancer Res 2008;68:7676-83.

27. Pasqualini R, Koivunen E, Kain R, et al. Aminopeptidase $N$ is a receptor for tumor-homing peptides and a target for inhibiting angiogenesis. Cancer Res 2000;60:722-7.

28. Schnolzer M, Alewood P, Jones A, Alewood D, Kent SB. In situ neutralization in 
Boc-chemistry solid phase peptide synthesis. Rapid, high yield assembly of difficult sequences. Int J Pept Protein Res 1992;40:180-93.

29. Meir KS, Leitersdorf E. Atherosclerosis in the apolipoprotein-E-deficient mouse: a decade of progress. Arterioscler Thromb Vasc Biol 2004;24:1006-14.

30. Megens RT, oude Egbrink MG, Cleutjens JP, et al. Imaging collagen in intact viable healthy and atherosclerotic arteries using fluorescently labeled CNA35 and two-photon laser scanning microscopy. Mol Imaging 2007;6:247-60.

31. Mulder WJ, Douma K, Koning GA, et al. Liposome-enhanced MRI of neointimal lesions in the ApoE-KO mouse. Magn Reson Med 2006;55:1170-4.

32. Kerwin WS, Oikawa M, Yuan C, Jarvik GP, Hatsukami TS. MR imaging of adventitial vasa vasorum in carotid atherosclerosis. Magn Reson Med 2008;59:507-14.

33. Zipfel WR, Williams RM, Webb WW. Nonlinear magic: multiphoton microscopy in the biosciences. Nat Biotechnol 2003;21:1369-77.

34. Engström KG, Taljedal IB. Altered shape and size of red blood cells in obese hyperglycaemic mice. Acta Physiol Scand 1987;130:535-43.

35. Pusztaszeri MP, Seelentag W, Bosman FT. Immunohistochemical expression of endothelial markers CD31, CD34, von Willebrand factor, and Fli-1 in normal human tissues. J Histochem Cytochem 2006;54:385-95.

36. von Wallbrunn $\mathrm{A}$, Waldeck J, Höltke $\mathrm{C}$, et al. In vivo optical imaging of $C D 13 / A P N$ expression in tumor xenografts. Journal of Biomedical Optics 2008;13:011007.

37. Curnis F, Sacchi A, Borgna L, Magni F, Gasparri A, Corti A. Enhancement of tumor necrosis factor alpha antitumor immunotherapeutic properties by targeted delivery to aminopeptidase N (CD13). Nat Biotechnol 2000;18:1185-90.

38. Prescott MF, McBride CH, Hasler-Rapacz J, Von Linden J, Rapacz J. Development of complex atherosclerotic lesions in pigs with inherited hyper-LDL cholesterolemia bearing mutant alleles for apolipoprotein B. Am J Pathol 1991;139:139-47.

39. Schwartz SM, Galis ZS, Rosenfeld ME, Falk E. Plaque rupture in humans and mice. Arterioscler Thromb Vasc Biol 2007;27:705-13.

40. Williams H, Johnson JL, Carson KG, Jackson CL. Characteristics of intact and ruptured atherosclerotic plaques in brachiocephalic arteries of apolipoprotein $E$ knockout mice. Arterioscler Thromb Vasc Biol 2002;22:788-92.

41. McConnell G. Improving the penetration depth in multiphoton excitation laser scanning microscopy. J Biomed Opt 2006;11:054020. 



\section{Chapter 5}

\section{Evaluation of magnetic resonance vessel size imaging by two-photon laser scanning microscopy}

Kim Douma*, Marlies Oostendorp*, Dick W. Slaaf, Mark J. Post, Walter H. Backes, and Marc A.M.J. van Zandvoort

* Authors have contributed equally

Magnetic Resonance in Medicine 


\begin{abstract}
Magnetic resonance vessel size imaging (MR-VSI) is increasingly applied to non-invasively assess microvascular properties of tumors and to evaluate tumor response to anti-angiogenic treatment. MRVSI provides measures for the microvessel radius and fractional blood volume of tumor tissue, which has not yet been evaluated with 3D microscopy techniques. Therefore, 3D two-photon laser scanning microscopy (TPLSM) was performed to assess microvascular radius and fractional vessel volume in tumor and muscle tissue. TPLSM data displayed a maze-like architecture of the tumor microvasculature and mainly parallel oriented muscle microvessels. For both MR-VSI and TPLSM, a larger vessel radius and fractional blood volume were found in the tumor rim than in the core. On average, the microvessel radius was approximately 6 times larger in tumor and muscle for MR-VSI than for TPLSM. The tumor blood volume was 4-fold lower with MR-VSI than with TPLSM, whereas muscle blood volume was comparable for both techniques. Differences between the tumor rim, core and muscle tissue showed similar trends for both MR-VSI and TPLSM parameters. These results indicate that MR-VSI does not provide absolute measures of microvascular morphology, however, reflects heterogeneity in microvascular morphology. Hence, MR-VSI may be used to assess differences in microvascular morphology.
\end{abstract}




\section{Introduction}

Tumor growth and metastasis formation are accompanied by the angiogenic expansion of the supporting microvascular network. ${ }^{1}$ Clinical studies have shown that the immunohistochemical microvessel density (MVD) is a valuable prognostic indicator for various tumor types. ${ }^{2}$ In addition, changes in MVD may provide a rough indication of therapeutic efficacy. ${ }^{2}$ However, tumor MVD as assessed on biopsy samples significantly hampers longitudinal evaluation, is prone to sampling errors in heterogeneous tumors, and is discomforting for patients. Magnetic resonance vessel size imaging (MR-VSI) has been proposed as a non-invasive alternative to the histologically determined MVD, as it allows in vivo estimation of a vessel radius index and fractional blood volume in whole tissue on a voxel-by-voxel basis. ${ }^{3}$

MR-VSI is based on the different nature of changes in the transverse relaxation rates $R_{2}$ and $R_{2}^{*}$ of blood and surrounding tissue as a function of microvascular dimensions. These changes can be induced either by endogenous contrast mechanisms, i.e., a change in blood deoxyhemoglobin concentration ${ }^{4}$ or by exogenous intravascular contrast agents such as ultra-small superparamagnetic iron oxide (USPIO) particles. ${ }^{5}$ In regions adjacent to large vessels, a strong increase in $R_{2}{ }^{*}$ and only a small increase in $R_{2}$ are expected, whereas changes in $R_{2}{ }^{*}$ and $R_{2}$ will be about the same near small capillaries. ${ }^{4}$ Therefore, the ratio of relaxation rate changes $\left(\Delta R_{2}^{*} / \Delta R_{2}\right)$ was shown to be related to the average dimensions of the microvessels. ${ }^{4,5}$ This principle was extended by Troprès et al., who suggested that MRVSI allows estimation of a tumor vessel radius index and fractional blood volume. ${ }^{3}$

MR-VSI has been applied to assess vascular development in various pre-clinical tumors, including brain tumors ${ }^{3,6,7}$ and subcutaneously induced solid tumors. ${ }^{8,9}$ It allowed monitoring of therapeutic intervention ${ }^{8-10}$ and the effects of stimulated pericyte recruitment $^{11}$ and hypoxia. ${ }^{12}$ However, evaluation of MR-VSI with standard histology showed a systematic overestimation of the MR-derived vessel radius index with a considerable inter-study variability. ${ }^{6,7,10}$ Pathak et al. developed a histological method based on tissue sectioning, three-dimensional (3D) reconstruction and stereological principles, to yield a fractional blood volume that correlated well with MR-VSI. ${ }^{13}$ However, the main drawback of histological methods for MVD and vessel size quantification is (non-) isotropic tissue shrinkage, thereby disturbing the morphological characteristics of the microvasculature. ${ }^{14,15} \mathrm{In}$ addition, histologic preparation results in loss of the endothelial glycocalyx, which constitutes a significant part of the total vascular volume, ${ }^{16}$ and hence, may result in an overestimation of vessel radius and volume.

The goal of the present study was to compare MR-VSI measurements with 3D two-photon laser scanning microscopy (TPLSM). TPLSM enables optical sectioning of intact tissue with high spatial resolution $(<1 \mu \mathrm{m})$ and penetration depths of more than $200 \mu \mathrm{m},{ }^{17}$ which allows visualization and quantification of individual microvessels.

In addition, MR-VSI has been applied predominantly to assess vascular morphology in brain tumors, in which the microvasculature is disorganized and the blood-brain-barrier may affect the observed contrast between healthy and cancer tissue. Therefore, an additional goal of this study was to apply 3D TPLSM and MR-VSI to both the disorganized and the highly organized microvasculature of subcutaneous tumors and skeletal muscle tissue, respectively. 


\section{Materials and methods}

\section{Contrast agents}

The USPIO contrast agent Sinerem ${ }^{\circledR}$ (ferumoxtran-10) was kindly provided by Guerbet (Aulnay-sous-Bois, France). The administered dose was $200 \mu \mathrm{mol} \mathrm{Fe} / \mathrm{kg}$ body weight, as described previously. ${ }^{3}$ USPIOs were diluted in saline to obtain a total administered volume of $100 \mu \mathrm{L}$.

For TPLSM, the vasculature was demarcated from surrounding tissue by fluorescent labeling of vascular endothelial cells. Therefore, excised tissues were incubated for 30 minutes in FITC-conjugated anti-mouse anti-CD31 ( $\alpha$ CD31-FITC, $0.5 \mathrm{mg} / \mathrm{mL}$, BD Biosciences Pharmingen, Alphen a/d Rijn, The Netherlands), diluted $20 \times$ in Hanks Balanced Saline Solution (HBSS, pH 7.4).

\section{Spectrophotometry}

The inherent fluorescence of the USPIOs was measured using a NanoDrop ND3300 fluorospectrometer (Thermo Fisher Scientific, Waltham, MA). The potential influence of USPIOs on the fluorescence intensity of $\alpha$ CD31-FITC was analyzed in triplicate using an UVIKON 923 spectrophotometer (Bio-Tek, Kontron Instruments, Milan, Italy). The intensity of diluted $\alpha \mathrm{CD} 31-\mathrm{FITC}(1 \mu \mathrm{M}$ in HBSS $)$ was measured at wavelengths of $500-700 \mathrm{~nm}$ (step size $4 \mathrm{~nm}$ ) with increasing USPIO concentration $(0,2.2,8.8$, and $22 \mathrm{mM} \mathrm{Fe})$. Fluorescence resonance energy transfer from $\alpha \mathrm{CD} 31-\mathrm{FITC}$ to USPIO was analyzed by comparing the fluorescence lifetime (SPC-830, Becker\&Hickl $\mathrm{GmbH}$, Berlin, Germany) of $\alpha \mathrm{CD} 31-\mathrm{FITC}(1 \mu \mathrm{M}$ in HBSS $)$ in the absence and presence of USPIOs (22 $\mathrm{mM} \mathrm{Fe})$.

\section{Animal model}

All animal experiments were approved by the institutional ethical review committee on animal experiments. Ten male Swiss ${ }^{\text {nu/nu }}$ mice (Charles River, Maastricht, The Netherlands) received a subcutaneous unilateral injection of approximately $3 \times 10^{6}$ human colorectal adenocarcinoma cells (LS174T, American Type Culture Collection CL188 , Rockville, MD) in the flank. MRI examinations were performed when tumors reached a volume of about $1 \mathrm{~cm}^{3}$ (approximately 14 days after tumor induction). For TPLSM imaging, a separate group of eleven LS174T tumor-bearing mice was used because USPIOs reduced the vascular fluorescence intensity (vide infra).

Mice were anesthetized using 1-2\% isoflurane (Abbott Laboratories Ltd, Queensborough, UK) in medical air. An infusion line of PE-10 tubing (Smiths Medical International Ltd, Hythe, UK) was placed in the jugular vein for contrast agent injection. Subsequently, mice were placed prone in an animal holder with built-in anesthesia mask. Body temperature and respiration rate were continuously monitored via an MR compatible small animal monitoring system (SA Instruments, Stony Brook, NY). Physiological body temperature was maintained using a warm water heating pad placed over the mouse.

\section{MRI protocol}

MRI was performed on a 7 Tesla Bruker Biospec 70/30 USR scanner (Bruker Biospin $\mathrm{GmbH}$, Ettlingen, Germany), using the BGA12-S mini-imaging gradient (maximum gradient strength $720 \mathrm{mT} \cdot \mathrm{m}^{-1}$, slew rate $6000 \mathrm{Tm}^{-1} \mathrm{~s}^{-1}$ ), interfaced to an AVANCE II console. All images were recorded with a $3.5 \mathrm{~cm}$ inner diameter quadrature volume resonator.

Tumors were localized using coronal and axial $T_{2}$-weighted spin echo images with a repetition time (TR) of $3000 \mathrm{~ms}$ and an echo time (TE) of $36 \mathrm{~ms}$. Pre- and post-contrast $R_{2}$ values were determined using a multi-slice multi-echo (MSME) spin echo sequence with

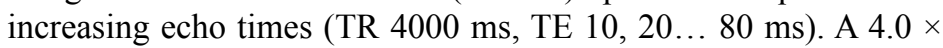
$4.0 \mathrm{~cm}^{2}$ field-of-view was used with a $128 \times 128$ matrix, resulting in an in-plane resolution of $0.31 \times 0.31 \mathrm{~mm}^{2}$. Slices were recorded in axial direction with a thickness of $1.2 \mathrm{~mm}$. Depending on tumor size 
and orientation, 12 slices (range 5 - 17) were recorded. Acquisition time of the MSME sequence was 6.5 minutes.

Pre- and post-contrast $R_{2}^{*}$ values were measured using sequentially recorded multi-slice gradient echo (FLASH) images with increasing echo times (TR $1000 \mathrm{~ms}$, TE 2, 4, 6, 8, 10, 15, 20 $\mathrm{ms}$, flip angle $35^{\circ}$ ). Spatial parameters were identical to those of the MSME measurements and the total acquisition time of the FLASH series was 15 minutes. Post-contrast image acquisition was started at least 5 minutes after USPIO injection to allow circulation and obtain adequate distribution.

The apparent diffusion coefficient (ADC) was determined using a diffusion-weighted spin echo sequence with 6 orthogonal directions (TR $2000 \mathrm{~ms}$, TE $30 \mathrm{~ms}, \mathrm{~b}=0$ and $572 \mathrm{~s} \cdot \mathrm{mm}^{-2}$, diffusion gradient duration $8 \mathrm{~ms}$, diffusion gradient separation $13 \mathrm{~ms}, 4$ axial slices positioned around the tumor centre, $1.2 \mathrm{~mm}$ thickness with 1.2 mm gap, $128 \times 64$ matrix, field-of-view $4.0 \times 4.0 \mathrm{~cm}^{2}, 2$ averages, acquisition time 30 minutes). Diffusion-weighted imaging was only performed before contrast administration.

After MRI, mice were sacrificed by cervical dislocation. Tumors were excised and embedded in optimal cutting temperature compound (Sakura Finetek Europe, Zoeterwoude, The Netherlands), snapfrozen in cold 2-methylbutane (Acros Organics, Geel, Belgium) and subsequently transferred to liquid nitrogen. The contralateral quadriceps femoris muscle was excised up to $\sim 1 \mathrm{~cm}$ proximal to the knee joint and frozen likewise. Tumor and muscle tissues were stored at $-80^{\circ} \mathrm{C}$ until TPLSM measurements.

\section{MRI data analysis}

All data processing was performed using customized software programmed in Matlab (The MathWorks, Natick, MA), unless indicated otherwise. Image coregistration was performed in SPM2 (Statistical Parametric Mapping, Wellcome Trust Centre for Neuroimaging, London, UK) to correct for any animal motion between the MSME and FLASH series. Images were smoothed using an in-plane Gaussian smoothing kernel with a full-width-athalf-maximum of $0.7 \times 0.7 \mathrm{~mm}^{2}$ in SPM2. Regions of interest were defined manually for tumor and muscle tissue using MRIcro. ${ }^{18}$

Pre- and post-contrast $R_{2}$ and $R_{2}^{*}$ values were determined on a voxel-by-voxel basis by non-linear curve fitting of the signal intensity versus TE function, obtained from spin echo and gradient echo acquisitions, respectively:

$$
\mathrm{S}(\mathrm{TE})=\mathrm{S}_{0} \exp \left(-\mathrm{TE} \cdot \mathrm{R}_{2}^{(*)}\right)
$$

using the Levenberg-Marquardt optimization algorithm. Here, $S_{0}$ is a scaling factor depending on TR, proton density, and general scanner settings including preamplifier and receiver gain, and pulse profiles. Subsequently, $\Delta R_{2}^{(*)}$ values were calculated as $\Delta R_{2}^{(*)}=R_{2, \text { post }}{ }^{(*)}-R_{2, \text { pre }}{ }^{(*)}$. The thresholds for significantly positive $\Delta R_{2}^{(*)}$ values were determined using Monte-Carlo simulations, as described previously. ${ }^{19}$

Mean tumor and muscle ADC values of 1334 and $1718 \mu \mathrm{m}^{2} \mathrm{~s}^{-1}$, respectively, were calculated using Paravision 4.0 (Bruker Biospin). Voxel-based ADC mapping was not performed due to the differences in spatial resolution between the ADC and $\Delta R_{2}^{(*)}$ measurements.

Next, the vessel radius index $\mathrm{RI}_{\mathrm{MRI}}$ and fractional blood volume $\mathrm{fBV}_{\mathrm{MRI}}$ were calculated on a voxel-by-voxel basis according to Troprès et al.: ${ }^{3}$

$$
\begin{aligned}
& \mathrm{RI}_{\mathrm{MRI}}(\mu \mathrm{m})=0.424 \sqrt{\frac{\mathrm{ADC}}{\gamma \Delta \chi \mathrm{B}_{0}}}\left[\frac{\Delta \mathrm{R}_{2}^{*}}{\Delta \mathrm{R}_{2}}\right]^{3 / 2} \\
& \mathrm{fBV}_{\mathrm{MRI}}(\%)=\frac{3}{4 \pi} \times \frac{\Delta \mathrm{R}_{2}^{*}}{\gamma \Delta \chi \mathrm{B}_{0}}
\end{aligned}
$$


Here, $\gamma$ is the gyromagnetic ratio, $\Delta \chi$ is the USPIO-induced susceptibility difference between blood and surrounding tissue, and $\mathrm{B}_{0}$ is the main magnetic field strength. $\Delta \chi$ was set to $0.571 \mathrm{ppm}^{3}$ Only voxels with a significantly positive $\Delta R_{2}^{(*)}$ were included in the calculation. For tumor rim, core and muscle tissue the resulting percentage of significant voxels was $59.0 \pm 6.1 \%, 57.8 \pm 5.7 \%$ and $86.1 \pm 4.2 \%$, respectively (mean \pm standard error). An upper boundary of $100 \mu \mathrm{m}$ was set for $\mathrm{RI}_{\mathrm{MRI}}$ to exclude unrealistically high values. ${ }^{6}$

To investigate differences in $\mathrm{RI}_{\mathrm{MRI}}$ and $\mathrm{fBV}_{\mathrm{MRI}}$ between the tumor rim and core, the rim was defined manually as an approximately 1 $\mathrm{mm}$ thick peripheral zone, as described previously. ${ }^{19}$ The tumor core was defined as the difference between whole tumor and tumor rim.

\section{TPLSM protocol}

Prior to TPLSM measurements, tumor and muscle tissue were thawed and washed with HBSS. Tumors were cut in half to resemble the central MR slices; muscle tissue was not processed. Tissues were incubated in $\alpha \mathrm{CD} 31-\mathrm{FITC}$, embedded in $2 \%(\mathrm{w} / \mathrm{v})$ agarose gel (Invitrogen, Breda, The Netherlands) and imaged with TPLSM. Note that due to the ex vivo labeling of the vascular endothelial cells, TPLSM detects all vessels resulting in the fractional vessel volume. In contrast, MR-VSI only detects the perfused vessels, resulting in the fractional blood volume.

TPLSM was performed as described previously at randomly selected locations within the tissue. ${ }^{19}$ In brief, in-depth images were recorded with an Eclipse E600FN upright microscope (Nikon, Tokyo, Japan) equipped with a Radiance 2100MP optical imaging system (Bio-Rad, Hemel Hempstead, UK). Fluorophores were excited by a mode-locked Tsunami Ti:Sapphire laser (SpectraPhysics, Mountain View, CA, USA) with a central wavelength of $800 \mathrm{~nm}$ and a $140 \mathrm{fs}$ pulse width. 3D datasets were acquired using a $60 \times$ water-dipping objective lens (Nikon) with a numerical aperture of 1.00 . Fluorescence $(520-560 \mathrm{~nm})$ was detected by a photo-multiplier tube (Electron Tubes, Ruislip, UK) and colorcoded in green. A $512 \times 512$ matrix was applied to the $196 \times 196$ $\mu \mathrm{m}^{2}$ field-of-view, resulting in in-plane pixels of $0.38 \times 0.38 \mu \mathrm{m}^{2}$. The pixel dwell time was $11.8 \mu \mathrm{s}$, which together with a two-fold Kalman averaging for noise reduction resulted in an acquisition rate of $0.16 \mathrm{~Hz}$ for each of the subsequent images in the $3 \mathrm{D}$ dataset. The interplanar distance was $1.05 \mu \mathrm{m}$ or $0.6 \mu \mathrm{m}$.

\section{TPLSM data analysis}

The acquired 3D datasets were deconvolved using AutoQuant X2 AutoDeblur (MediaCybernetics, Bethesda, MD, USA) in 3D blind deconvolution mode, which required objective lens specifications, refractive index of the medium $(n=1.33)$, spatial parameters, and the emission wavelength maximum of FITC $(\lambda=518 \mathrm{~nm})$ to estimate the initial point spread function. Deconvolution was optimized using $4.43 \pm 0.31 \mu \mathrm{m}$ diameter fluorescent microspheres (Polysciences Inc., Warrington, PA, USA), which were diluted $20 \times$ in $2 \%(\mathrm{w} / \mathrm{v})$ hot agarose gel, homogenized, solidified at room temperature, and imaged with TPLSM. Using 10 iterations, 3D blind deconvolution reduced the microsphere volume from $100.11 \pm 3.46 \mu \mathrm{m}^{3}$ to 42.41 $\pm 4.02 \mu \mathrm{m}^{3}$ (mean $\pm \mathrm{SD}, \mathrm{n}=5$ ), which is not different from the theoretical volume $\left(45.52 \mu \mathrm{m}^{3}, \mathrm{P}=0.1\right)$.

After 3D blind deconvolution of the vasculature datasets, in-plane radiuses $\left(\mathrm{R}_{\text {TPLSM }}\right)$ of the tumor and muscle microvasculature were determined using Image Pro Plus V6.2 (MediaCybernetics). $\mathrm{R}_{\text {TPLSM }}$ values were determined manually between vessel bifurcations at 8 random locations in each 3D dataset to yield the median vessel radius.

The fractional vessel volume $\left(\mathrm{fVV}_{\text {TPLSM }}\right)$ and total microvessel length $\left(\mathrm{MVL}_{\text {TPLSM }}\right)$ were determined using 3D Constructor 5.1 (MediaCybernetics), as outlined in Figure 1. In short, (1) the deconvolved $3 \mathrm{D}$ datasets (Figure $1 \mathrm{~A} / \mathrm{E}$ ) were smoothed using a $3 \times 3 \times 3$ voxel Gaussian kernel, (2) a 3D closing filter was applied to create massive 
cylinder-shaped structures and (3) the dataset was convolved with an isotropic 3D Gaussian filter with dimensions of the dataset's median microvessel diameter (Figure $1 \mathrm{~B} / \mathrm{F}$ ), (4) an isosurface (Figure $1 \mathrm{C} / \mathrm{G}$ ) was applied by means of intensity thresholding such that the applied isosurface closely matched the raw dataset (visual inspection), (5) the volume of all voxels within the isosurface was integrated and divided by the total dataset volume to yield the $\mathrm{fVV}_{\text {TPLSM }}$, (6) a skeletonization procedure was applied to yield the central lines of the microvasculature, and (7) a pruning filter was set to twice the median microvessel diameter as a restriction for the side branches. Next, the $\mathrm{MVL}_{\text {TPLSM }}$ was calculated and expressed per unit of volume (Figure $1 \mathrm{D} / \mathrm{H}$ ). In addition, the total number of branching points in the skeletonized dataset was expressed per unit of volume to obtain the branching index $\mathrm{B}_{\text {TPLSM }}$.

\section{Statistical analysis}

Statistical analysis was performed using SPSS 15.0 (SPSS, Chicago, Ill). MRI data were tested using a paired non-parametric Wilcoxon signed-rank test. For TPLSM, the datasets from the tumor rim and core originated from different mice. Therefore, these data were analyzed using a non-paired non-parametric Mann-Whitney U-test.

Figure 1 Schematic representation of the TPLSM data processing steps (left) with corresponding images for representative tumor (panels $A-D$, box size $179 \times 179 \times 77 \mu^{3}$ ) and muscle (panels E-H, box size $179 \times$ $\left.179 \times 52 \mu m^{3}\right)$ datasets. The different post-processing steps are indicated in different colors. Grey: data after $3 D$ blind deconvolution (A/E). The median vessel radius $R_{\text {TPLSM }}$ was measured during this step. Green: Data after application of a $3 \times 3 \times 3$ Gauss filter, a closing filter, and a second Gauss filter (B/F). Red: Data after isosurface rendering, which was used to determine the fractional vessel volume $f V V_{T P L S M}(C / G)$. Blue: Skeletonized data $(D / H)$ used to extract the total microvessel length $M V L_{T P L S M}$ and degree of branching $B_{T P L S M}$

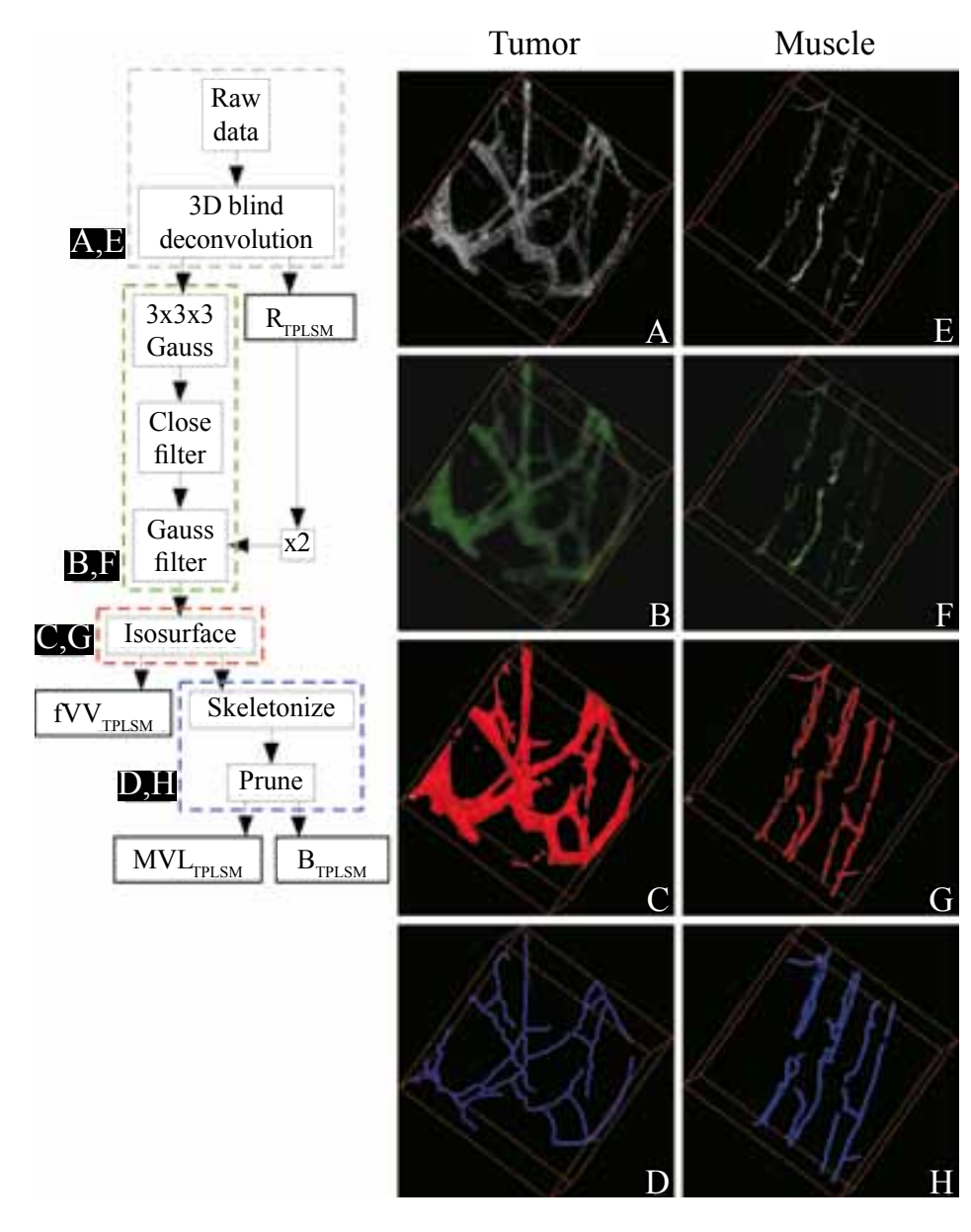




\section{Results}

\section{Spectrophotometry}

Spectrophotometry revealed no inherent fluorescent signal of the USPIOs. However, the fluorescence intensity of $\alpha \mathrm{CD} 31-\mathrm{FITC}$ decreased with increasing USPIO concentrations (Figure 2). Fluorescence lifetime imaging displayed no alterations in $\alpha \mathrm{CD} 31-\mathrm{FITC}$ lifetime (not shown), indicating that fluorescence resonance energy transfer was absent. The low intensity of $\alpha \mathrm{CD} 31-\mathrm{FITC}$ was probably caused by scattering/absorption of $\alpha \mathrm{CD} 31-\mathrm{FITC}$ fluorescence and/or absorption of excitation light by the USPIOs.

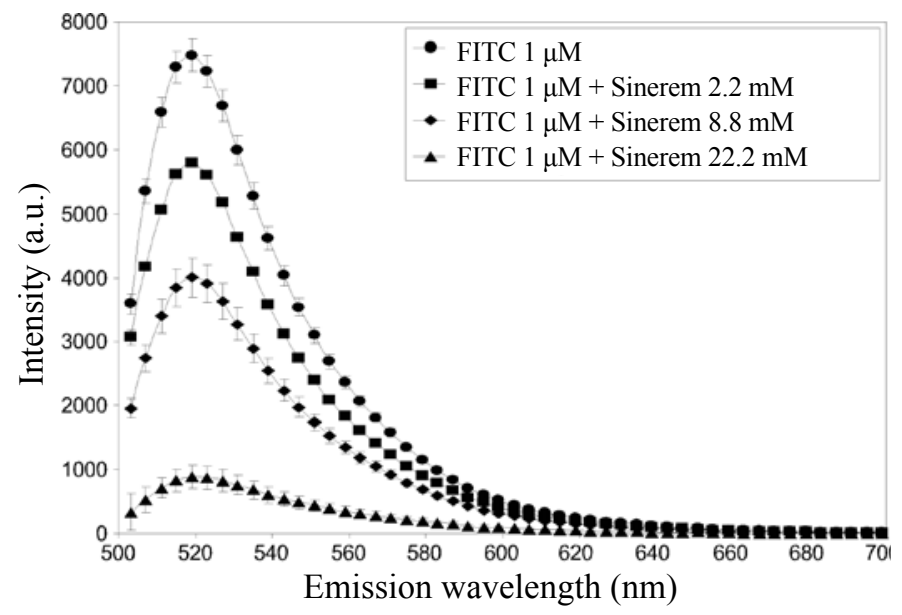

Figure 2 Negative effect of USPIOs on the fluorescence intensity of $\alpha C D 31$ FITC. A clearly decreasing signal intensity is observed in the emission spectrum of $\alpha C D 31-F I T C$ with increasing USPIO concentration. The concentrations of $\alpha C D 31-F I T C$ and USPIO in the tissue were estimated to be approximately $0.7 \mu \mathrm{M}$ and $5 \mathrm{mM}$, respectively. Values are presented as mean \pm standard deviation.

\section{Animal inclusion}

Eight out of ten mice successfully developed a subcutaneous tumor. Therefore, tumor MR-VSI was performed in 8 mice, whereas muscle imaging was performed in 10. For TPLSM, a separate group of 11 tumor-bearing mice was used since a low and discontinuous fluorescent signal of the vasculature was observed in tissue of mice injected with USPIOs (data not shown). The total number of 3D TPLSM datasets for the tumor rim, tumor core, and muscle tissue was 10 (5 mice), 13 (6 mice), and 32 (9 mice), respectively.

\section{MR-VSI vascular morphology}

The mean pre- and post-contrast $R_{2}$ and $R_{2}{ }^{*}$ values and the differences $\Delta R_{2}$ and $\Delta R_{2}{ }^{*}$ that were used for the MR-VSI calculations are summarized in Table 1. Figure 3 shows $T_{2}$-weighted anatomical images of a tumor with color-coded overlay of the calculated vessel radius index $\mathrm{RI}_{\mathrm{MRI}}$ and fractional blood volume $\mathrm{fBV}_{\mathrm{MRI}}$. A heterogeneous distribution of $\mathrm{RI}_{\mathrm{MRI}}$ and $\mathrm{fBV}_{\mathrm{MRI}}$ was found throughout the tumor, with both parameters showing higher values in the tumor rim than in the tumor core (Figure $3 \mathrm{~A} / \mathrm{C}$ ). In healthy muscle tissue, the distribution was more homogeneous and significantly lower values of $\mathrm{RI}_{\mathrm{MRI}}$ and $\mathrm{fBV}_{\mathrm{MRI}}$ values were found compared with tumor tissue (Figure $3 \mathrm{~B} / \mathrm{D}$ ).

Table 1 Overview of the mean pre- and post-contrast $R_{2}$ and $R_{2}{ }^{*}$ values for tumor rim, tumor core and muscle. Values are presented as mean \pm standard error.

\begin{tabular}{lllllll}
\hline & $R_{2, \text { pre }}\left(\mathrm{s}^{-1}\right)$ & $R_{2, \text { post }}\left(\mathrm{s}^{-1}\right)$ & $\Delta R_{2}\left(\mathrm{~s}^{-1}\right)$ & $R_{2, \text { pre }}{ }^{*}\left(\mathrm{~s}^{-1}\right)$ & $R_{2, \text { pre }}{ }^{*}\left(\mathrm{~s}^{-1}\right)$ & $\Delta R_{2}^{*}\left(\mathrm{~s}^{-1}\right)$ \\
\hline $\begin{array}{l}\text { Tumor } \\
\text { rim }\end{array}$ & $24.4 \pm 1.0$ & $25.8 \pm 1.1$ & $1.6 \pm 0.2$ & $173.5 \pm 28.9$ & $254.6 \pm 34.8$ & $81.2 \pm 19.7$ \\
$\begin{array}{l}\text { Tumor } \\
\text { core }\end{array}$ & $22.3 \pm 0.9$ & $23.4 \pm 0.9$ & $1.3 \pm 0.1$ & $133.0 \pm 23.9$ & $193.8 \pm 26.3$ & $60.7 \pm 13.3$ \\
$\begin{array}{l}\text { Muscle } \\
\text { n }\end{array}$ & $47.9 \pm 2.2$ & $55.8 \pm 2.0$ & $8.2 \pm 0.7$ & $132.0 \pm 140$ & $200.2 \pm 20.4$ & $68.4 \pm 12.3$ \\
\hline
\end{tabular}




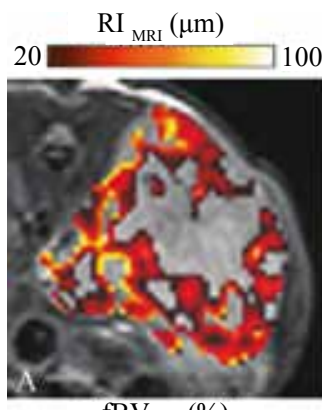

$\mathrm{fBV}_{\mathrm{MRI}}(\%)$
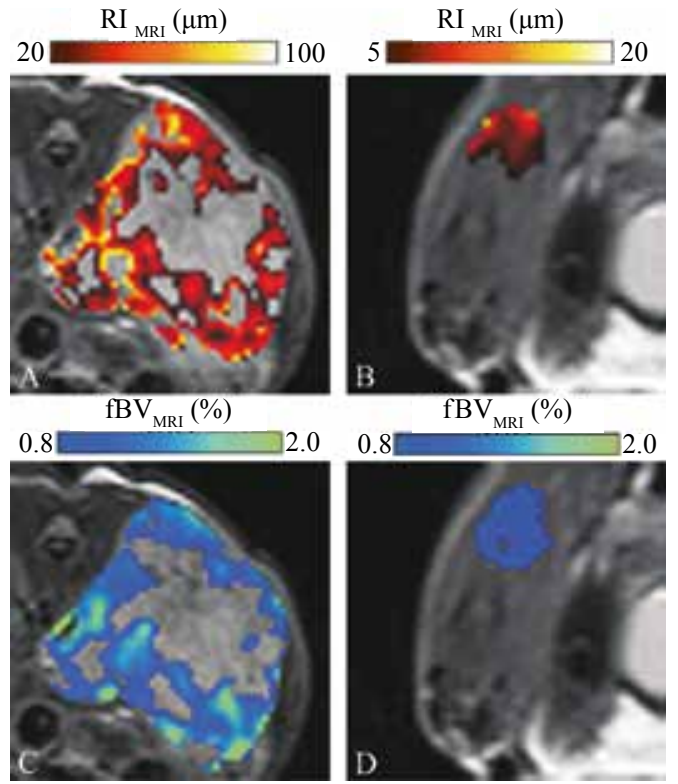

Figure 3 Sections of $T$-weighted images $(T E=30 \mathrm{~ms})$ of tumor $(A / C)$ and muscle $(B / D)$ with color-coded overlay of $R I_{M R I}(A / B)$ and $f B V_{M R I}(C / D)$. Note the different scales for $R_{M R I}$ for tumor and muscle tissue.

The differences in $\mathrm{RI}_{\mathrm{MRI}}$ and $\mathrm{fBV}_{\mathrm{MRI}}$ between tumor rim, tumor core, and muscle tissue were further investigated by histogram analysis (Figure 4), which confirmed a wide distribution for the tumor and a narrow distribution centered at relatively low values for muscle (Table 2). RI values in tumor rim and tumor core were approximately 3-fold higher compared with muscle tissue. Although $\mathrm{RI}_{\mathrm{MRI}}$ was slightly higher in the tumor rim than in the tumor core, this difference was not significant. In contrast, $\mathrm{fBV}_{\mathrm{MRI}}$ was significantly higher in tumor rim compared with core, and in tumor rim compared with muscle (Table 2).

\section{TPLSM vascular morphology}

Qualitative comparison of the tumor and muscle tissue datasets showed clear differences in vessel radius and orientation (Figure 1). In muscle tissue, vessels were generally oriented parallel with the muscle fibers with occasional interconnecting side branches, whereas the tumor microvasculature lacked a distinct orientation and displayed a more arbitrary, maze-like architecture. In correspondence with MR-VSI data, tumor tissue displayed a wide distribution in vessel radius (Figure 5).

$\mathrm{R}_{\text {TPLSM }}$ was significantly larger in the tumor rim and core compared to muscle tissue (Table 2). Similar to MR-VSI, no significant difference was observed in $\mathrm{R}_{\text {TPLSM }}$ between tumor rim and core. However, the histogram of microvessel radius displayed a slight left-shift in $\mathrm{R}_{\text {TPLSM }}$ in the tumor core compared to the rim, suggesting that the tumor core holds smaller sized microvessels (Figure 5). In accordance, the tumor rim displayed a significantly larger $\mathrm{fVV}_{\mathrm{TPLSM}}$ compared with the tumor core and muscle tissue (Table 2). Moreover, the $\mathrm{fVV}_{\text {TPLSM }}$ in the tumor core was significantly larger than in muscle tissue. In addition, significantly higher MVL $\mathrm{TPLSM}_{\text {and }}$ an $\mathrm{B}_{\text {TPLS }}$ values were found in the tumor rim and core compared with muscle tissue.

Table 2 Overview of microvascular morphology parameters for blood vessels in the tumor rim, tumor core and muscle tissue, as determined by MR-VSI and TPLSM. All values are presented as median with their quartile ranges indicated in parentheses. Note that no MRI equivalent is available for the total microvessel length $\mathrm{MVL}_{\text {TPLSM }}$ and the degree of vessel branching $\mathrm{B}_{\text {TPLSM }}$.

\begin{tabular}{llll}
\hline & Tumor rim & Tumor core & Muscle \\
\hline $\mathrm{RI}_{\text {MRI }}(\mu \mathrm{m})$ & $38.0(33.6-49.9){ }^{*}$ & $34.3(22.8-47.8)^{*}$ & $11.9(7.0-16.7)$ \\
$\mathrm{R}_{\text {TPLSM }}(\mu \mathrm{m})$ & $6.0(4.5-6.6)^{*}$ & $4.3(3.1-4.8)^{*}$ & $2.2(1.7-2.7)$ \\
$\mathrm{fBV}_{\text {MRI }}(\%)$ & $1.8(1.2-2.2)^{* \dagger}$ & $1.2(0.9-1.7)$ & $1.2(0.9-1.5)$ \\
$\mathrm{fVV}_{\text {TPLSM }}(\%)$ & $8.9(6.1-11.8)^{* \dagger}$ & $4.6(4.0-6.5)^{*}$ & $1.5(1.0-1.9)$ \\
$\mathrm{MVL}_{\text {TPLSM }}\left(\times 10^{-4} \mu \mathrm{m}^{-2}\right)$ & $8.1(5.2-11.4)^{*}$ & $7.3(6.3-9.4)^{*}$ & $3.5(2.7-5.3)$ \\
$\mathrm{B}_{\mathrm{TPLSM}}\left(\times 10^{-6} \mu \mathrm{m}^{-3}\right)$ & $7.9(3.5-13.8)^{*}$ & $11.0(9.8-14.9){ }^{*}$ & $3.3(1.6-5.1)$ \\
${ }^{*} \mathrm{P}<0.05$ compared with muscle tissue. ${ }^{\dagger} \mathrm{P}<0.05$ compared with tumor core.
\end{tabular}



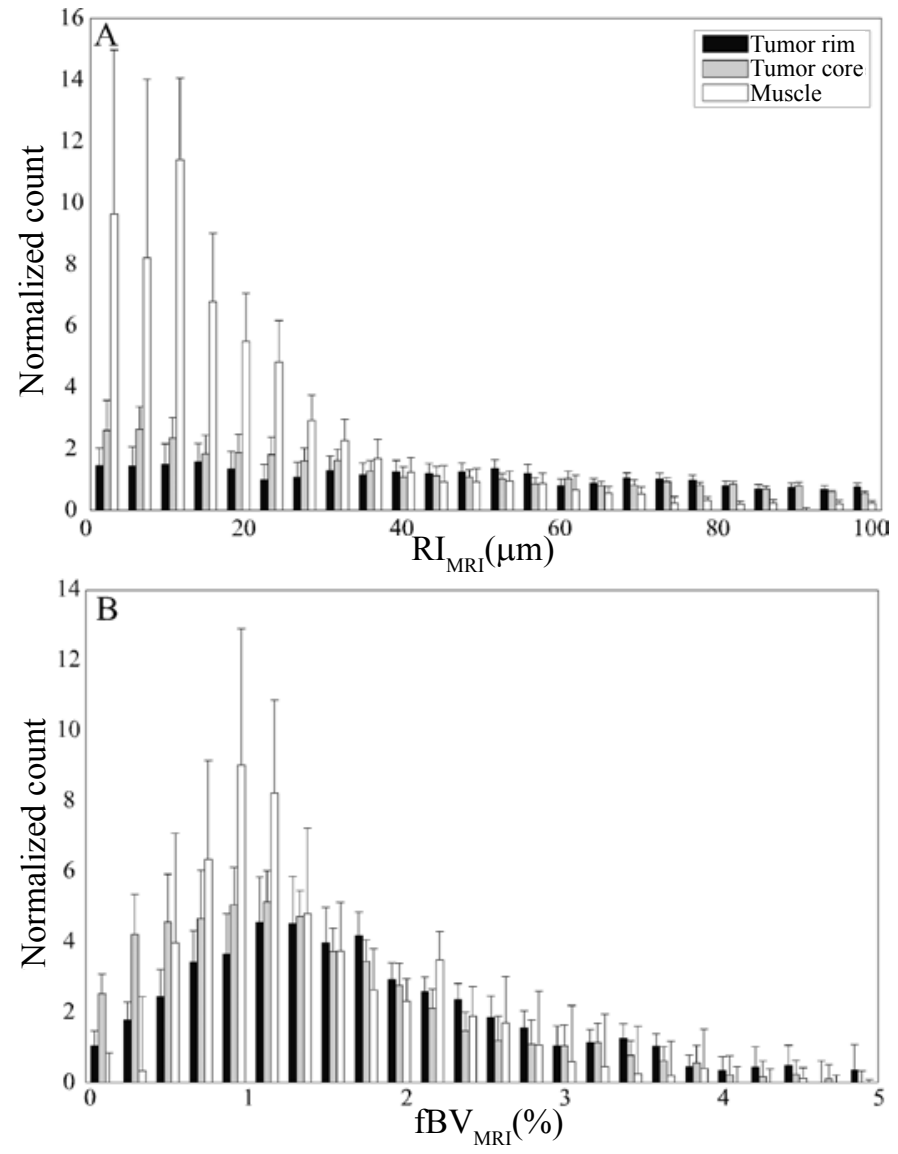

Figure 4 Histograms of the vessel radius index (A) and fractional blood volume (B) for the tumor rim (black), tumor core (grey) and muscle tissue (white), as determined using MR-VSI. Values were normalized to tissue volume and are represented as median \pm standard error.

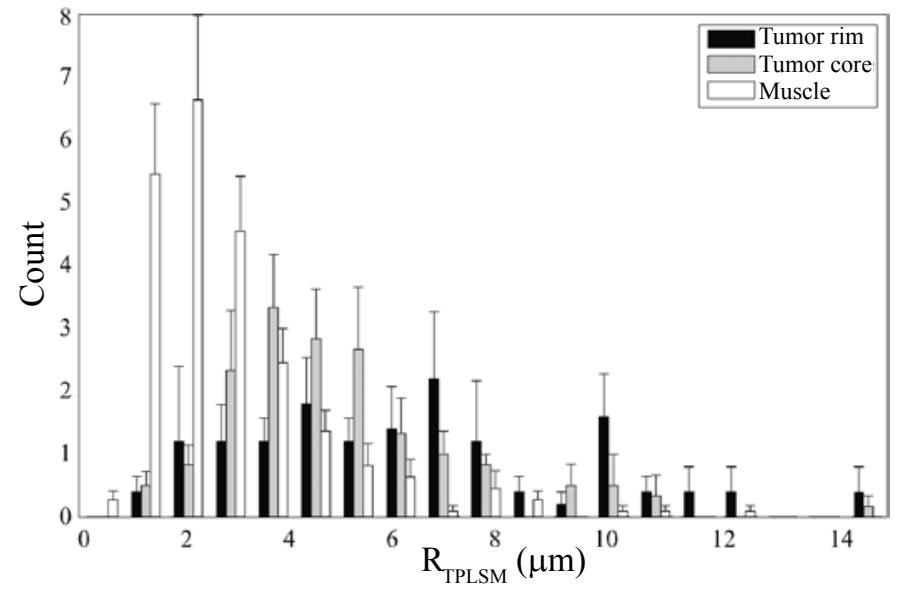

Figure 5 Histogram of the vessel radius as determined with TPLSM for the tumor rim (black), tumor core (grey) and muscle tissue (white). Values are presented as mean \pm standard error. Due to the limited number of available data points for $f V V_{T P I S M} M V L_{T P L S M}$ and $B_{\text {TPISM }}$ (1 per animal versus 8 for $\left.R_{\text {TPLSM }}\right)$, histogram analysis was impractical for these parameters.

\section{Discussion}

\section{Current findings}

In the present study, the vessel radius index and fractional blood volume, as determined by MR-VSI in subcutaneous tumors, were evaluated using 3D TPLSM. In addition, the performance of MR-VSI was investigated in healthy muscle tissue, which, in contrast to tumors, has a fully matured and highly organized microvasculature. Image processing of the TPLSM datasets resulted in values for the vessel radius and the fractional vessel volume that comply with literature (cf. Table 2 and 3). ${ }^{20,21}$ MR-VSI displayed non-physiological vessel radius values for both the tumor and muscle tissue, thereby indicating that 
Table 3 Overview of available literature values for the average tumor vessel radius (index) R and fractional blood volume fBV, measured by MR-VSI, histology, or intravital microscopy. The applied tumor model, tumor location, animal kind, and contrast agent are also presented. The contrast agent dose was $200 \mu \mathrm{mol}$ Fe/kg body weight, unless indicated otherwise. Values are given as mean \pm standard deviation.

\begin{tabular}{|c|c|c|c|c|c|c|c|}
\hline Tumor model & Location & Animal & Contrast agent [a] & $\mathrm{R}(\mu \mathrm{m})$ & fBV (\%) & Technique & Reference \\
\hline \multirow[t]{3}{*}{ C6 glioma } & Brain & Rat & MION & $12.5 \pm 6.8$ & $\mathrm{NA}[\mathrm{b}]$ & MR-VSI & 5 \\
\hline & & & Sinerem $^{\circledR}$ & $\begin{array}{l}20.0 \pm 6.3 \\
5.8 \pm 4.1\end{array}$ & $\begin{array}{l}\text { NA } \\
2.0 \pm 0.7\end{array}$ & $\begin{array}{l}\text { MR-VSI } \\
\text { Histology }\end{array}$ & 6 \\
\hline & & & Sinerem ${ }^{\circledR}$ & $\begin{array}{l}19.5 \pm 4.8 \\
9.9 \pm 2.1\end{array}$ & $\begin{array}{l}4.0 \pm 1.4 \\
2.9 \pm 0.6\end{array}$ & $\begin{array}{l}\text { MR-VSI } \\
\text { Histology }\end{array}$ & 7 \\
\hline RG2 glioma & Brain & Rat & Sinerem $^{\circledR}$ & $\begin{array}{l}11.0 \pm 2.0 \\
7.4 \pm 1.3\end{array}$ & $\begin{array}{l}5.2 \pm 1.6 \\
\mathrm{NA}\end{array}$ & $\begin{array}{l}\text { MR-VSI } \\
\text { Histology }\end{array}$ & 7 \\
\hline GH3 prolactinoma & S.c. $[\mathrm{c}]$ & Rat & Sinerem $^{\sqrt{ }}$ & $13 \pm 4$ & $2.9 \pm 0.8$ & MR-VSI & 8 \\
\hline $\begin{array}{l}\text { Shionogi prostate } \\
\text { carcinoma }\end{array}$ & S.c. & Mouse & Sinerem $^{\circledR}$ & $35.2 \pm 25.5$ & NA & MR-VSI & 9 \\
\hline B16 melanoma & S.c. & Mouse & $\begin{array}{l}\text { Clariscan } \\
45 \mu \mathrm{mol} \mathrm{Fe} / \mathrm{kg}\end{array}$ & $13.5 \pm 1$ & $4.1 \pm 0.5$ & MR-VSI & 11 \\
\hline $\begin{array}{l}\text { LS174T colorectal } \\
\text { adenocarcinoma }\end{array}$ & Skin-fold chamber & Mouse & $\begin{array}{l}\text { Texas-Red labeled } \\
\text { bovine serum } \\
\text { albumin and FITC- } \\
\text { dextran }\end{array}$ & $6.1 \pm 0.5$ & $9.2 \pm 2.9$ & $\begin{array}{l}\text { Intra-vital } \\
\text { microscopy }\end{array}$ & 20,21 \\
\hline $\begin{array}{l}\text { HaCaT-ras- } \\
\text { A-5RT3 skin } \\
\text { squamous cell } \\
\text { carcinoma }\end{array}$ & S.c. & Mouse & $\begin{array}{l}\text { VSOP C200 } \\
\text { (Ferropharm) }\end{array}$ & $\begin{array}{l}62 \pm 18 \\
10 \pm 7[\mathrm{~d}]\end{array}$ & $\begin{array}{l}\text { NA } \\
1.4 \pm 0.2\end{array}$ & $\begin{array}{l}\text { MR-VSI } \\
\text { Histology }\end{array}$ & 10 \\
\hline $\begin{array}{l}\text { A431 skin } \\
\text { squamous cell } \\
\text { carcinoma }\end{array}$ & S.c. & Mouse & $\begin{array}{l}\text { VSOP C200 } \\
\text { (Ferropharm) }\end{array}$ & $\begin{array}{l}42 \pm 7 \\
10 \pm 3[d]\end{array}$ & $\begin{array}{l}\text { NA } \\
1.1 \pm 0.3\end{array}$ & $\begin{array}{l}\text { MR-VSI } \\
\text { Histology }\end{array}$ & 10 \\
\hline Various & Brain & Human & $\begin{array}{l}\text { Magnevist }{ }^{\circledR} \\
0.2 \mathrm{mmol} / \mathrm{kg}\end{array}$ & $79 \pm 68$ & NA & MR-VSI & 24 \\
\hline
\end{tabular}

[a] MION: Monocrystalline iron oxide nanoparticle; VSOP: Very small superparamagnetic iron oxide particle.

[b] NA: Not available.

[c] S.c.: subcutaneous.

[d] Calculated from reported vessel diameters. 
MR-VSI provides an index, and not an absolute measure, of the vessel radius. However, TPLSM and MR-VSI showed similar trends for the vessel radius (index) and the fractional blood volume in the observed tissues, i.e., generally higher values in the strongly vascularized tumor rim compared with the tumor core and muscle tissue.

The MR-derived vessel radius index was significantly higher in the tumor compared with muscle tissue, with no significant difference between tumor rim and core. The latter may be due to the heterogeneous distribution of vessel radius index found over the tumor. The fractional blood volume obtained with MR-VSI indicated that the tumor rim was more vascularized than the tumor core and muscle tissue. This corresponds with the reported higher level of angiogenic activity in the tumor rim $^{19,22,23}$ and with more necrosis and higher interstitial pressures in the core.

With TPLSM, a heterogeneous distribution of vessel radius was observed over the tumor, showing higher values in the tumor rim than in the core. However, these differences were not statistically significant. Muscle tissue displayed a significantly smaller radius, which was approximately 2-3 fold smaller compared with the tumor (Table 2). The TPLSM-derived fractional vessel volume was significantly higher in the tumor rim compared with tumor core and muscle tissue, and in the tumor core compared with muscle tissue. The total microvessel length and the degree of vessel branching, which can be uniquely assessed by TPLSM, were also significantly higher in the tumor than in muscle tissue. Although the individual tumor vessels may appear shorter than the muscle vessels (Figure 1), note that TPLSM measures the total, and not the average, microvessel length. Taken together, these results indicate that the tumors were more strongly vascularized than skeletal muscle tissue.

In comparison with TPLSM, MR-VSI showed a 6-8 fold overestimation of the vessel radius index for all tissue types. This may be explained by partial volume effects due to the limited spatial resolution of MR-VSI, relative to the dimensions of the microvessels in tumor and muscle tissue. In addition, Kiselev et al. suggested that an overestimation of vessel caliber can be explained by a deviation from the static dephasing regime of relaxation around capillaries, and by the native paramagnetism of venous blood, which are both neglected in the simplified MR-VSI theory. ${ }^{24}$ Interestingly, lower intratumoral blood volumes were found for MR-VSI than for TPLSM, whereas these values for the skeletal muscle were similar. These observations may be related to the heterogeneous perfusion effects observed in tumors. ${ }^{25}$ Hence, tumor regions with no or relatively low USPIO concentration will result in a lower detected blood volume. This heterogeneous perfusion may also have contributed to the exclusion of approximately $40 \%$ of the tumor voxels in the VSI calculations (see Materials and methods). The good correspondence of the present TPLSM results with literature values $^{20,21}$ suggests that the differences in vascular labeling between MR-VSI and TPLSM, i.e., in vivo versus ex vivo, did not contribute to the observed discrepancies between the two methods.

Although the MR vessel radius index and fractional blood volumes did not correspond with their TPLSM equivalents, the observed differences between tumor rim, tumor core and muscle showed the same trends for both methods. MR-VSI is therefore not suited for absolute quantification of vascular morphology, but does allow detection of differences within tumors and between tissues. This suggest that MR-VSI may be applied for longitudinal in vivo evaluation of relative changes in vessel architecture, induced for instance by tumor growth or by anti-angiogenic therapy.

\section{Quantitative vascular morphology in current literature}

Table 3 provides an overview of available literature values for tumor vessel radius (index) and blood volume, measured either by MR-VSI, histology, or microscopy techniques, and the applied 
experimental setup. Direct comparison with the present results is hampered due to large differences in tumor models. Different tumor locations, stages of tumor growth, and animal species have been studied and a distinction between the tumor rim and core is usually not made. Moreover, tumor vasculature typically harbors unpredictable flow, adding non-systematic variability to MR-VSI measurements as these were shown to depend on the intravascular USPIO concentration. ${ }^{26}$ Also, $\Delta R_{2}$ and $\Delta R_{2}{ }^{*}$ measurements depend on technical parameters such as field strength, pulse sequence, field homogeneity and shimming, echo times, etc.

Extensive data processing is required to convert contrast agent induced changes in signal intensity into quantitative vessel parameters, and different approaches have been described in literature. For instance, different maximum $\mathrm{RI}_{\mathrm{MRI}}$ values were applied, above which vessel radius was considered unrealistic: an upper limit of $100 \mu \mathrm{m}$ was set by Troprès et al., ${ }^{3}$ whereas Valable et al. used a $50 \mu \mathrm{m}$ threshold. ${ }^{7}$ In addition, diffusion-weighted experiments are not always conducted, although the measurement of individual ADC values was shown to be important for accurate MR-VSI. ${ }^{24}$

Taken together, reported literature values are highly variable, indicating that MR-VSI is strongly dependent on experimental setup (Table 3). Also, vessel radius and diameter appear to be used interchangeably, thereby adding a factor 2 to the observed variability.

\section{Limitations}

Direct comparison of the MR-VSI results with 3D TPLSM in the same tumors was unfeasible in the present study due to a reduction in $\alpha$ CD31-FITC intensity by USPIO. This necessitated the use of two separate animal groups for MR-VSI and TPLSM. Moreover, tissue freezing and thawing may have caused deformation and hence affect TPLSM quantification of microvascular morphology. These problems may be circumvented by applying long-circulating bimodal, i.e., fluorescent and superparamagnetic, nanoparticles. ${ }^{27}$ Combined with in vivo TPLSM, ${ }^{17}$ this would theoretically provide the optimal validation method for MR-VSI. Nevertheless, the current ex vivo TPLSM results are in good agreement with previous in vivo studies..$^{20,21}$

During TPLSM post-processing, blind 3D deconvolution was performed iteratively using an initial point spread function based on the configuration of the optical system. Although the validity of this approach was confirmed using fluorescent microspheres, von Tiedemann et al. showed that significant improvements may be obtained when using an a depth-dependent point spread function that is automatically estimated from the dataset. ${ }^{28}$ However, this method is still under development.

\section{Conclusions}

MR-VSI allows in vivo estimation of the microvascular radius index and blood volume in both tumor and healthy muscle tissue. TPLSM offers high-resolution $3 \mathrm{D}$ visualization of the microvasculature and provides a useful tool in pre-clinical research. Compared with 3D TPLSM, MR-VSI resulted in a large overestimation of the average vessel radius index, whereas the fractional blood volume was slightly lower. However, for both techniques, morphologic measures were higher for tumor than for muscle tissue, and higher for tumor rim relative to core. Thus, although MR-VSI is not suitable for absolute quantification of vessel radius and blood volume, the image contrast of MR-VSI reflects microvascular morphology and spatial heterogeneity thereof. MR-VSI may therefore be suitable to investigate relative microvascular differences between tissues and the effects of anti-angiogenic therapy in longitudinal studies. 


\section{References}

1. Folkman J. Angiogenesis in cancer, vascular, rheumatoid and other disease. Nat Med 1995;1(1):27-31.

2. Hlatky L, Hahnfeldt P, Folkman J. Clinical application of antiangiogenic therapy: microvessel density, what it does and doesn't tell us. J Natl Cancer Inst 2002;94(12):883-893. 3. Troprès I, Grimault S, Vaeth A, Grillon E, Julien C, Payen JF, Lamalle L, Decorps M. Vessel size imaging. Magn Reson Med 2001;45(3):397-408.

4. Prinster A, Pierpaoli C, Turner R, Jezzard P. Simultaneous measurement of DeltaR2 and DeltaR $2 *$ in cat brain during hypoxia and hypercapnia. Neuroimage 1997;6(3):191-200. 5. Dennie J, Mandeville JB, Boxerman JL, Packard SD, Rosen BR, Weisskoff RM NMR imaging of changes in vascular morphology due to tumor angiogenesis. Magn Reson Med 1998;40(6):793-799.

6. Troprès I, Lamalle L, Peoc'h M, Farion R, Usson Y, Decorps M, Remy C. In vivo assessment of tumoral angiogenesis. Magn Reson Med 2004;51(3):533-541.

7. Valable S,Lemasson B, Farion R, BeaumontM, SegebarthC, Remy C, BarbierEL.Assessment of blood volume, vessel size, and the expression of angiogenic factors in two rat glioma models: a longitudinal in vivo and ex vivo study. NMR Biomed 2008;21(10):1043-1056.

8. Howe FA, McPhail LD, Griffiths JR, McIntyre DJ, Robinson SP. Vessel size index magnetic resonance imaging to monitor the effect of antivascular treatment in a rodent tumor model. Int J Radiat Oncol Biol Phys 2008;71(5):1470-1476.

9. Wade TP, Kozlowski P. Longitudinal studies of angiogenesis in hormone-dependent Shionogi tumors. Neoplasia 2007;9(7):563-568.

10. Zwick S, Strecker R, Kiselev V, Gall P, Huppert J, Palmowski M, Lederle W, Woenne EC, Hengerer A, Taupitz M, Semmler W, Kiessling F. Assessment of vascular remodeling under antiangiogenic therapy using DCE-MRI and vessel size imaging. J Magn Reson Imaging 2009;29(5):1125-1133.

11. Robinson SP, Ludwig C, Paulsson J, Ostman A. The effects of tumor-derived platelet-derived growth factor on vascular morphology and function in vivo revealed by susceptibility MRI. Int J Cancer 2008;122(7):1548-1556.

12. Julien C, Payen JF, Tropres I, Farion R, Grillon E, Montigon O, Remy C. Assessment of vascular reactivity in rat brain glioma by measuring regional blood volume during graded hypoxic hypoxia. Br J Cancer 2004;91(2):374-380.

13. Pathak AP, Schmainda KM, Ward BD, Linderman JR, Rebro KJ, Greene AS. MRderived cerebral blood volume maps: issues regarding histological validation and assessment of tumor angiogenesis. Magn Reson Med 2001;46(4):735-747.

14. Bucher D, Scholz M, Stetter M, Obermayer K, Pfluger HJ. Correction methods for three-dimensional reconstructions from confocal images: I. Tissue shrinking and axial scaling. J Neurosci Methods 2000;100(1-2):135-143.

15. Dorph-Petersen KA, Nyengaard JR, Gundersen HJ. Tissue shrinkage and unbiased stereological estimation of particle number and size. J Microsc 2001;204(Pt 3):232-246.
16. Nieuwdorp M, Mooij HL, Kroon J, Atasever B, Spaan JA, Ince C, Holleman F, Diamant M, Heine RJ, Hoekstra JB, Kastelein JJ, Stroes ES, Vink H. Endothelial glycocalyx damage coincides with microalbuminuria in type 1 diabetes. Diabetes 2006;55(4):1127-1132.

17. Brown EB, Campbell RB, Tsuzuki Y, Xu L, Carmeliet P, Fukumura D, Jain RK. In vivo measurement of gene expression, angiogenesis and physiological function in tumors using multiphoton laser scanning microscopy. Nat Med 2001;7(7):864-868.

18. Rorden C, Brett M. Stereotaxic display of brain lesions. Behav Neurol 2000;12(4):191-200. 19. Oostendorp M, Douma K, Hackeng TM, Dirksen A, Post MJ, van Zandvoort MA, Backes WH. Quantitative molecular magnetic resonance imaging of tumor angiogenesis using cNGR-labeled paramagnetic quantum dots. Cancer Res 2008;68(18):7676-7683.

20. Leunig M, Yuan F, Menger MD, Boucher Y, Goetz AE, Messmer K, Jain RK. Angiogenesis, microvascular architecture, microhemodynamics, and interstitial fluid pressure during early growth of human adenocarcinoma LS174T in SCID mice. Cancer Res 1992;52(23):6553-6560.

21. Yuan F, Leunig M, Berk DA, Jain RK. Microvascular permeability of albumin vascular surface area, and vascular volume measured in human adenocarcinoma LS174T using dorsal chamber in SCID mice. Microvasc Res 1993;45(3):269-289.

22. de Lussanet QG, Backes WH, Griffioen AW, van Engelshoven JM, Beets-Tan RG. Gadopentetate dimeglumine versus ultrasmall superparamagnetic iron oxide for dynamic contrast-enhanced MR imaging of tumor angiogenesis in human colon carcinoma in mice. Radiology 2003;229(2):429-438.

23. Mulder WJ, Strijkers GJ, Habets JW, Bleeker EJ, van der Schaft DW, Storm G, Koning GA, Griffioen AW, Nicolay K. MR molecular imaging and fluorescence microscopy for identification of activated tumor endothelium using a bimodal lipidic nanoparticle. FASEB J 2005;19(14):2008-2010.

24. Kiselev VG, Strecker R, Ziyeh S, Speck O, Hennig J. Vessel size imaging in humans. Magn Reson Med 2005;53(3):553-563.

25. Brurberg KG, Benjaminsen IC, Dorum LM, Rofstad EK. Fluctuations in tumor blood perfusion assessed by dynamic contrast-enhanced MRI. Magn Reson Med 2007;58(3):473-481.

26. Troprès I, Lamalle L, Farion R, Segebarth C, Remy C. Vessel size imaging using low intravascular contrast agent concentrations. Magma 2004;17(3-6):313-316.

27. Jaffer FA, Nahrendorf M, Sosnovik D, Kelly KA, Aikawa E, Weissleder R. Cellular imaging of inflammation in atherosclerosis using magnetofluorescent nanomaterials. Mol Imaging 2006;5(2):85-92.

28. von Tiedemann M, Fridberger A, Ulfendahl M, Tomo I, Boutet de Monvel J. Image adaptive point-spread function estimation and deconvolution for in vivo confocal microscopy. Microsc Res Tech 2006;69(1):10-20. 


\section{Chapter 6}

\section{Quantitative molecular magnetic resonance imaging of tumor angiogenesis using cNGR-labeled paramagnetic quantum dots}

Kim Douma*, Marlies Oostendorp*, Tilman M. Hackeng, Anouk Dirksen, Mark J. Post, Marc A.M.J. van Zandvoort, and Walter H. Backes

* Authors have contributed equally

Canc Res 2008;68(18):7676-7683 


\section{Abstract}

The objective of this study was to develop and apply cyclic Asn-GlyArg-labeled paramagnetic quantum dots (cNGR-pQDs) for the noninvasive assessment of tumor angiogenic activity using quantitative in vivo molecular magnetic resonance imaging (MRI). cNGR was previously shown to colocalize with CD13, an aminopeptidase that is highly over-expressed on angiogenic tumor endothelium. Since angiogenesis is important for tumor growth and metastatization, its in vivo detection and quantification may allow objective diagnosis of tumor status and evaluation of treatment response.

Intravenous injection of cNGR-pQDs in tumor-bearing mice resulted in increased quantitative contrast, comprising increased longitudinal relaxation rate and decreased proton visibility, in the tumor rim but not in tumor core or muscle tissue. This demonstrated that cNGR-pQDs allow in vivo quantification and accurate localization of angiogenic activity. MRI results were validated using ex vivo two-photon laser scanning microscopy (TPLSM), which showed that cNGR-pQDs were primarily located on the surface of tumor endothelial cells and to a lesser extent in the vessel lumen. In contrast, unlabeled pQDs were not or only sparsely detected with both MRI and TPLSM, supporting a high specificity of cNGR-pQDs for angiogenic tumor vasculature. 


\section{Introduction}

Angiogenesis, the formation of new capillaries from existing blood vessels, is key to tumor growth and metastatization by providing proliferating tumor cells with oxygen and nutrients. ${ }^{1,2}$ Moreover, angiogenic activity is related to tumor malignancy. ${ }^{3,4}$ Non-invasive detection of angiogenic activity is therefore highly relevant for adequate tumor diagnosis. Quantification of angiogenesis may furthermore allow objective monitoring of tumor progression, for instance in response to treatment.

Currently, molecular imaging techniques are being developed that allow direct visualization and characterization of cellular or molecular activation of angiogenesis-related pathways..$^{5}$ More specifically, molecular imaging uses contrast agents that home to upregulated biomolecules (e.g., receptors and enzymes) via interaction with highaffinity ligands coupled to the contrast agent. Ideally, this results in an altered signal intensity at the location of these molecules. Of the different imaging modalities, magnetic resonance imaging (MRI) may be the most desirable for molecular imaging due to its excellent spatial resolution and soft tissue contrast. Moreover, molecular MRI potentially allows direct covisualization of tumor angiogenic activity with anatomy. However, the inherently low sensitivity of MRI is a problem due to the typically low abundance of upregulated biomolecules. This can be overcome by large molecular weight constructs carrying a high payload of gadolinium or iron, and multiple targeting ligands to enhance the particle's relaxivity and targeting efficacy, respectively. ${ }^{6}$

One of the best-defined ligands for molecular imaging of angiogenesis is the cyclic Arg-Gly-Asp (cRGD) peptide, which binds specifically to the $\alpha_{v} \beta_{3}$-integrin. ${ }^{7,8}$ However, for the cyclic Asn-GlyArg (cNGR) motif, the tumor-homing capability was shown to be 3-fold higher compared with cRGD. ${ }^{9}$ The clinical applicability of cNGR as a tumor-homing ligand was previously demonstrated by conjugating cNGR to tumor necrosis factor $\alpha(\mathrm{TNF} \alpha)$. Compared with unlabeled TNF $\alpha$, cNGR-TNF $\alpha$ displayed a significantly increased anti-tumor activity with similar systemic toxicity. ${ }^{10-12}$

The vascular address of cNGR is a specific isoform of CD13 (aminopeptidase $\mathrm{N}$ ), a transmembrane glycoprotein involved in cancer angiogenesis, tumor invasion and metastasis, which is overexpressed by activated vascular endothelial cells (VECs) of tumor vasculature. ${ }^{9,13,14} \mathrm{CD} 13$ is not required for vessel growth during embryonic development and normal adult function, as shown in $\mathrm{CD} 13^{-/}$mice. ${ }^{15}$ In a model of retinal neo-vascularization, these mice had significantly decreased vessel growth, suggesting that CD13 is important in pathological neovascularization. In addition, fluorophoreconjugated cNGR allowed detection of the in vivo expression of CD13 in tumors and infarcted myocardium. ${ }^{16,17}$ Competition with unconjugated cNGR significantly decreased the fluorescence signal, indicating high specificity of cNGR for CD13. ${ }^{16,17}$

Despite the aforementioned high tumor-homing capability of $\mathrm{cNGR}$, its potency as a targeting ligand for molecular imaging of tumor angiogenesis is currently unknown. Therefore, the objective of this study was to explore cNGR-labeled paramagnetic quantum dots (cNGR-pQDs) for the non-invasive and selective in vivo detection of tumor neovascularization using quantitative molecular MRI. QDs were chosen as contrast agent scaffolds because of their excellent photophysical properties, i.e., broad excitation, small emission spectra and limited photo-bleaching. ${ }^{18,19}$ Furthermore, QDs enabled binding of multiple targeting ligands and gadolinium chelates. The particle's bimodal nature (i.e., paramagnetic and fluorescent) allowed validation of the results with ex vivo two-photon laser scanning microscopy (TPLSM). With TPLSM, three-dimensional contrast agent localization can be obtained at subcellular resolution with a penetration depth reaching $250 \mu \mathrm{m}$ in tumors.

MRI data were analyzed via absolute quantification of contrast agent induced changes in the tissue's longitudinal relaxation rate $R_{1}$ $\left(1 / T_{1}\right)$, which is proportional to contrast agent concentration, and 
proton visibility. The latter expectedly decreases at high densities of paramagnetic contrast material. Quantitative analysis requires acquisition of a series of images and may provide improved sensitivity of molecular MRI. Theoretically, the employed inversion recovery (IR) technique has an inherent two-fold higher sensitivity than spin echo pulse sequences and by measuring a series of images it potentially allows detection of smaller changes in $R_{1}$ than a single image.

Both MRI and TPLSM showed specific binding of cNGR-pQDs to VECs in the angiogenic tumor rim, but not in tumor core or muscle tissue. Furthermore, a significantly lower quantitative contrast was found with unlabeled pQDs, indicating a high specificity of the cNGR-labeled contrast agent for angiogenic VECs. To our knowledge, this is the first non-invasive in vivo application of cNGR as a targeting ligand for molecular MRI of tumor angiogenesis.

\section{Materials and methods}

\section{Preparation of cNGR-labeled paramagnetic quantum dots}

NAc-Cys(4MeBzl)-Asn(Xanthyl)-Gly-Arg(Tosyl)-Cys(4MeBzl)Gly-Gly-Lys(Fmoc)-peptide was synthesized by tBoc solid phase peptide synthesis, as described previously. ${ }^{16,20}$ On the resin, the lysine side chain was selectively deprotected by treatment with $20 \%$ piperidine/dimethylformamide $(4 \times 3$ minutes). After covalent coupling of biotin-succinimidyl ester(Molecular Probes, Eugene, OR) to the lysine $\varepsilon$-amino group to obtain biotinylated peptide-resin, the peptide was deprotected and cleaved from the resin using anhydrous hydrogen fluoride for $1 \mathrm{~h}$ at $0{ }^{\circ} \mathrm{C}$ with $4 \% \mathrm{p}$-cresol as scavenger and lyophilized. Electrospray ionization mass spectrometry (ESI-MS) revealed a mass of 1287.4 , corresponding well to the theoretical average mass (1288.7) of the reduced biotinylated Nac-Cys-Asn-GlyArg-Cys-Gly-Gly-Lys(biotin)- $\mathrm{NH}_{2}$ peptide. Oxidative folding of the crude product in $0.1 \mathrm{M}$ Tris, $\mathrm{pH} 8,1 \mathrm{M}$ guanidin at $4{ }^{\circ} \mathrm{C}$ for 16 hours yielded the internal disulfide bridged biotin-cyclic NGR, which was HPLC-purified (C18 RP-HPLC) and lyophilized. ESI-MS confirmed a mass decrease of 2 , representing the loss of 2 protons from the cystein side chains due to the generation of 1 disulfide bond (S-S). Biotinylated poly(lysine) dendritic wedge, a construct comprising 8 Gd-DTPA moieties, was synthesized and purified similarly. ${ }^{21,22}$

Curnis et al. previously showed that cNGR spontaneously converts into isoDGR by asparagine deamidation at slightly basic $\mathrm{pH}$, generating an $\alpha_{v} \beta_{3}$-integrin ligand. ${ }^{23}$ Using a combination of HPLC and mass spectrometry up to 24 hours after dissolving cNGR in water ( $\mathrm{pH} 6.0$ ) and $1 \mu \mathrm{M}$ borate buffer ( $\mathrm{pH} 8.3$, supplemented with $0.05 \% \mathrm{NaN}_{3}$ ), respectively, it was found that this process did not occur in the timeperiod of the experiments (data not shown).

Bi-modal, multivalent contrast agent was prepared as follows. Streptavidin-conjugated QDs ( $1 \mu \mathrm{M}$ in borate buffer $\mathrm{pH} 8.3$, emission at $585 \mathrm{~nm}$ ) were purchased from Invitrogen (Breda, The Netherlands). QDs were composed of a CdSe core with a $\mathrm{ZnS}$ shell and covered with polyethyleneglycol-2000. Each QD holds approximately 10 surface-bound streptavidins, allowing 30 biotinylated compounds to bind on average (personal communication with Invitrogen). For each experiment, cNGR-pQDs were prepared freshly at room temperature by sequential mixing of $100 \mu \mathrm{L}$ QD solution with biotincNGR and biotin-poly(lysine) dendritic wedge, both dissolved in Hanks Balanced Salt Solution (HBSS, pH 7.4, Invitrogen), in a molar ratio of 1:6:24 to a total volume of approximately $120 \mu \mathrm{L}$. Samples were mildly vortexed during each preparation step to ensure a homogeneous distribution of biotin-cNGR and biotin-poly(lysine) dendritic wedge over the QD surface. Overall, each QD carried a maximum of $192 \mathrm{Gd}$ ions and $6 \mathrm{cNGR}$ peptides. Unlabeled pQDs carried the same number of Gd constructs but no cNGR. A schematic representation of the cNGR-pQD particle is shown in Figure 1. 


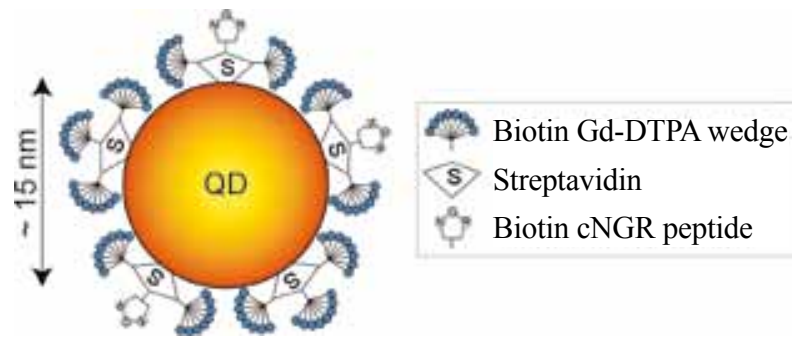

Figure 1 Schematic representation of a cNGR-labeled paramagnetic quantum dot. Each particle carries approximately 10 streptavidin moieties to which 6 cNGR groups and 24 dendritic gadolinium constructs were bound. The total number of gadolinium ions per particle was maximally 192.

\section{Animal model}

All animal studies were approved by the institutional animal welfare committee. $1.5-3 \times 10^{6}$ human colorectal adenocarcinoma cells (LS174T, American Type Culture Collection CL-188, Rockville, MD) were subcutaneously and unilaterally injected on the flank of $\sim 15$ week old male Swiss ${ }^{\text {nu/nu }}$ mice (Charles River, Maastricht, The Netherlands). Mice were subjected to the MRI examination when the tumor diameter was greater than $1.0 \mathrm{~cm}$, which was approximately 16 days after LS174T injection.

For in vivo MRI, mice were anesthetized using $1.5-2.0 \%$ isoflurane (Abbott Laboratories Ltd, Queensborough, UK) in medical air and were placed prone in a dedicated animal holder with built-in mask for anesthesia gas supply. An infusion line was placed in the jugular vein for contrast agent administration during the MRI experiment. A heating pad was placed over the mice to maintain normothermic conditions. Respiration rate and body temperature were continuously monitored via a balloon sensor and rectal temperature probe, respectively, interfaced to an MR compatible small animal monitoring system (SA Instruments Inc, Stony Brook, NY).
Mice were randomly selected for injection with either cNGR- or unlabeled pQDs. Seven mice were included for each contrast agent group. Mice were kept inside the magnet during the entire MRI experiment to preserve their position.

\section{MRI protocol}

All MRI experiments were performed on a 7 T Bruker Biospec 70/30 USR MRI system, interfaced to an AVANCE II console (Bruker Biospin $\mathrm{GmbH}$, Ettlingen, Germany). The BGA12-S mini imaging gradient (maximum gradient strength $720 \mathrm{mTm}^{-1}$, slew rate $6000 \mathrm{Tm}^{-1} \mathrm{~s}^{-1}$ ) and a $3.5 \mathrm{~cm}$ inner diameter quadrature volume resonator were used.

\section{Molecular MRI}

Tumors were localized using $T_{2}$-weighted anatomical images (TR 4200, TE $37.4 \mathrm{~ms}$ ). Next, pre-contrast $R_{1}$ values were determined using a series of IR measurements with increasing inversion times (TR 4000, TE 8.4, TI 500, 1000, 1500, 2000, 2500 and $3500 \mathrm{~ms}$; total scan time 18 minutes). Subsequently, mice were injected with $120 \mu \mathrm{L}$ of cNGR- or unlabeled pQDs, followed by a $50 \mu \mathrm{L}$ saline flush. IR experiments were repeated approximately 30 minutes postcontrast to ensure adequate contrast agent circulation and a reduced level of intravascular contrast agent. Images were recorded using a field-of-view (FOV) of $4.0 \times 4.0 \mathrm{~cm}^{2}$, a $192 \times 192$ acquisition matrix interpolated to $256 \times 256$ by means of zero-filling, and a slice thickness of $1.2 \mathrm{~mm}$, resulting in $0.16 \times 0.16 \times 1.2 \mathrm{~mm}^{3}$ sized voxels. On average, 15 contiguous slices were recorded in multi-slice mode (range $11-22$ slices, depending on tumor size and orientation). After MRI, mice were euthanized by cervical dislocation.

\section{Competition experiment}

Four tumor-bearing mice were randomly selected for a competition experiment of cNGR-pQDs with unconjugated cNGR, i.e., non- 
biotinylated, non-paramagnetic, and non-fluorescent. Imaging was performed as described above, except that $525 \mu \mathrm{g} /$ mouse of unconjugated cNGR, i.e., a 1000-fold excess as compared to QD-bound cNGR, was injected intravenously 10 minutes after administration of cNGR-pQDs.

\section{Biodistribution}

Healthy Swiss mice (Charles River) were injected with either cNGRpQDs, unlabeled pQDs or no contrast agent. After approximately 1 hour circulation time, mice were sacrificed and whole body $T_{1}$ weighted spin echo images were recorded (TR 1100, TE $8.5 \mathrm{~ms}$, FOV $4.0 \times 6.0 \mathrm{~cm}^{2}$, matrix $256 \times 512$, resolution $0.16 \times 0.12 \times 1.2$ $\mathrm{mm}^{3}$ ). Two mice were included per group.

\section{Tissue harvesting}

After MRI, tumor, spleen, liver, kidney, hind limb muscle, heart and lung were excised and embedded in optimal cutting temperature (OCT) compound (Sakura Finetek Europe, Zoeterwoude, The Netherlands). Next, tissues were snap-frozen in cold 2-methylbutane (Acros Organics, Geel, Belgium) for approximately 2 minutes and subsequently transferred to liquid nitrogen. Tissues were stored at $-80{ }^{\circ} \mathrm{C}$ until TPLSM measurements.

\section{Contrast agent relaxivity}

$T_{1}$ relaxivity $\left(r_{1}\right)$ was determined by diluting cNGR-pQDs in HBSS in 9 steps to concentrations of $0-0.001 \mathrm{mM}$ (corresponding gadolinium concentrations: $0-0.192 \mathrm{mM}$ ). The $R_{1}$ of each sample was determined using the IR series as described above. Absolute gadolinium concentrations were measured using inductively coupled plasma mass spectrometry. Longitudinal relaxivity was determined by the slope of a linear fit of $R_{1}$ versus gadolinium concentration.

\section{MRI data analysis}

All data processing was performed in Matlab (The Mathworks, Natick, MA), unless stated otherwise. IR images were first spatially coregistered using the mutual information algorithm in the MIRIT software package ${ }^{24}$ to correct for possible animal motion in the images with different $T_{1}$ contrast, and smoothed with a three dimensional Gaussian kernel with a full-width-at-half-maximum of $0.4 \times 0.4 \times 3.0 \mathrm{~mm}^{3}$. Regions of interest (ROIs) were drawn manually in MRIcro $^{25}$ to define tumor and muscle tissue. Both $T_{1}$ - and $T_{2}$-weighted images were used to accurately delineate tumors from surrounding tissue and edema.

Pre- and post-contrast $R_{1}$ values were determined on a voxelby-voxel basis by non-linear curve fitting of the IR signal intensity function: ${ }^{26}$

$$
\mathrm{S}=\mathrm{S}_{0}\left(1-2 \exp \left(-\mathrm{TI} \cdot \mathrm{R}_{1}\right)+\exp \left(-\mathrm{TR} \cdot \mathrm{R}_{1}\right)\right)
$$

using the Levenberg-Marquardt optimization algorithm. $S_{0}$ is a scaling factor including proton density, excitation pulse profile, echo time and pre-amplifier gain.

The detection limit for changes in $R_{1}\left(\Delta R_{1}=R_{1, \text { post }}-R_{1, \text { pre }}\right)$ was determined with a Monte Carlo simulation using equation 1 , in vivo relaxation rates and representative noise levels as derived from the in vivo experiments. A voxel was considered significantly enhanced when $\Delta R_{1}$ was more than 1.96 (i.e., 95\% confidence interval) times higher than the detection limit of $0.005 \mathrm{~s}^{-1}$. We defined the quantitative contrast derived from the $\Delta R_{1}$ measurements $\left(\mathrm{QC}_{\mathrm{R} 1}\right)$ as the product of the mean $\Delta R_{1}$ and the percentage of significantly enhanced voxels for each tissue type, i.e., tumor rim and core, and muscle tissue. $\mathrm{QC}_{\mathrm{R} 1}$ indicates both the level and spatial extent of contrast agent binding. Changes in $S_{0}\left(\Delta S_{0}=S_{0 \text {,post }}-S_{0, \text { pre }}\right)$ were also evaluated and the quantitative contrast from $S_{0}\left(\mathrm{QC}_{\mathrm{S} 0}\right)$ was defined analogously to $\mathrm{QC}_{\mathrm{R} 1}$ to yield a quantity that reflects proton 
visibility. ${ }^{27}$

Tumor rim/core analysis

To investigate the differences between tumor rim, i.e., the region with the highest expected angiogenic activity, and core, the tumor rim was first defined as an approximately $1 \mathrm{~mm}$ thick peripheral zone with the strongest enhancement in $R_{1}$, in accordance with the approach taken by others. ${ }^{28,29}$ Using this thickness, the difference between cNGRand unlabeled pQDs was maximal (Figure 3C). The rim comprised $29.0 \pm 5.8 \%$ and $31.6 \pm 3.5 \%$ of all tumor voxels for mice injected with cNGR- and unlabeled pQDs, respectively. The tumor core was defined as the difference between whole tumor and tumor rim ROIs. Secondly, a contour was drawn to calculate the number of voxels with a significantly increased $\Delta R_{1}$ as a function of the distance to the tumor rim. As an empiric measure of spatial heterogeneity in angiogenic tumor activity, the half-value-depth was defined as the distance from the rim at which the percentage of enhanced voxels has decreased by $50 \%$ compared to its value at zero distance, i.e., the rim. The half-value-depth was calculated by fitting the group-averaged data presented in Figure 3C with a mono-exponential decay function.

\section{Biodistribution}

ROIs defining the spleen, liver, kidney, heart, lung and aorta were drawn manually in MRIcro. Signal intensities were averaged over the entire tissue and normalized to hind limb muscle.

\section{Statistical analysis}

Analysis of paired samples was performed using a non-parametric Wilcoxon signed ranks test in SPSS 14.0 (SPSS, Chicago, Ill).

As both $\mathrm{QC}_{\mathrm{R} 1}$ and $\mathrm{QC}_{\mathrm{S} 0}$ represent contrast agent presence, $\mathrm{QC}_{\mathrm{R} 1}$ and $\mathrm{QC}_{\mathrm{S} 0}$ were combined to a summary value according to $\mathrm{O}$ 'Brien and Läuter, ${ }^{30,31}$ which is more sensitive to contrast effects than the individual measures. Therefore, $\mathrm{QC}_{\mathrm{R} 1}$ and $\mathrm{QC}_{\mathrm{S} 0}$ were first standardized by $\mathrm{z}=(\mathrm{QC}-$ mean $(\mathrm{QC}) / \mathrm{sd}(\mathrm{QC}))$. Subsequently, the absolute values of $z_{\mathrm{QCR} 1}$ and $z_{\mathrm{QCS} 0}$ were averaged per animal. The resulting summary measure was tested using a non-parametric Mann-Whitney U-test. $\mathrm{P}<0.05$ was considered statistically significant.

\section{TPLSM data acquisition}

Tissue samples were thawed and washed with HBSS to remove OCT compound. Except for the spleen and liver, tissues were incubated with 25-fold diluted $\alpha$ CD31-FITC $(0.5 \mathrm{mg} / \mathrm{mL}$, BD Biosciences Pharmingen, Alphen aan de Rijn, The Netherlands) to fluorescently label VECs. Next, tissues were embedded in $2 \%(\mathrm{w} / \mathrm{v})$ agarose gel (Invitrogen), with their rim upwards. For measurements in the tumor core, tumors were cut transversally to resemble the slice orientation of the MRI measurements.

TPLSM imaging was performed using a Nikon Eclipse E600FN upright microscope (Tokyo, Japan), incorporated in the Bio-Rad Radiance 2100MP imaging system and operated by Lasersharp2000 V6.0 (Bio-Rad, Hemel Hempstead, UK). Tissue samples were excited by the Tsunami Ti:sapphire laser (Spectra-Physics, Mountain View, CA), which was pumped by a Millennia Vs $5 \mathrm{~W}$ pump laser (SpectraPhysics) and mode-locked at $800 \mathrm{~nm}$, with a $82.5 \mathrm{MHz}$ repetition rate and $140 \mathrm{fs}$ pulse width. Tissues were observed through a water dipping 60× fluor objective with a 1.00 numerical aperture (Nikon). Photomultiplier tubes (PMTs 9108B02 and 9136B05, Electron Tubes Limited, Ruislip, UK) were used to acquire fluorescence photons in three spectral regions: 420 - $470 \mathrm{~nm}$ (autofluorescence), 520 - $560 \mathrm{~nm}$ (FITC) and 570 - $600 \mathrm{~nm}$ (QDs). Each PMT was tuned for minimal bleed-through of the fluorescent markers to adjacent PMTs. Images, color-coded blue, green and red, respectively, were subsequently merged into a single image. The in-plane pixel dwell time was 11.8 $\mu \mathrm{s}$, which, together with a 2-fold Kalman averaging, resulted in an imaging speed of $0.16 \mathrm{~Hz}$. The FOV was $179 \times 179 \mu \mathrm{m}^{2}$ with a matrix 
size of $512 \times 512$, resulting in $0.35 \times 0.35 \mu \mathrm{m}^{2}$ sized pixels.

\section{TPLSM data analysis}

Data were analyzed with Image-Pro Plus 6.0 (MediaCybernetics, Silver Spring, MD) and ImageJ 1.35 (NIH, Bethesda, MD). Image quality was improved by convolution with a $1.05 \times 1.05 \mu^{2}$ Gaussian filter. Spatial distribution of pQDs was classified into four groups: intravascular, intracellular, colocalized with the EC membrane or extravasated to the interstitium.

\section{Results}

\section{In vivo targeting of activated tumor endothelium}

The ability of cNGR to target angiogenic tumor VECs was evaluated in tumor-bearing nude mice by injecting them with cNGR- or unlabeled pQDs. Tumor volumes of cNGR and control groups did not differ on MR images (mean \pm SD $1.0 \pm 0.7 \mathrm{~cm}^{3}$ and $1.0 \pm 0.6 \mathrm{~cm}^{3}$, respectively).

For both cNGR- and unlabeled pQDs, changes in $R_{1}\left(\Delta R_{1}\right)$ were spatially heterogeneous throughout the tumor and were most pronounced at the tumor rim (Figure 2A). Averaged over all mice, the $\Delta R_{1}$ induced by cNGR-pQDs ranged up to approximately 0.3 $\mathrm{s}^{-1}$, which was considerably larger than the intrinsic variation in pre-contrast tumor $R_{1}$ of $0.1 \mathrm{~s}^{-1}$. Furthermore, the range in $\Delta R_{1}$ was relatively large compared with the pre-contrast tumor $R_{1}$ of 0.8 $\mathrm{s}^{-1}$. Administration of unlabeled $\mathrm{pQDs}$ resulted in a 3-fold lower response range $\left(\Delta R_{1}<0.1 \mathrm{~s}^{-1}\right)$ compared with cNGR-pQDs.

Subsequent investigation by TPLSM allowed localization of cNGR- and unlabeled pQDs at a subcellular resolution. cNGRpQDs were found to colocalize approximately three times more often with tumor VECs than unlabeled pQDs (Figure 2). cNGR- and unlabeled pQDs were also found in the vessel lumen, albeit that cNGR-pQDs were approximately three times more prevalent than unlabeled pQDs. Both contrast agents were only sparsely found to have extravasated into the tumor interstitium. Although cNGR was previously reported to be an internalizing peptide, ${ }^{32} \mathrm{cNGR}-\mathrm{pQDs}$ were not detected inside VECs with TPLSM.

Further evidence for the specificity of $\mathrm{cNGR}$ was provided by $\Delta R_{1}$ in hind limb muscle. Here, average $\Delta R_{1}$ upon administration of cNGR-pQDs was considerably lower than in the tumor and ranged up to $0.05 \mathrm{~s}^{-1}$. TPLSM did not display colocalization of cNGRpQD with VECs of muscle vasculature. However, the incidence of cNGR-pQDs in the muscle vascular lumen was almost two-fold higher than for unlabeled pQDs (Figure 2D).

\section{$S_{0}$-effect}

For both cNGR- and unlabeled pQDs, changes in the scaling factor $S_{0}$ colocalized strongly with $\Delta R_{1}$ (Figure $2 \mathrm{~B}$ ). The $S_{0}$-effect is likely caused by field inhomogeneities ( $T_{2}^{*}$ effect) in the vicinity of the contrast agent, induced by the magnetic properties of QDs ${ }^{33}$ and the dense gadolinium concentration on the particle. Analogous to iron oxide particles, such properties result in a locally reduced transverse relaxation times $T_{2}$ and $T_{2}{ }^{*}$, a shift in local resonance frequency and a broader water resonance line, which is reflected by a decrease in $S_{0}$, i.e., a reduced proton visibility. ${ }^{27,34}$ Therefore, $\Delta R_{1}$ and $\Delta S_{0}$ both represent contrast agent presence.

\section{Spatial heterogeneity}

To explore the absolute differences between tumor rim, tumor core and muscle, $\mathrm{QC}_{\mathrm{R} 1}$ and $\mathrm{QC}_{\mathrm{S} 0}$ were determined for each tissue type for cNGR- and unlabeled pQDs (Figure 3A/B). Administration of cNGR-pQDs resulted in an approximately 50-fold increase in $\mathrm{QC}_{\mathrm{R} 1}$ in the angiogenic rim compared with tumor core or muscle tissue. For unlabeled pQDs, significant differences were also found between tumor rim and core, and tumor rim and muscle tissue, although the net increase in $\mathrm{QC}_{\mathrm{R} 1}$ was lower than for cNGR-pQDs. The decreases 
cNGR-pQDs
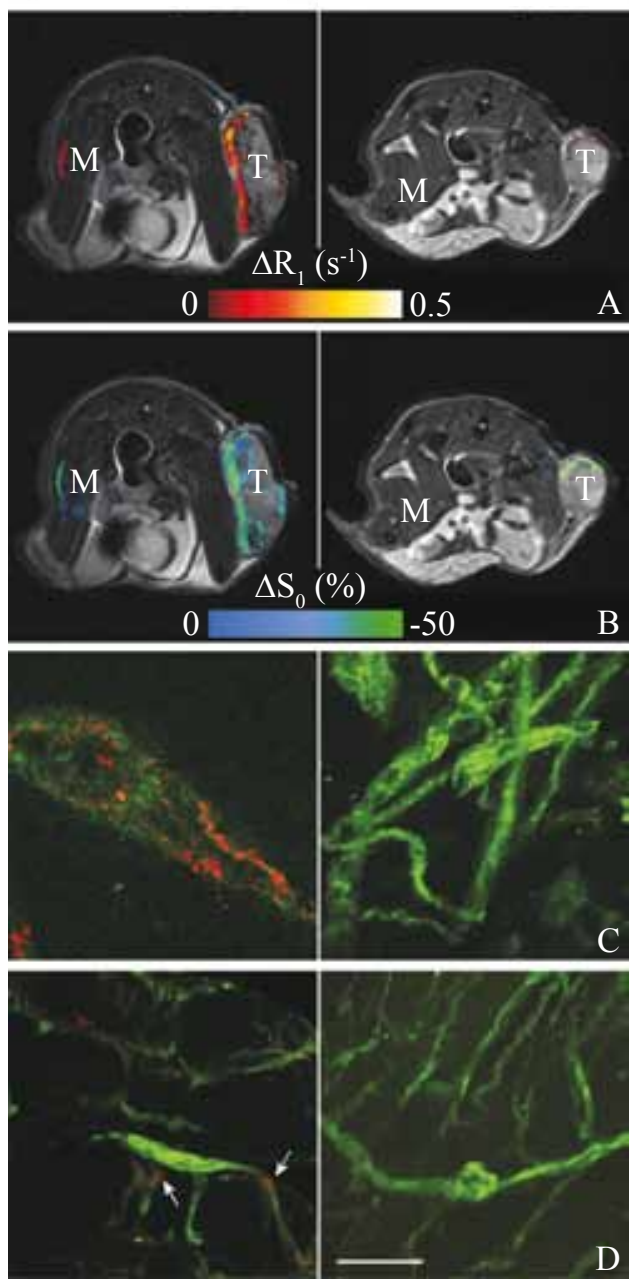

Figure $2 A$-B) $T_{2}$-weighted anatomical images with color overlay of $\Delta R_{1}$ $(A)$ and $\triangle S_{0}(B)$ for tumor $(T)$ and muscle $(M)$ tissue of mice injected with $c N G R$ - or unlabeled $p Q D s$. Changes in $R_{1}$ were most pronounced at the tumor rim for $c N G R-p Q D s$. Although an $R_{1}$ increase in the tumor rim was also observed for unlabeled $p Q D$ s, the average response was 3-fold lower when compared with $c N G R-p Q D$ s, indicating a high specificity of $c N G R$ for angiogenic tumor endothelium. This is further supported by the low changes in $R_{1}$ found in muscle tissue. Changes in $S_{0}(B)$ colocalized almost completely with changes in $R_{1}(A)$. Representative TPLSM images of tumor (C) and muscle tissue (D) showing $p Q D$ signal in red and endothelial cell specific $\alpha C D 31-F I T C$ in green. $c N G R-p Q D s$ accurately colocalized with tumor endothelial cells, indicating binding of the contrast agent to the tumor endothelium (C). cNGR-pQDs were also detected in muscle tissue with TPLSM (D, arrows), although to a much lesser extent than in tumor tissue. $c N G R-p Q D$ s did not display any colocalization with muscle endothelial cells and were only found intraluminally. Unlabeled $p Q D$ s were not or only sparsely detected in both tumor and muscle tissue. Bar: $50 \mu \mathrm{m}$. in $S_{0}$ showed the same trend as the increases in $R_{1}$ (cf. Figure $3 \mathrm{~A} / \mathrm{B}$ ).

For each of the three tissue types, no significant differences in $\mathrm{QC}_{\mathrm{R} 1}$ or $\mathrm{QC}_{\mathrm{S} 0}$ were found between cNGR- and unlabeled $\mathrm{pQDs}$. Since $\Delta R_{1}$ and $\Delta S_{0}$ were shown to accurately colocalize (Figure 2), $\mathrm{QC}_{\mathrm{R} 1}$ data were combined with $\mathrm{QC}_{\mathrm{S} 0}$ to a summary measure as described above. This resulted in a statistically significant difference between cNGR- and unlabeled pQDs for the tumor rim only (Figure 3A/B).

To further investigate the spatial distribution of angiogenic activity in the tumor, the percentage of significantly enhanced voxels was calculated as a function of the distance to the tumor rim (Figure 3C). Although the highest signal increase was found at the tumor rim for both contrast agents, more than twice as many rim voxels were enhanced for cNGR-pQDs than for unlabeled pQDs. In the tumor core, similar enhancements were found for both contrast agents. These findings qualitatively concur with previous findings showing that angiogenic activity is most pronounced at the tumor 

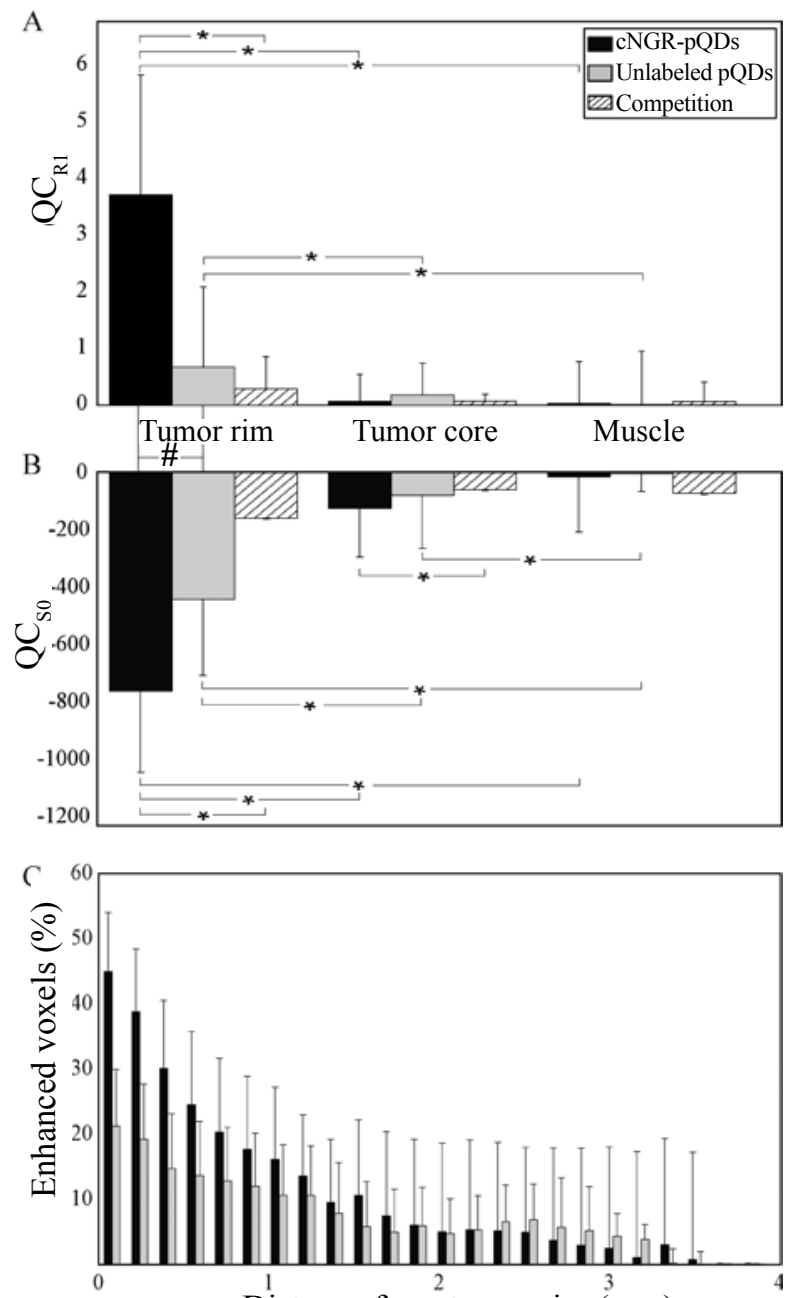

Distance from ${ }^{2}$ tumor $\left.\operatorname{rim}^{(3} \mathrm{mm}\right)$
Figure 3 Spatial distribution of angiogenic activity. A-B) Quantitative contrast as derived from changes in $R_{1}\left(Q C_{R l}, A\right)$ and from changes in $S_{0}$ $\left(Q C_{S O}, B\right)$ for tumor rim, tumor core, and hind limb muscle tissue. Data are shown for $c N G R-p Q D s(n=7)$, unlabeled $p Q D s(n=7)$, and the competition experiment of $c N G R-p Q D$ s with excess unconjugated $c N G R$ $(n=4) . C)$ Percentage of enhanced voxels at a certain distance versus distance from the tumor rim for cNGR-labeled and unlabeled $p Q D s$. Although enhanced voxels were mostly found at the tumor rim for both contrast agents, more than twice as many rim voxels were enhanced for $c N G R-p Q D s$ than for unlabeled $p Q D s$. In the tumor core, similar values were found for both cNGR-labeled and unlabeled $p Q D s$. Values are presented as median \pm standard error. *, $P<0.05$; \#, $P<0.05$ for the $O$ 'Brien- Läuter summary measure of $Q C_{R I}$ and $Q C_{S 0}$ (see text).

rim for this tumor model. ${ }^{7,3}$

Subsequently, half-value-depths were calculated for both cNGRand unlabeled pQDs. High values indicate a more homogeneous distribution of enhanced voxels over the entire tumor and thus a low spatial heterogeneity, whereas low values indicate a high spatial variation. For cNGR- and unlabeled pQDs, the half-value-depths were 0.6 and $1.1 \mathrm{~mm}$, respectively, indicating a stronger contrast between tumor rim and core for cNGR-pQDs, which suggests that cNGR-pQDs allow a better differentiation between tumor rim and core than unlabeled pQDs.

\section{Competition experiment}

Intravenous injection of a 1000-fold excess of unconjugated cNGR 10 minutes after administration of cNGR-pQDs resulted in a statistically significant decrease in $\mathrm{QC}_{\mathrm{R} 1}$ and $\mathrm{QC}_{\mathrm{S} 0}$ for the tumor rim (Figure 3A/B). With TPLSM, cNGR-pQDs were barely detected in the tumor rim, which confirmed the MRI results (data not shown). These results therefore indicate that binding of cNGR-pQDs to tumor VECs is specific, reversible and can be competed with 


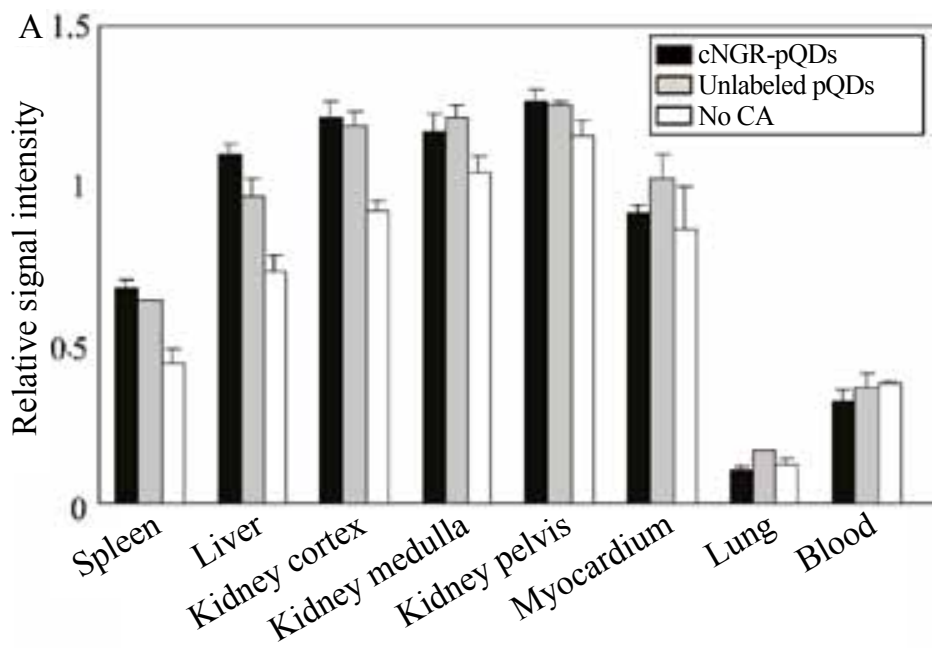

B
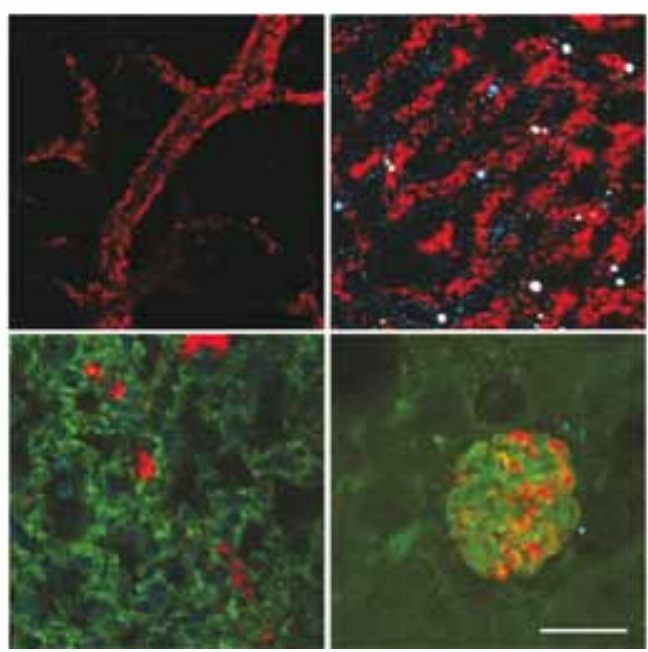

Figure 4 Biodistribution of $c N G R$ - and unlabeled $p Q D s$. A) Post mortem $T_{I}$-weighted MRI results. Signal intensities were normalized to hindlimb muscle signal and subsequently averaged. No CA: no contrast agent administration. Both $c N G R$ - and unlabeled $p Q D s$ were found to accumulate mainly in the spleen, liver and kidneys. Values are represented as median \pm standard error. B) Representative TPLSM images of spleen, liver, lung and kidney. Since a similar biodistribution was found for $c N G R-$ and unlabeled $p Q D$ s, no differentiation was made for the TPLSM results. Red: pQDs, Green: $\alpha C D 31-F I T C$, Blue: autofluorescence, Bar: $50 \mu \mathrm{m}$.

unconjugated $\mathrm{cNGR}$.

\section{Biodistribution}

Figure 4 shows the relative MRI signal intensities for the blood and major organs recorded approximately one hour after the administration of cNGR-pQDs, unlabeled pQDs or no contrast agent. No differences were found between cNGR- and unlabeled pQDs. Both contrast agents accumulated mainly in the spleen, liver and kidneys (Figure 4), which was confirmed by TPLSM and corresponds to previous findings. ${ }^{36}$ Due to the intravenous administration, pQDs were also expected to accumulate in the lung. However, MRI has only limited signal sensitivity in the lung due to inherent low signal intensity and air-tissue interfaces. With TPLSM, pQDs could be clearly detected in the lung (Figure 4), although imaging was hampered by tissue movement caused by heating of the sample during excitation, resulting in expansion of air in the pulmonary alveoli.

\section{Contrast agent relaxivity}

The ionic $T_{1}$ relaxivity of cNGR-pQDs, i.e., per Gd ion, was 7.1 $\pm 0.4 \mathrm{mM}^{-1} \mathrm{~s}^{-1}$ at $7 \mathrm{~T}$ and $20^{\circ} \mathrm{C}$, which lies in the expected range for macromolecular contrast agents and is in correspondence with previously reported values for Annexin A5 conjugated pQDs. ${ }^{37}$ 


\section{Discussion}

\section{Current findings}

In this study, the ability of cNGR-labeled paramagnetic QDs to visualize and quantify angiogenic activity in LS174T tumors was evaluated using two complementary imaging modalities: in vivo MRI and ex vivo TPLSM. To our knowledge, this study shows the first results of the application of cNGR for molecular MRI. First, cNGRpQDs were found to have a 3-fold higher quantitative MRI contrast in the tumor rim, i.e., the tumor region with the highest angiogenic activity, compared with unlabeled pQDs. Second, cNGR-pQDs were barely detectable in muscle tissue, indicating a high specificity of cNGR-pQDs for angiogenic vessels. Third, ex vivo TPLSM showed colocalization of cNGR-pQDs, but not unlabeled pQDs, with VECs in tumor vasculature. Fourth, cNGR-pQDs allowed a more accurate assessment of the rim-core heterogeneity in tumor angiogenic activity. Fifth, the competition experiment indicated that the binding of cNGRpQDs to tumor VECs is specific, reversible and can be competed with excess unconjugated cNGR. Finally, no qualitative differences in biodistribution were found between cNGR- and unlabeled pQDs with MRI and TPLSM. For a full quantitative biodistribution assessment, positron emission tomography (PET) would be better suited since the local relaxivity of the MRI contrast agent, which is required to convert $R_{1}$ to concentrations, is unknown. Taken together, the presented results designate cNGR as an effective ligand for discriminating between quiescent and activated endothelium and for quantifying the extent of tumor angiogenic activity.

In correspondence with other studies, ${ }^{7,35}$ our results indicate that angiogenic activity is highest at the tumor rim, which was reflected by a high $\mathrm{QC}_{\mathrm{R} 1}$ and a strongly negative $\mathrm{QC}_{\mathrm{S} 0}$ for $\mathrm{cNGR}-\mathrm{pQDs}$. This was supported by the statistically significant difference between
cNGR- and unlabeled pQDs found using the summary value. Unlabeled $\mathrm{pQDs}$ also showed differences between tumor rim versus core and muscle, albeit smaller than for the cNGR-pQDs. This is likely due to the tumor rim's intrinsically higher vascular density and corresponding blood pool fraction, resulting in a larger amount of circulating contrast agent compared with tumor core or muscle tissue. ${ }^{35}$ Additionally, heterogeneous blood flow and long washin and -out times of macromolecular contrast agents, previously described for dendritic agents ${ }^{38}$ may have contributed to prolonged retention of unlabeled pQDs in the tumor rim.

\section{Methodological considerations}

Non-linear fitting of the IR-signal over a range of inversion times provided a sensitive and reliable method for detecting $R_{1}$ changes induced by contrast agent binding. Compared to signal intensity measurements, it is relatively independent of technical settings, e.g., repetition time, echo time and flip angle, thereby allowing objective comparison between different subjects, both spatially and temporally. A disadvantage of the quantitative approach is the lengthy acquisition time since an adequate number of data points is required for accurate fitting of the IR curve. Although prolonged pre- and post-contrast acquisition of a single image at a fixed inversion time may also allow accurate detection of changes in signal intensity, this will not provide quantitative information on $R_{1}$ and $S_{0}$. In our quantitative approach, coregistration of these parameters ensured increased sensitivity to detect differences between cNGR- and unlabeled pQDs and is therefore preferred over acquisition of a single image.

Theoretically, the measured longitudinal relaxation rates and contrast agent relaxivity allow estimation of local contrast agent concentration and might be used to gain insight in the density of the molecular target. However, the conditions under which the relaxivity was determined differ strongly from the in vivo situation. Not only is 
the relaxivity affected by the particle's chemical environment, i.e., aqueous buffer versus blood plasma, ${ }^{39}$ specific binding to vascular endothelium reduces its tumbling rate, thereby increasing the relaxivity. Taken together, this would lead to an overestimation of the local concentration in vivo. Unfortunately, accurate measurements of in vivo relaxivity are currently unavailable.

\section{Contrast agent}

Quantum dots were chosen as scaffold to enable bi-modal, i.e., MRI and TPLSM, visualization of tumor angiogenic activity, which is an essential step in the characterization and validation of cNGR as a targeting ligand. Furthermore, streptavidin-coated QDs provide a suitable and versatile research scaffold to identify and test other potential targeting ligands. In addition, QDs show minimal extravasation, both from healthy and hyperpermeable tumor vasculature (unpublished observations), which is beneficial for VEC targeting. However, QDs may pose serious health limitations due to the potential release of toxic cadmium ions. Although this can be prevented by effective shielding of the core, ${ }^{40,41}$ QDs are not cleared from the body and accumulate in spleen, liver and kidneys. Cadmium-based QDs will therefore not be approved for clinical application. Recently developed non-toxic and renally excretable QDs may provide a potential solution for this problem..$^{42,43}$ Nevertheless, once a robust MRI method has been accepted in clinical practice, validation with luminescent particles is no longer necessary and clinically more suitable particles may be applied.

The magnetic and semi-conductive properties of QDs give rise to field inhomogeneities when placed inside a magnetic field, ${ }^{33}$ which likely result in a local decrease of the transverse relaxation times $T_{2}$ and $T_{2}{ }^{*}$. In addition, $T_{2}$ contrast becomes more effective at high field strength, whereas $T_{1}$ contrast decreases. Using a standard multi-slice multi-echo spin echo sequence, an average $R_{2}$ increase of
$5.7 \mathrm{~s}^{-1}$ upon cNGR-pQD injection was detected in the tumor rim at a mean tumor pre-contrast $R_{2}$ of approximately $27 \mathrm{~s}^{-1}$. However, the percentage of significantly enhanced voxels in the tumor rim was only $4 \%$, which is considerably lower than the $42 \%$ found for $R_{1}$. This demonstrates that $T_{2}$ changes did not interfere with the effects on $T_{1}$ and $S_{0}$. Consequently, the $T_{1}$ and $S_{0}$ quantification was more sensitive in discriminating between angiogenic activity in the tumor rim, tumor core and muscle tissue than $T_{2}$.

\section{Clinical perspectives}

Regarding the potential clinical applicability, quantitative molecular MRI with a suitable contrast agent has a number of advantages over the currently used immunohistochemical methods to quantify tumor angiogenic activity. First, molecular MRI is non-invasive and does not interfere with tissue integrity. Second, it can probe the entire tumor, whereas immunohistochemistry requires biopsies at one or multiple selected locations. Third, it allows covisualization of angiogenic activity with local anatomy. Fourth, tumor status or therapeutic response may be objectively monitored over time due to the absolute quantification methodology. Finally, molecular MRI allows direct detection of activated endothelium in functional vasculature, while immunohistochemistry measures both perfused and non-perfused vessels.

With respect to the applied tumor model, a human colorectal adenocarcinoma, MRI is clinically important for local T-staging of rectal cancer and for the identification of tumors close to or invading the mesorectal fascia. ${ }^{44}$ On diagnostic $T_{2}$-weighted images however, it remains difficult to differentiate between fibrotic tissue and viable tumor cells. Molecular MRI of angiogenesis may facilitate this demarcation, since only viable tumor cells induce angiogenesis, which may be visualized upon administration of the targeted contrast agent.

Besides the availability of suitable contrast agents, clinical 
implementation of quantitative molecular MRI requires rapid imaging sequences, including Look-Locker, ${ }^{45}$ IR-true-FISP, ${ }^{46}$ and the recently described QRAPTEST ${ }^{47}$ However, these methods are relatively sensitive to subject movement and field inhomogeneities, although the Look-Locker method was recently modified to allow in vivo $T_{1}$-mapping of the heart. ${ }^{48}$ Thus, the development of fast quantification of relaxation rates may support future clinical application of quantitative molecular MRI.

In summary, we have shown that cNGR-labeled paramagnetic quantum dots are suitable for the non-invasive visualization and quantification of tumor angiogenic activity using in vivo molecular MRI. These results provide a promising basis for further developments in contrast agent design and synthesis, data acquisition and post-processing techniques, which may be valuable for future clinical applications to pathologies in which abnormal vessel growth plays a pivotal role. 


\section{References}

1. Carmeliet P. Angiogenesis in health and disease. Nat Med 2003;9:653-60.

2. Folkman J. Tumor angiogenesis: therapeutic implications. N Engl J Med 1971;285: 1182-6.

3. Meitar D, Crawford SE, Rademaker AW, Cohn SL. Tumor angiogenesis correlates with metastatic disease, $N$-myc amplification, and poor outcome in human neuroblastoma. J Clin Oncol 1996;14:405-14.

4. Daldrup H, Shames DM, Wendland M, et al. Correlation of dynamic contrastenhanced MR imaging with histologic tumor grade: comparison of macromolecular and small-molecular contrast media. AJR Am J Roentgenol 1998;171:941-9.

5. Massoud TF, Gambhir SS. Molecular imaging in living subjects: seeing fundamental biological processes in a new light. Genes Dev 2003;17:545-80.

6. Sipkins DA, Cheresh DA, Kazemi MR, Nevin LM, Bednarski MD, Li KC. Detection of tumor angiogenesis in vivo by alphaVbeta3-targeted magnetic resonance imaging. Nat Med 1998;4:623-6.

7. Mulder WJ, Strijkers GJ, Habets JW, et al. MR molecular imaging and fluorescence microscopy for identification of activated tumor endothelium using a bimodal lipidic nanoparticle. Faseb J 2005;19:2008-10.

8. Zhang C, Jugold M, Woenne EC, et al. Specific targeting of tumor angiogenesis by $R G D$-conjugated ultrasmall superparamagnetic iron oxide particles using a clinical 1.5-T magnetic resonance scanner. Cancer Res 2007;67:1555-62.

9. Arap W, Pasqualini R, Ruoslahti E. Cancer treatment by targeted drug delivery to tumor vasculature in a mouse model. Science 1998;279:377-80.

10. Curnis F, Sacchi A, Borgna L, Magni F, Gasparri A, Corti A. Enhancement of tumor necrosis factor alpha antitumor immunotherapeutic properties by targeted delivery to aminopeptidase N (CD13). Nat Biotechnol 2000;18:1185-90.

11. Zarovni N, Monaco L, Corti A. Inhibition of tumor growth by intramuscular injection of cDNA encoding tumor necrosis factor alpha coupled to NGR and RGD tumor-homing peptides. Hum Gene Ther 2004;15:373-82.

12. van Laarhoven HW, Gambarota G, Heerschap A, et al. Effects of the tumor vasculature targeting agent NGR-TNF on the tumor microenvironment in murine lymphomas. Invest New Drugs 2006;24:27-36.

13. Curnis F, Arrigoni G, Sacchi A, et al. Differential binding of drugs containing the NGR motif to CD13 isoforms in tumor vessels, epithelia, and myeloid cells. Cancer Res 2002;62:867-74.

14. Pasqualini R, Koivunen E, Kain R, et al. Aminopeptidase $N$ is a receptor for tumor-homing peptides and a target for inhibiting angiogenesis. Cancer Res 2000;60:722-7.
15. Rangel R, Sun Y, Guzman-Rojas L, et al. Impaired angiogenesis in aminopeptidase N-null mice. Proc Natl Acad Sci U S A 2007;104:4588-93.

16. Buehler A, van Zandvoort MA, Stelt BJ, et al. $c N G R$ : a novel homing sequence for CD13/APN targeted molecular imaging of murine cardiac angiogenesis in vivo. Arterioscler Thromb Vasc Biol 2006;26:2681-7.

17. von Wallbrunn A, Waldeck J, Holtke C, et al. In vivo optical imaging of CD13/ APN-expression in tumor xenografts. J Biomed Opt 2008;13:011007.

18. Chan WC, Nie S. Quantum dot bioconjugates for ultrasensitive nonisotopic detection. Science 1998;281:2016-8.

19. Michalet X, Pinaud FF, Bentolila LA, et al. Quantum dots for live cells, in vivo imaging, and diagnostics. Science 2005;307:538-44.

20. Schnolzer M, Alewood P, Jones A, Alewood D, Kent SB. In situ neutralization in Boc-chemistry solid phase peptide synthesis. Rapid, high yield assembly of difficult sequences. Int J Pept Protein Res 1992;40:180-93.

21. Dirksen A, Langereis S, de Waal BF, van Genderen MH, Hackeng TM, Meijer EW. A supramolecular approach to multivalent target-specific MRI contrast agents for angiogenesis. Chemical Communications 2005:2811-3.

22. Dirksen A, Meijer EW, Adriaens W, Hackeng TM. Strategy for the synthesis of multivalent peptide-based nonsymmetric dendrimers by native chemical ligation. Chem Commun (Camb) 2006:1667-9.

23. Curnis F, Longhi R, Crippa L, et al. Spontaneous formation of L-isoaspartate and gain of function in fibronectin. Journal of Biological Chemistry 2006;281:36466-76.

24. Maes F, Collignon A, Vandermeulen D, Marchal G, Suetens P. Multimodality image registration by maximization of mutual information. IEEE Trans Med Imaging 1997; 16:187-98.

25. Rorden C, Brett M. Stereotaxic display of brain lesions. Behav Neurol 2000;12: 191-200.

26. Haacke EM, Brown RW, Thompson MR, Venkatesan R. Introductory signal acquisition methods: free induction decay, spin echoes, inversion recovery and spectroscopy. Magnetic resonance imaging physical principles and sequence design. 1st ed. New York: John Wiley \& Sons, Inc.; 1999. p. 111-38.

27. Gambarota G, van Laarhoven HW, Philippens M, et al. Assessment of absolute blood volume in carcinoma by USPIO contrast-enhanced MRI. Magn Reson Imaging 2006;24:279-86.

28. de Lussanet QG, Beets-Tan RG, Backes WH, et al. Dynamic contrast-enhanced magnetic resonance imaging at 1.5 Tesla with gadopentetate dimeglumine to assess the angiostatic effects of anginex in mice. Eur J Cancer 2004;40:1262-8.

29. Padhani AR. Functional MRI for anticancer therapy assessment. Eur J Cancer 2002;38:2116-27. 
30. O'Brien PC. Procedures for comparing samples with multiple endpoints. Biometrics 1984;40:1079-87.

31. Läuter J. Exact t and F tests for analyzing studies with multiple endpoints. Biometrics 1996;52:964-70.

32. Ellerby HM, Arap W, Ellerby LM, et al. Anti-cancer activity of targeted proapoptotic peptides. Nat Med 1999;5:1032-8.

33. Manninen A, Koskinen M, Reimann SM, Mottelson B. Magnetic properties of quantum dots and rings. European Physical Journal D 2001;16:381-5.

34. Wismer GL, Buxton RB, Rosen BR, et al. Susceptibility induced MR line broadening: applications to brain iron mapping. J Comput Assist Tomogr 1988;12:259-65.

35. de Lussanet QG, Backes WH, Griffioen AW, van Engelshoven JM, Beets-Tan RG. Gadopentetate dimeglumine versus ultrasmall superparamagnetic iron oxide for dynamic contrast-enhanced MR imaging of tumor angiogenesis in human colon carcinoma in mice. Radiology 2003;229:429-38.

36. Yang RS, Chang LW, Wu JP, et al. Persistent tissue kinetics and redistribution of nanoparticles, quantum dot 705, in mice: ICP-MS quantitative assessment. Environ Health Perspect 2007;115:1339-43.

37. Prinzen L, Miserus RJ, Dirksen A, et al. Optical and magnetic resonance imaging of cell death and platelet activation using annexin a5-functionalized quantum dots. Nano Lett 2007;7:93-100.

38. Langereis S, de Lussanet $\mathrm{QG}$, van Genderen $\mathrm{MH}$, et al. Evaluation of Gd(III) DTPA-terminated poly(propylene imine) dendrimers as contrast agents for $M R$ imaging. NMR in Biomedicine 2006;19:133-41.

39. Stanisz GJ, Henkelman RM. Gd-DTPA relaxivity depends on macromolecular content. Magn Reson Med 2000;44:665-7.

40. Cho SJ, Maysinger D, Jain M, Roder B, Hackbarth S, Winnik FM. Long-term exposure to CdTe quantum dots causes functional impairments in live cells. Langmuir 2007;23:1974-80.

41. Yu WW, Chang E, Falkner JC, et al. Forming biocompatible and nonaggregated nanocrystals in water using amphiphilic polymers. J Am Chem Soc 2007;129:2871-9. 42. Soo Choi H, Liu W, Misra P, et al. Renal clearance of quantum dots. Nat Biotech 2007;25:1165-70.

43. Zimmer JP, Kim SW, Ohnishi S, Tanaka E, Frangioni JV, Bawendi MG. Size series of small indium arsenide-zinc selenide core-shell nanocrystals and their application to in vivo imaging. J Am Chem Soc 2006;128:2526-7.

44. Vliegen RF, Beets GL, von Meyenfeldt MF, et al. Rectal cancer: MR imaging in local staging--is gadolinium-based contrast material helpful? Radiology 2005;234:179-88.

45. Freeman A, Gowland P, Jellineck D, et al. Dynamic T1 studies of gadolinium uptake in brain tumors using LL-EPI. MAGMA 1994;2:409-12.
46. Schmitt P, Griswold MA, Jakob PM, et al Inversion recovery TrueFISP quantification of T(1), T(2), and spin density. Magn Reson Med 2004;51:661-7.

47. Warntjes JB, Dahlqvist O, Lundberg P. Novel method for rapid, simultaneous T1, $T^{*} 2$, and proton density quantification. Magn Reson Med 2007;57:528-37.

48. Messroghli DR, Radjenovic A, Kozerke S, Higgins DM, Sivananthan MU,

Ridgway JP. Modified Look-Locker inversion recovery (MOLLI) for high-resolution T1 mapping of the heart. Magn Reson Med 2004;52:141-6. 


\section{Chapter 7}

\section{General discussion}



Neo-vascularization contributes to development and destabilization of atherosclerotic plaques and to growth and metastazation of solid tumors. The studies presented in this thesis demonstrate that the combination of two-photon laser scanning microscopy (TPLSM) and magnetic resonance imaging (MRI) allows visualization and quantification of microvascular morphology and angiogenic activity in murine models of atherosclerosis and cancer. MRI allows in vivo visualization and gross localization of angiogenic activity. Furthermore, our data indicate that MRI is able to detect differences in microvascular morphological quantities and localization. $E x$ vivo, TPLSM permits high resolution assessment of angiogenic activity and accurate visualization and quantification of microvessel morphology and angiogenic activity thereof at the level of the individual microvessel.

However, several biological and technical limitations may apply to the presented studies, including fluorescent labeling of vascular endothelial cell membranes for quantification of vasa vasorum and tumoral microvessels (chapter 5), the lack of an atherosclerosis mouse model with high vasa vasorum density (chapter 4), and the limited tissue penetration depth of TPLSM, relative to MRI (chapter 5 and 6).

\section{CD31 for demarcation of microvessels}

In the studies described in chapters 4,5 , and $6, \alpha \mathrm{CD} 31$-FITC was used to fluorescently label endothelial cells by in vivo injection (chapter 4) and ex vivo incubation (chapter 5 and 6). The former allowed visualization of functional, i.e., perfused vasa vasorum microvessels only, whereas the latter presumably allowed visualization of both functional and nonfunctional tumor microvessels with TPLSM. In future experiments, discrimination of functional from non-functional vasculature may be achieved by systematic administration of fluorophores that reside in the blood phase ${ }^{1}$ and subsequent ex vivo incubation with spectroscopically distinct $\alpha \mathrm{CD} 31$. Neo-vasculature may exhibit a discontinuous endothelial layer. Although this may have minimal effect on the visualization of the microvasculature, quantification of microvessel density may lead to underestimation. In chapter 5 , this was countered by application of a closing and blurring filter to the acquired dataset in order to obtain solid cylindrical structures.

Endothelial cells of mature and angiogenic (micro-) vasculature express CD $31 .{ }^{2}$ In addition, CD31 is expressed by endothelial cells of lymphatic vessels as well. ${ }^{3-5}$ Since lymphangiogenesis is associated with intimal thickening ${ }^{6}$ and tumor development, ${ }^{7}$ one might argue that the observed adventitial and tumoral vascular structures, labeled with $\alpha$ CD31-FITC, are partially lymphatic vessels. However, a recent FACS study showed that mouse lymphatic endothelial cells are only $3 \%$ positive for $\mathrm{CD} 31 .{ }^{8}$ In that study, the same antibody clone (MEC13.3) was used as in the experiment presented in chapters 4, 5, and 6 . These studies indicate that the differential expression pattern of CD31 did not overestimate microvessel density in tumors compared with muscle tissue and the expression of CD31 by lymphatic vessels is too low for imaging purposes.

\section{Vasa vasorum of atherosclerotic plaques}

In vivo intravenous injection of fluorophore-conjugated antibodies against vascular endothelial cells allowed visualization of plaque vasa vasorum ex vivo with TPLSM (chapter 4). Interestingly, vasa vasorum (an adventitial plexus of microvessels in the wall of larger blood vessels) were observed in the plaque region of the abdominal aorta of $\mathrm{ApoE}^{-/-}$mice, fed a Western type diet for approximately 20 weeks, and not in other aortic segments. In murine atherosclerotic plaques, neo-vascularization and hypoxia have both been related to inflammatory content, however, not to intimal thickness. ${ }^{9,10}$ This implies that, irrespective of plaque size, angiogenic activity may be present in all atherosclerotic lesions, albeit at different intensities, and lead to the expansion of vasa vasorum and formation of intraplaque 
microvasculature. A major future challenge in TPLSM is to extend these studies to specifically and sensitively detect alterations in expression patterns of angiogenesis markers in vivo, since this would allow recognition of neo-vascularization in the early stage of development.

The density of plaque vasa vasorum could, unfortunately, not be quantified due to the low prevalence of microvessels in this mouse model of atherosclerosis. In murine models of more extensive atherosclerosis, including long-term high fat diets, collar-induced intimal thickening, and $\mathrm{ApoE}^{-/} / \mathrm{LDL}^{-/}$double knockout mice, the vasa vasorum density will be increased. ${ }^{9}, 11$ This would not only facilitate longitudinal and quantitative correlation of microvessel development to plaque growth, but also facilitate functional studies of these microvessels, e.g., visualization of inflammatory cell transport through the vasa vasorum and of their angiogenic activity. In $30 \%$ of the observed, axially orientated vasa vasorum, colocalization of cNGR-QDs with endothelial cells was observed, indicating significant angiogenic activity (chapter 4 ). Although $\alpha$ CD31-FITC and cNGR-QDs were injected in vivo, TPLSM observations were performed ex vivo. Tissue excision and handling may have induced artifacts. Furthermore, future (in vivo) experiments, will show whether cNGR, in addition to cRGD, ${ }^{12,13}$ is suitable for molecular imaging and therapy of plaque-associated angiogenesis.

\section{Neo-vasculature of solid tumors}

As observed with TPLSM, tumor neo-vasculature was highly tortuous and displayed a wide range in radiuses $(1.2-14.9 \mu \mathrm{m})$, whereas the microvasculature of skeletal muscle was highly organized (chapter 5). Using dedicated image processing, values were obtained for microvessel density and radius for LS174T tumors that are in agreement with literature. ${ }^{14,15}$ These results indicate that deconvolution of TPLSM data leads to reliable quantitative information. However, TPLSM experiments were performed ex vivo, whereas Leunig et al. ${ }^{14}$ and Yuan et al. ${ }^{15}$ used intravital microscopy to obtain the microvessel density and radius under physiological circumstances. Magnetic resonance vessel size imaging (MR-VSI) offered the ability to obtain values related to microvessel density and radius on a voxel-by-voxel basis (voxel volume of approximately $0.1 \mathrm{~mm}^{3}$ ). Although, TPLSM and MR-VSI displayed similar trends in their respective microvessel density and radius data when comparing tumor rim, tumor core, and muscle, MRVSI displayed non-physiological values for the microvessel density and radius (chapter 5). However, similar values were observed in other MR-VSI studies. ${ }^{16-18}$ These results suggest that MR-VSI is, at best, suitable for longitudinal assessment in detecting changes in microvessel density and radius during tumor growth and antiangiogenic therapy. In addition to the causes addressed in chapter 5 , the heterogeneity in microvascular morphology between the tumors observed with MR-VSI and with TPLSM and the increased permeability of angiogenic endothelium, causing extravasation of the intravascular MRI contrast agent to the interstitial space, may have affected the MRI results and thus may have contributed to the discrepancy between TPLSM and MR-VSI.

In chapter 6, cNGR-labeled paramagnetic quantum dots (cNGRpQDs), specific for the angiogenesis marker CD13, were used to visualize angiogenic activity in tumors with in vivo MRI. The competition of the binding of cNGR-pQDs to angiogenic endothelial cells with unconjugated cNGR resulted in decreased quantitative contrast. Moreover, observation of the excised tumor with TPLSM indicated colocalization of cNGR-pQDs with endothelial cells. These findings confirmed the presence of angiogenic activity in tumors. However, since tumors were excised approximately 1 hour after injection of the cNGR-pQDs and the binding of cNGR to the angiogenesis marker CD13 is reversible, detachment of cNGR-pQDs may have caused an underestimation in the angiogenic activity 
observed with TPLSM, although this was not quantitatively assessed. Therefore, in order to prevent dynamic influences and accurately evaluate the obtained MRI results, TPLSM experiments should ideally not be performed in succession, but in parallel and in vivo under the same experimental conditions with a separate group of animals.

\section{Neo-vascularization: atherosclerosis versus cancer}

Atherosclerosis and cancer share molecular pathways of development and progression, including cell proliferation, cell adhesion molecules, and proteolytic enzymes. ${ }^{19}$ Early atherosclerotic lesions and small (less than $1 \mathrm{~mm}$ in diameter) solid tumors are typically avascular and their development appears to be angiogenesis-independent. ${ }^{20,21}$ The common denominator of advanced atherosclerotic plaques and solid tumors is the presence of an extensive microvascular network. Considering the similarity in morphology, including fragility and permeability, and functionality of plaque and tumor neo-vasculature, similar imaging approaches may be utilized for visualization and/or quantification of microvascular morphology and angiogenic activity. In chapters 4 and 6, the aminopeptidase CD13 was successfully used as target for molecular imaging of angiogenic activity in plaqueassociated vasa vasorum with ex vivo TPLSM and in tumors with in vivo MRI and subsequent ex vivo TPLSM. In addition, Buehler et $a l$. and von Wallbrunn et al. showed that CD13 is a suitable target for optical molecular imaging of angiogenesis after myocardial infarction and in tumors. ${ }^{22,23}$ Although there is an increasing interest in the microvasculature as target for anti-angiogenic therapy in atherosclerosis and cancer, and for pro-angiogenic therapy after myocardial infarction, clinical evidence of efficacy has been minimal to date. Winter et al. successfully explored the feasibility of the $\alpha_{v} \beta_{3}$ integrin as target for molecular imaging and therapy of neo-vasculature in atherosclerosis and cancer. ${ }^{12,13,24,25}$ However, compared to cRGD, the ligand for the $\alpha_{v} \beta_{3}$ integrin, cNGR was shown to have a 3-fold higher tumor-homing capability. ${ }^{26}$ The use of cNGR as ligand for molecular imaging and therapy of angiogenesis in atherosclerosis is therefore promising.

Hypoxia has been accepted as the main initiator of angiogenesis in tumors, whereas in atherosclerotic plaques both inflammation and hypoxia are related to angiogenesis. Despite the similarities in molecular pathways during development of these diseases, differences in risk factors and initiators of angiogenesis may not designate atherosclerosis as "a cancer of the blood vessels", as was proposed by Ross et al..$^{27}$

\section{Future perspectives}

Due to the absorption of excitation light and fluorescence by foam cells and extracellular lipids, the penetration depth of TPLSM in atherosclerotic plaques is limited (chapter 4). However, in tumors a penetration depth of up to $250 \mu \mathrm{m}$ was obtained with TPLSM (chapters 5 and 6). Penetration depth may be increased in three independent ways. First, narrowing of the excitation pulse width presumably increases the penetration depth up to $800 \mu \mathrm{m}$, depending on tissue composition. ${ }^{28}$ Second, optimization of the point spread function using adaptive optics. To produce the smallest point spread function, a flexible membrane mirror may be deformed based on on the fly variations in refractive index within tissue and between immersion and mounting media. ${ }^{29,30}$ This increases fluorescence intensity and resolution, thereby improving the penetration depth. Third, using an optical parametric oscillator (OPO) laser system, operating at wavelengths 1000 $1500 \mathrm{~nm}$, increased penetration depths can be obtained since tissue absorption is minimal in this spectral region. In addition, by using dedicated (near) infrared fluorophores, such as mCherry, ${ }^{31}$ fluorescence may be detected more efficiently. Which of the proposed methods or combinations thereof yields the greatest increase in penetration depth remains to be elucidated for each of the observed tissues. 
TPLSM has proven a valuable tool for visualizing and quantifying microvascular characteristics in atherosclerosis and cancer. Although TPLSM is increasingly being applied as stand-alone in vivo imaging modality, in vivo TPLSM evaluation of molecular MRI would have great benefits over ex vivo evaluation. These benefits include measuring under physiological circumstances and avoidance of artifacts induced by tissue excision. The influence of motional artifacts on TPLSM image resolution, induced by respiration and heartbeat, may be reduced by triggering methods and increasing the rate at which images are acquired. ${ }^{32}$ In addition, for optimal evaluation of molecular MRI results, multi-modal contrast agents should be optimized to allow efficient detection with both MRI and TPLSM. 


\section{References}

1. Brown EB, Campbell RB, Tsuzuki Y, et al. In vivo measurement of gene expression, angiogenesis and physiological function in tumors using multiphoton laser scanning microscopy. Nat Med 2001;7:864-8.

2. Feng D, Nagy JA, Pyne K, Dvorak HF, Dvorak AM. Ultrastructural localization of platelet endothelial cell adhesion molecule (PECAM-1, CD31) in vascular endothelium. J Histochem Cytochem 2004;52:87-101.

3. Podgrabinska S, Braun P, Velasco P, Kloos B, Pepper MS, Skobe M. Molecular characterization of lymphatic endothelial cells. Proc Natl Acad Sci U S A 2002;99:16069-74.

4. Baluk P, McDonald DM. Markers for microscopic imaging of lymphangiogenesis and angiogenesis. Ann N Y Acad Sci 2008;1131:1-12.

5. Tripp $\mathrm{CH}$, Haid $\mathrm{B}$, Flacher $\mathrm{V}$, et al. The lymph vessel network in mouse skin visualised with antibodies against the hyaluronan receptor LYVE-1. Immunobiology 2008;213:715-28

6. Xu X, Lu H, Lin $\mathrm{H}$, et al. Lymphangiogenesis promotes inflammation and neointimal hyperplasia after adventitia removal in the rat carotid artery. Int J Cardiol 2008.

7. Stacker SA, Achen MG, Jussila L, Baldwin ME, Alitalo K. Lymphangiogenesis and cancer metastasis. Nat Rev Cancer 2002;2:573-83.

8. Sironi M, Conti A, Bernasconi S, et al. Generation and characterization of a mouse lymphatic endothelial cell line. Cell Tissue Res 2006;325:91-100.

9. Moulton KS, Vakili K, Zurakowski D, et al. Inhibition of plaque neovascularization reduces macrophage accumulation and progression of advanced atherosclerosis. Proc Natl Acad Sci U S A 2003;100:4736-41.

10. Sluimer JC, Gasc JM, van Wanroij JL, et al. Hypoxia, hypoxia-inducible transcription factor, and macrophages in human atherosclerotic plaques are correlated with intraplaque angiogenesis. J Am Coll Cardiol 2008;51:1258-65.

11. Langheinrich AC, Michniewicz A, Sedding DG, et al. Correlation of vasa vasorum neovascularization and plaque progression in aortas of apolipoprotein E(-/-)/low-density lipoprotein(-/-) double knockout mice. Arterioscler Thromb Vasc Biol 2006;26:347-52. 12. Winter PM, Morawski AM, Caruthers SD, et al. Molecular imaging of angiogenesis in early-stage atherosclerosis with alpha(v)beta3-integrin-targeted nanoparticles. Circulation 2003;108:2270-4.

13. Winter PM, Neubauer AM, Caruthers SD, et al. Endothelial alpha(v)beta3 integrin-targeted fumagillin nanoparticles inhibit angiogenesis in atherosclerosis. Arterioscler Thromb Vasc Biol 2006;26:2103-9.

14. Leunig M, Yuan F, Menger MD, et al. Angiogenesis, microvascular architecture, microhemodynamics, and interstitial fluid pressure during early growth of human adenocarcinoma LS174T in SCID mice. Cancer Res 1992;52:6553-60.
15. Yuan F, Leunig M, Berk DA, Jain RK. Microvascular permeability of albumin, vascular surface area, and vascular volume measured in human adenocarcinoma LS174T using dorsal chamber in SCID mice. Microvasc Res 1993;45:269-89.

16. Kiselev VG, Strecker R, Ziyeh S, Speck O, Hennig J. Vessel size imaging in humans. Magn Reson Med 2005;53:553-63.

17. Wade TP, Kozlowski P. Longitudinal studies of angiogenesis in hormonedependent Shionogi tumors. Neoplasia 2007;9:563-8.

18. Zwick S, Strecker R, Kiselev V, et al. Assessment of vascular remodelling under antiangiogenic therapy using DCE-MRI and vessel size imaging. J. Magn. Reson. Im. 2009; accepted.

19. Ross JS, Stagliano NE, Donovan MJ, Breitbart RE, Ginsburg GS. Atherosclerosis and cancer: common molecular pathways of disease development and progression. Ann N Y Acad Sci 2001;947:271-92; discussion 292-3.

20. Li XF, Carlin S, Urano M, Russell J, Ling CC, O’Donoghue JA. Visualization of hypoxia in microscopic tumors by immunofluorescent microscopy. Cancer Res 2007;67:7646-53.

21. Khurana R, Zhuang Z, Bhardwaj S, et al. Angiogenesis-dependent and independent phases of intimal hyperplasia. Circulation 2004;110:2436-43.

22. Buehler A, van Zandvoort MA, Stelt BJ, et al. cNGR: a novel homing sequence for CD13/APN targeted molecular imaging of murine cardiac angiogenesis in vivo. Arterioscler Thromb Vasc Biol 2006.

23. von Wallbrunn A, Waldeck J, Höltke C, et al. In vivo optical imaging of CD13/APNexpression in tumor xenografts. Journal of Biomedical Optics 2008;13:011007.

24. Winter PM, Schmieder AH, Caruthers SD, et al. Minute dosages of alpha(nu) beta3-targeted fumagillin nanoparticles impair $V x-2$ tumor angiogenesis and development in rabbits. Faseb J 2008;22:2758-67.

25. Winter PM, Caruthers SD, Kassner A, et al. Molecular imaging of angiogenesis in nascent $V x-2$ rabbit tumors using a novel alpha(nu)beta3-targeted nanoparticle and 1.5 tesla magnetic resonance imaging. Cancer Res 2003;63:5838-43.

26. Arap W, Pasqualini R, Ruoslahti E. Cancer treatment by targeted drug delivery to tumor vasculature in a mouse model. Science 1998;279:377-80.

27. Ross JS, Stagliano NE, Donovan MJ, Breitbart RE, Ginsburg GS. Atherosclerosis: a cancer of the blood vessels? Am J Clin Pathol 2001;116 Suppl:S97-107.

28. McConnell G. Improving the penetration depth in multiphoton excitation laser scanning microscopy. J Biomed Opt 2006;11:054020.

29. Booth MJ, Neil MA, Juskaitis R, Wilson T. Adaptive aberration correction in a confocal microscope. Proc Natl Acad Sci U S A 2002;99:5788-92.

30. Wright AJ, Burns D, Patterson BA, Poland SP, Valentine GJ, Girkin JM. Exploration of the optimisation algorithms used in the implementation of adaptive optics in confocal and multiphoton microscopy. Microsc Res Tech 2005;67:36-44. 
31. Subach FV, Patterson GH, Manley S, Gillette JM, Lippincott-Schwartz J, Verkhusha VV. Photoactivatable mCherry for high-resolution two-color fluorescence microscopy. Nat Methods 2009;6:153-9.

32. Megens RT, Reitsma S, Prinzen L, et al. In vivo high resolution structural imaging

of large murine arteries using two-photon laser scanning microscopy. (submitted) 


\section{Summary}



Neo-vascularization, more specifically angiogenesis, contributes to growth of atherosclerotic plaques and solid tumors by providing conduits for transport and microvasculature for exchange of nutrients, oxygen, and waste products to the increasing cell mass. The shoulders of advanced atherosclerotic plaques are characterized by a network of microvessels predominantly originating from the vasa vasorum, whereas solid tumors are provided with an internal and peripheral microvascular network. Visualization and quantification of neo-vascular morphology and of angiogenic activity would allow monitoring of the development of (vulnerable) atherosclerotic plaques and (malignant) tumors. Therefore, in this thesis, twophoton laser scanning microscopy (TPLSM) and magnetic resonance imaging (MRI) were utilized to visualize angiogenic activity in atherosclerotic mice and in tumor-bearing mice and to quantify neovascular morphology in tumor-bearing mice. The sub-micrometer spatial resolution of TPLSM also enables validation of the MRI observations.

In chapter 2, a brief overview is provided on the mechanisms of angiogenesis and hypoxia as its main initiator. The processes of atherogenesis and carcinogenesis are shortly described, followed by the contribution of the vasa vasorum (VV) and intraplaque microvasculature to the growth and rupture of atherosclerotic plaques and the contribution of microvasculature to tumor growth. Animal models for atherosclerosis and cancer are described and methods to visualize morphology, permeability, and angiogenic activity are provided. This chapter concludes with the basic principles of two-photon laser scanning microscopy (TPLSM), its application to visualizing and quantifying neo-vasculature, and the application of TPLSM as high resolution imaging validation method.

Molecular imaging methods currently under development may contribute to future personalized medicine in treating cardiovascular disease. Endoscope-compatible optical techniques, including TPLSM,
Raman microspectroscopy (RMS), optical coherence tomography (OCT), and photoacoustic tomography (PAT) would allow intravascular molecular imaging of vulnerable atherosclerotic lesions. Efficient optical visualization of molecular epitopes specific for vulnerable atherosclerotic lesions requires targeting of high quality optical contrast-enhancing nanoparticles. In chapter 3, a review is provided on current optical nanoparticles, confined to quantum dots (QDs), gold nanoparticles (AuNPs), diamond nanoparticles (DNPs), carbon nanoparticles (CNPs), and silica nanoparticles (SNPs), and targeting ligands for optical molecular imaging of atherosclerotic lesions. It is concluded that, based on the limited toxicity and favorable optical properties, AuNPs and SNPs provide the most promising perspective for future optical molecular imaging of atherosclerosis in the clinical environment.

Atherosclerotic plaques are constantly evolving structures, which are associated with an increase in vasa vasorum (VV) density, as shown by several histological and micro-computed tomography (micro-CT) studies of ApoE $\mathrm{E}^{-/}$mice. However, these methods require tissue processing, thereby affecting tissue integrity and morphology. Therefore, in chapter 4 we investigated the feasibility of TPLSM to ex vivo image the $\mathrm{VV}$ of intact atherosclerotic aortas of $\mathrm{ApoE}^{-/-}$ mice. Vascular endothelial cells (VECs) were fluorescently labeled via intravenous injection of $\alpha \mathrm{CD} 31-\mathrm{FITC}$, whereas angiogenic activity of VECs was assessed by in vivo targeting with QDs of CD13, expressed by angiogenic VECs, by binding cyclic Ans-Gly$\operatorname{Arg}$ (cNGR) to the QD surface (cNGR-QDs). VV were observed in the aortic abdominal bifurcation of $\mathrm{ApoE}^{-/-}$mice fed a Western type diet for 20 weeks, abluminal from the atherosclerotic lesion, with microvessels penetrating the media up to $60 \mu \mathrm{m}$. Interestingly, VV were not observed in other aortic segments of these mice. cNGRQDs colocalized with $30 \%$ of the $\mathrm{ApoE}^{-/-} \mathrm{VV}$, indicating angiogenic activity. The sporadically observed adventitial microvessels of 
the abdominal aorta of control $\mathrm{C} 57 \mathrm{BL} / 6 \mathrm{~J}$ mice displayed no angiogenic activity. This study indicates a higher plaque-associated $\mathrm{VV}$ prevalence in the abdominal aorta bifurcation of $\mathrm{ApoE}^{-/-}$mice than of control C57BL/6J mice. TPLSM proved a practical tool in visualizing the $\mathrm{VV}$ of intact arterial segments and may be employed to evaluate the contribution of the VV and intraplaque microvessels underlying the potential destabilization of atherosclerotic lesions in longitudinal studies.

Non-invasive assessment of microvascular morphology and density would allow estimation of disease progression, i.e., development of vulnerable atherosclerotic plaques and tumor growth and metastasis formation, and the response to anti-angiogenic therapy. Magnetic resonance vessel size imaging (MR-VSI) non-invasively provides measures for the microvessel radius and fractional blood volume of biological tissue. In chapter 5 , the validity of in vivo MR-VSI in assessing these measures for tumor and muscle tissue of mice was evaluated using ex vivo 3D TPLSM. Dedicated image processing was applied to the acquired TPLSM datasets to quantify microvessel radius, density, and length of microvasculature of these excised, but intact tissues. TPLSM data displayed a randomly oriented tumor microvasculature, whereas muscle microvessels were mainly oriented parallel to each other. For both MR-VSI and TPLSM, a larger vessel radius and fractional blood volume were found in the tumor rim than in the core. Compared with TPLSM, MR-VSI resulted in a large overestimation of the average vessel radius index, whereas the fractional blood volume was slightly lower. However, the trends for both techniques were the same: morphologic measures were higher for tumor than for muscle tissue, and higher for tumor rim than for the core. Thus, although MR-VSI is not suitable for absolute quantification of vessel radius and blood volume, it may be used to assess the heterogeneity in microvascular morphology within tissue. In addition, MR-VSI may be suitable to investigate relative inter-tissue microvascular differences and intratissue effects of anti-angiogenic therapy in longitudinal studies.

In addition to the morphological characteristics of microvasculature, the angiogenic activity of solid tumors provides information on the expansive capability of their microvascular network. For the study described in chapter 6, cNGR-labeled paramagnetic quantum dots (cNGR-pQDs) were developed and applied to non-invasively assess tumor angiogenic activity using quantitative in vivo molecular MRI. Intravenous injection of the cNGR-pQDs in tumor-bearing mice resulted in an increased quantitative MRI contrast, comprising both increased longitudinal relaxation and decreased proton visibility, in the tumor rim but not in the tumor core or control muscle tissue. Thus, cNGR-pQDs allow in vivo quantification and localization of angiogenic activity with MRI. Validation of the MRI results with ex vivo TPLSM showed that cNGR-pQDs colocalized primarily with the tumor VEC membrane, were to a lesser extent found in the vessel lumen, and were not internalized by VECs. In contrast, unlabeled pQDs were not or only sparsely detected with both MRI and TPLSM. These results indicate a high specificity of cNGR-pQDs for angiogenic tumor vasculature.

Numerous studies have established that neo-vasculature affects the development of atherosclerotic plaques and solid tumors and tentatively contributes to plaque destabilization and spread of metastasis. The studies presented in this thesis demonstrate that two-photon laser scanning microscopy (TPLSM) and magnetic resonance imaging (MRI), at different levels of spatial resolution and sensitivity, enable visualization and quantification of microvascular morphology and angiogenic activity in murine models of atherosclerosis and cancer. However, as described in the general discussion (chapter 7), several biological and technical limitations may apply to the presented studies, including the use 
of CD31 as beacon for demarcation of VECs (chapters 4, 5, and 6), the relatively low incidence of $\mathrm{VV}$ microvessels in atherosclerotic mice (chapter 4), and the limited penetration depth of TPLSM in atherosclerotic plaques and tumor tissue (chapter 4, 5, and 6). Nevertheless, TPLSM has offered the ability to visualize and, with dedicated image processing, quantify microvasculature in associated with atherosclerotic plaques and tumors. Recent developments in endoscope-based TPLSM may widen the scope of these optical diagnostics to clinical applications. 

Samenvatting 

Nieuwvorming van kleine bloedvaten (angiogenese) levert een belangrijke bijdrage aan de ontwikkeling van atherosclerose ("aderverkalking") en kanker, de twee voornaamste doodsoorzaken in de Westerse maatschappij. Atherosclerotische plaques en tumoren kunnen namelijk groeien doordat nieuw gevormde bloedvaten het weefsel voorzien van voedingstoffen en zuurstof en afvalstoffen afvoeren. Bloedvaatjes in atherosclerotische plaques ontstaan voornamelijk uit de vasa vasorum, een netwerk van bloedvaten in de (atherosclerotische) vaatwand, terwijl tumoren door zowel een centraal als perifeer netwerk van bloedvaten wordt gevoed. De klinische relevantie van atherosclerotische plaques en tumor kan in kaart worden gebracht door de morfologie, denk aan de straal en dichtheid van de vaten, en de angiogene activiteit van deze bloedvaten af te beelden en te kwantificeren. In dit proefschrift werden twee-foton laser scanning microscopie (TPLSM) en magnetische resonantie beeldvorming (MRI) gebruikt om in atherosclerotische muizen en in tumordragende muizen angiogene activiteit van de nieuw gevormde bloedvaatjes aan te tonen. Vanwege de sub-micrometer resolutie, maakt TPLSM het mogelijk de MRI resultaten met grote nauwkeurigheid te valideren. Daarnaast werden deze technieken gebruikt om in tumor-dragende muizen de morfologie van de nieuw gevormde bloedvaatjes te kwantificeren.

In hoofdstuk 2 wordt een overzicht gegeven van de mechanismen achter angiogenese en de rol die een lage zuurstofspanning (hypoxie) hierin speelt. Daarnaast wordt de ontwikkeling van atherosclerotische plaques (atherogenese) en tumoren (carcinogenese) beschreven en wordt er aandacht besteed aan de bijdrage die nieuwvorming van bloedvaatjes in en rond atherosclerotische plaques levert aan de mechanische instabiliteit van plaques en de groei van tumoren. Verder worden enkele diermodellen van atherosclerose en kanker beschreven en worden technieken gepresenteerd om morfologie, permeabiliteit en angiogene activiteit van bloedvaten af te beelden.
Het hoofdstuk eindigt met de basis principes van TPLSM, de mogelijkheden die deze techniek biedt om nieuw gevormde bloedvaten af te beelden en te kwantificeren, en om als validatie van andere beeldvormingstechnieken te dienen.

Detectie van moleculaire veranderingen (moleculaire beeldvorming) in weefsel maakt het mogelijk om ziektes in een vroeger stadium te diagnosticeren dan met conventionele middelen. Hierdoor kan mede de behandeling van bijvoorbeeld cardiovasculaire aandoeningen op individueel niveau worden aangepast. Naast de bestaande klinische beeldvormingstechnieken kan de verhoogde ruimtelijke resolutie en gevoeligheid van optische beeldvormingstechnieken hier een aanzienlijke bijdrage aan leveren. Met name de technieken die endoscopisch toepasbaar zijn zoals TPLSM, Raman microspectroscopie (RMS), optische coherentie tomografie (OCT) en fotoakoestische tomografie (PAT) zijn geschikt voor moleculaire beeldvorming van atherosclerotische plaques vanuit het lumen van het atherosclerotische bloedvat. Echter, optische moleculaire beeldvorming vereist contrastverhogende deeltjes (nanopartikels) die specifiek aan het pathologische molecuul binden. In hoofdstuk 3 wordt een literatuur overzicht gegeven van enkele, mogelijk klinisch toepasbare, optische nanopartikels en liganden, welke specifiek zijn voor atherosclerotische plaques. De nanopartikels zijn quantum dots (QDs), goud nanopartikels (AuNPs), diamant nanopartikels (DNPs), koolstof nanoparticles (CNPs) en silica nanopartikels (SNPs). Op basis van de minimale toxiciteit bij langdurige blootstelling en de gunstige optische eigenschappen zijn AuNPS en SNPs veelbelovend voor toekomstige optische moleculaire beeldvormingstechnieken in de kliniek.

Atherosclerotische $\mathrm{ApoE}^{-/-}$muizen worden veelvuldig gebruikt in onderzoek naar atherosclerose. In deze dieren gaat de ontwikkeling van atherosclerotische plaques gepaard met een toename in vasa vasorum dichtheid, zoals gebleken is uit studies met positron emissie 
tomografie (PET) en histologische technieken. In hoofdstuk 4 is onderzocht of middels TPLSM (angiogene activiteit van) de vasa vasorum van intacte atherosclerotische aorta's van $\mathrm{ApoE}^{-/}$muizen afgebeeld kunnen worden. De endotheelcellen van de bloedvaten werden fluorescerend gelabeld door intraveneus $\alpha \mathrm{CD} 31-\mathrm{FITC}$ toe te dienen. De angiogene activiteit van deze endotheelcellen werd bepaald door QDs specifiek te laten binden aan CD13 door middel van het cyclische tripeptide Ans-Gly-Arg (cNGR) aan het QD oppervlak (cNGR-QDs). Vasa vasorum werden gevonden in de bifurcatie van de abdominal aorta van $\mathrm{ApoE}^{-/-}$muizen die 20 weken een hoogcholesterol dieet hadden gekregen. Enkele kleine bloedvaatjes, ontsprongen uit de vasa vasorum, drongen in de media van de vaatwand door tot een diepte van $60 \mu \mathrm{m}$. Vasa vasorum werden niet gevonden in andere slagaders van deze muizen. De cNGR-QDs hechtten aan de endotheelcellen bij 30\% van de vasa vasorum, wat erop duidde dat de endotheelcellen daar angiogene activiteit vertoonden. Bloedvaatjes in de adventitia van bloedvaten waren weliswaar sporadisch aanwezig in de abdominale aorta van controle $\mathrm{C} 57 \mathrm{BL} / 6 \mathrm{~J}$ muizen, maar vertoonden geen angiogene activiteit. Deze studie wijst daarmee op hogere prevalentie van vasa vasorum in de abdominale aorta van $\mathrm{ApoE}^{-/-}$muizen dan in controle C57BL/6J muizen. TPLSM is een goede techniek om de vasa vasorum van intacte arteriën af te beelden en kan mogelijk gebruikt worden in longitudinale studies ter bepaling van de bijdrage van de vasa vasorum aan de mechanische instabiliteit van atherosclerotische plaques.

Een niet-invasieve bepaling van de morfologie en dichtheid van bloedvaatjes zou het mogelijk maken om ziekteverloop te voorspellen, bijvoorbeeld de ontwikkeling van (instabiele) atherosclerotische plaques, tumor groei en vorming van uitzaaiing, en de effecten van anti-angiogene therapie vast te stellen. Met behulp van MRI is het mogelijk om niet-invasief een schatting te maken van de straal van de bloedvaten en het fractioneel bloedvolume van biologisch weefsel. In hoofdstuk 5 werd de nauwkeurigheid van deze techniek geëvalueerd door TPLSM. Hiertoe werden de straal en dichtheid van bloedvaten in tumoren en spierweefsel van muizen middels beide technieken bepaald. Digitale beeldbewerking werd toegepast op de verkregen TPLSM gegevens om de straal, dichtheid en de totale lengte van bloedvaten in intact weefsel te bepalen. In tumor weefsel waren de bloedvaten willekeurig georiënteerd, terwijl in spierweefsel de bloedvaatjes sterk parallel georiënteerd waren. Middels beide technieken werd een grotere straal van de bloedvaten en een groter fractioneel bloed volume gevonden in de tumor periferie dan in de kern. In vergelijking met TPLSM, liet de MRI techniek een sterke overschatting zien van de straal van de bloedvaten, maar een lager fractioneel bloed volume. Echter, beide technieken lieten eenzelfde trend zien: de morfologische grootheden in de tumor waren groter dan in de spier en groter in de tumor periferie in vergelijking met de kern. Uit deze studie kan geconcludeerd worden dat de MRI techniek niet geschikt is voor absolute bepaling van de straal van de bloedvaten en het fractioneel bloed volume, maar wel gebruikt worden ter bepaling van de heterogeniteit in bloedvat morfologie en relatieve verschillen tussen weefsels en binnen een weefsel in de tijd.

Naast detectie van de morfologie biedt het afbeelden van de angiogene activiteit van tumoren de mogelijkheid om veranderingen in bloedvat dichtheid vast te stellen. Voor de studie beschreven in hoofdstuk 6 werden cNGR-QDs zichtbaar gemaakt voor MRI door ze paramagnetisch te maken. Deze paramagnetische cNGRQDs (cNGR-pQDs) werden toegepast in tumordragende muizen om niet-invasief angiogene activiteit te kwantificeren met in vivo MRI. Na intraveneuze toediening zorgden de cNGR-pQDs voor een verandering in contrast in de tumor periferie, maar niet in de kern van de tumor of in het spierweefsel. Validatie van de MRI resultaten met 
ex vivo TPLSM liet zien dat cNGR-pQDs voornamelijk gebonden waren aan endotheelcellen van de bloedvaatjes, in mindere mate aanwezig waren in het bloed en niet door de endotheelcellen waren opgenomen. Controle pQDs werden nauwelijks tot niet gedetecteerd met MRI en TPLSM, wat wijst op een hoge specificiteit van cNGRpQDs voor angiogene bloedvaten in tumoren.

Wetenschappelijke studies hebben veelvuldig aangetoond dat nieuw gevormde bloedvaten de groei van atherosclerotische plaques en tumoren beïnvloeden. Daarnaast dragen de bloedvaten bij aan een mechanische instabiliteit van atherosclerotische plaques en vergroten ze de kans op uitzaaiing van tumoren. De in dit proefschrift beschreven studies laten zien dat twee-foton laser scanning microscopie (TPLSM) en magnetische resonantie beeldvorming (MRI) het afbeelden en kwantificeren van de morfologie en angiogene activiteit van nieuw gevormde bloedvaten mogelijk maken in muismodellen van atherosclerose en kanker. Zoals beschreven in de algemene discussie (hoofdstuk 7) zijn enkele mogelijke biologische en technische beperkingen van toepassing op de opzet van de experimenten: mogelijk is er een betere marker voor endotheelcellen dan CD31 voor het onderscheiden van bloedvaten in biologisch weefsel (hoofdstukken 4, 5 en 6), moet er naar een diermodel gezocht worden met een hogere vasa vasorum dichtheid om deze te kunnen kwantificeren (hoofdstuk 4), en zal de doordringdiepte van TPLSM in atherosclerotische plaques en tumoren vergroot moeten worden (hoofdstukken 4, 5 en 6). Desalniettemin, TPLSM maakt het mogelijk om, in combinatie met daartoe ontwikkelde beeldbewerkingssoftware, nieuw gevormde bloedvaten rond atherosclerotische plaques en in tumoren af te beelden en te kwantificeren. Recente ontwikkelingen in endoscopische TPLSM maakt deze techniek mogelijk geschikt voor toekomstige wetenschappelijke en klinische in vivo toepassingen. 



\section{Dankwoord}



Dick, als eerste promotor heeft jouw destructief/constructieve kritiek tijdens het schrijven van dit proefschrift zijn weerslag gehad. Dank dat je tussen de holes door naar de unversiteit wilde komen voor de nodige besprekingen. Als tweede promotor, Mark, heeft jouw bij tijd en wijlen onorthodoxe visie op de wetenschap mij geleerd wetenschappelijke literatuur van een niet-algemeen-geaccepteerde kant te benaderen ("De bijdrage van angiogenese is niet éénduidig is de destabilisatie van atherosclerotische plaques"). Marc, mijn dagelijkse begeleider, je hebt je continu meegaand en meedenkend opgesteld tegenover mijn wetenschappelijke en persoonlijke problemen. Bedankt dat je me (grotendeels) mijn eigen pad heb laten kiezen.

Dit alles heeft mij geholpen een stukje werk af te leveren waar ik trots op ben. Mijn dank daarvoor!

Wim "Youth is a state of mind" wil ik bedanken voor het (onuitputtelijke?) technische advies. Of het nu over de TPLSM/ FLIM opstelling ging (die we toch een aantal malen hebben moeten reanimeren), deconvolutie, sportklimmen of GS brommers, jij hielp me om steeds een stapje verder te komen. Wat mij betreft volgen er nog de nodige avonden Karmeliet en Kwekkeboom bij Thembi!

Marlies, hoeveel uren hebben wij doorgebracht achter de MRI en twee-foton microscoop om tumoren en hartjes en andere organen te scannen? Mede door jouw enthousiasme en frisse kijk op de wetenschap heb ik onze periode van samenwerking als zeer prettig en productief ervaren. Veel succes met jouw promotie en dank dat je mijn paranimf wilt zijn!

Van de vakgroep Biomedische Technologie ("The Department Formerly Known As Biophysics") wil ik een aantal mensen in het bijzonder bedanken. Remco, inmiddels ben je werkzaam in Aken, maar een aantal van jouw "uitvindingen" wordt nog altijd op het lab gebruikt. Dank voor de adviezen op het werk, de espresso, de MTBtochten door het mooie Limburgse heuvelland en feit dat je mijn paranimf wilt zijn! Lenneke, we zijn begonnen aan een gelijksoortig project en gaandeweg hebben we ons eigen wetenschappelijk pad gekozen. Toch is het ons gelukt om tussen alle experimenten door samen een review te publiceren. Succes met je volgende quantum dot avontuur! Als kamergenoot, Sietze, heb ik je om je rust en kunde erg gewaardeerd. Het duurt nog even, maar alvast veel geluk met de laatste promotie-loodjes! Timo, maak iets moois van het plaque angiogenese project! Mitrajit, good luck with your $\mathrm{PhD}$ project on optical nanoparticles. Voor de vakgroep Biomedische Technologie in het algemeen: dank voor een aangename (dagjes-uit, kerstdiners) en leerzame (labmeetings) promotie-periode!

Ludwig, dank dat je altijd voor me klaar stond als ik nieuwe tumorcellen nodig had of andere zaken wilde weten. Die Jupilers hebben dat ene weekend goed gesmaakt. Onze kort-maar-krachtige samenwerking heeft een mooi artikel opgeleverd. Succes met jouw promotie!

Multi-disciplinair onderzoek vereist een multi-disciplinaire aanpak en een dito team. Dit boekje was niet tot stand gekomen zonder de (prettige!) samenwerking met de volgende mensen. Walter, Eline, Robbert-Jan en Jos van de vakgroep Radiologie bedankt voor de vele vruchtbare discussies en hulp bij het opzetten en uitvoeren van de MRI experimenten. RJ, ik zal jouw project een mooie voortgang geven! Bij Fysiologie wil ik Viviane, Niek en Allard bedanken voor hun hulp tijdens proefdierexperimenten, Henny, Daniel en Mirjam voor de vruchtbare "vasculaire" discussies en Sonia en Vivian voor de secretariële ondersteuning. Erik en Sylvia van Pathologie bedankt voor jullie kritische bijdragen aan respectievelijk 
hoofdstuk drie en vier en Anique, Linda en Jeffrey als ik weer 's een immunohistochemische vraag had. Tilman, Wencke en Anouk van Biochemie bedankt voor de synthese van de nodige peptides en de flexibiliteit waarmee dit gebeurde! Chris, bedankt voor je bijdrage aan hoofdstuk drie. Alle medewerkers van het CPV Maastricht bedankt voor alle "hulp achter de schermen", in het bijzonder Rik, Richard, Pauline, Nadine, en Marlies.

Jasper en Guido van PrimaID, het is een boekje geworden dat (uiteraard) afwijkt van de fysieke standaard. Ik wil jullie beide bedanken voor het deskundige advies met betrekking tot de lay-out van mijn proefschrift. Jullie zijn kanjers!

Lieve familie en vrienden, zoals jullie hebben kunnen lezen ging mijn onderzoek ietsje verder dan "muizen pesten" en zal het relatief hoge abstractie-niveau het proefschrift niet altijd even makkelijk leesbaar hebben gemaakt (en zo heeft ieder vakgebied haar eigen ongeschreven regels). Ik wil jullie allen bedanken voor de getoonde interesse en steun van de afgelopen jaren. Mam, bedankt voor alles.

Marelle. Bij het ouder worden verdwijnen doorgaans de wilde haren. In mijn geval lijken ze juist te ontstaan. Dank dat je dit ongeleide projectiel in goede banen hebt weten te leiden. 


\section{Curriculum vitae}





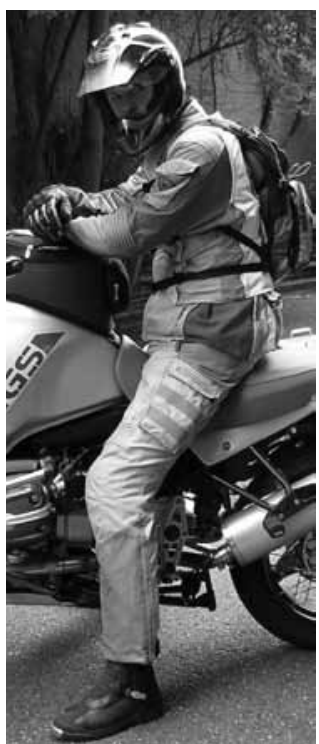

Kim Douma was born on August 7, 1979 in Apeldoorn, The Netherlands. After completing pre-university education (VWO) at the Anton van Duinkerken College in 1998 (Veldhoven, The Netherlands), he started his study Biomedical Engineering at the Eindhoven University of Technology (Eindhoven, The Netherlands). In November 2004, he obtained his master degree with great appreciation and subsequently commenced his PhD-project entitled "Two-photon microscopic imaging of neo-vasculature in atherosclerotic plaques and tumors" at the Department of Biomedical Engineering of Maastricht University Medical Centre (MUMC ${ }^{+}$, Maastricht, The Netherlands). From March to May 2009 , he explored the feasibility of two-photon spectral imaging in discriminating between healthy and diseased arteries in a cooperative pilot-project between $\mathrm{MUMC}^{+}$and Utrecht University. As of June 2009, he is working as a post-doctoral researcher at the Department of Radiology at $\mathrm{MUMC}^{+}$, exploring the feasibility of nuclear molecular imaging techniques to assess the development of vulnerable atherosclerotic lesions. 



\section{List of publications}



Douma K*, Prinzen L*, Slaaf DW, Reutelingsperger CPM, Biessen EAL, Hackeng TM, Post MJ, van Zandvoort MAMJ. Nanoparticles for optical molecular imaging of atherosclerosis. Small 2009;5(5):544-557

Douma K*, Oostendorp $M^{*}$, Slaaf DW, Post MJ, Backes WH, van Zandvoort MAMJ. Evaluation of magnetic resonance vessel size imaging by two-photon laser scanning microscopy. (accepted for publication in Magnetic Resonance in Medicine)

Oostendorp M*, Douma K*, Hackeng TM, Dirksen A, Post MJ, van Zandvoort MAMJ, Backes WH. Quantitative molecular magnetic resonance imaging of tumor angiogenesis using cNGR-labeled paramagnetic quantum dots. Cancer Research 2008;68(18):7676-7683.

Douma K, Heeneman S, Hackeng TM, Kooi ME, Slaaf DW, Post MJ, van Zandvoort MAMJ. High resolution vasa vasorum imaging in intact murine atherosclerotic arteries. (in preparation)

Oostendorp M, Douma K, Wagenaar A, Slenter JMGM, Hackeng TM, van Zandvoort MAMJ, Post MJ, Backes WH. Molecular MRI of myocardiac angiogenesis after acute myocardial infarction. (under revision)

Oostendorp M, Douma K, Hackeng TM, Post MJ, van Zandvoort MAMJ, Backes WH. Gadolinium-labeled quantum dots for molecular magnetic resonance imaging: $R_{1}$ versus $R_{2}$ mapping. (submitted)

Oostendorp M, Douma K, Hackeng TM, van Zandvoort MAMJ, Post MJ, Backes WH. Pharmacokinetics of contrast agents to the tumor vasculature in molecular magnetic resonance imaging. (submitted)
Douma K, Megens RTA, Reitsma S, Prinzen L, Slaaf DW, van Zandvoort MAMJ. Two-photon lifetime imaging of fluorescent probes in intact blood vessels: a window to sub-cellular structural information and binding status. Microscopy Research and Technique 2007;70:467-75.

Dubois L, Douma K, Supuran CT, Chiu RK, van Zandvoort MAMJ, Pastorekova S, Scozzafava A, Wouters BG, Lambin P. Imaging the hypoxia surrogate marker CA IX requires expression and catalytic activity for binding fluorescent sulfonamide inhibitors. Radiotherapy \& Oncology 2007;83(3):367-373.

Prinzen L, Miserus RJJHM, Dirksen A, Hackeng TM, Deckers N, Bitsch NJ, Megens RTA, Douma K, Heemskerk JW, Kooi ME, Frederik PM, Slaaf DW, van Zandvoort MAMJ, Reutelingsperger CPM. Optical and magnetic resonance imaging of cell death and platelet activation using Annexin A5-functionalized quantum dots. Nano Letters 2007;7(1):93-100.

Mulder WJM, Douma K,. Koning GA, van Zandvoort MAMJ, Lutgens E, Daemen MJAP, Nicolay K, Strijkers GJ. Liposomeenhanced MRI of neotintimal lesions in the ApoE-KO mouse. Magnetic Resonance in Medicine 2006;55(5):1170-1174

van Zandvoort MAMJ, Engels W, Douma K, Beckers L, oude Egbrink MGA, Mat J.A.P. Daemen MJAP, Slaaf DW. Two-photon microscopy for imaging of the (atherosclerotic) vascular wall: a proof of concept study. Journal of Vascular Research 2004;41(1):54-63.

* Authors have contributed equally 

